\title{
Toolbox: Verbreitete und leistungsfähige Fragebögen, Tests und Skalen
}

6.1 Die Toolbox im Überblick - 119

6.2 Diagnose der Leistungsfähigkeit und Persönlichkeit von Führungskräften - 119

6.2.1 Die Intelligenz - 120

6.2.2 Die Persönlichkeit in ihrer Gesamtheit - 123

6.2.3 Die Persönlichkeit im beruflichen Kontext - 133

6.2.4 Einzelne Aspekte der Persönlichkeit - 136

6.3 Diagnose von Einstellungen - 151

6.3.1 Vertrauen und Loyalität gegenüber der Führungskraft - 151

6.3.2 Feedbackorientierung - 153

6.3.3 Selbstwirksamkeitsüberzeugung - 155

6.4 Diagnose der Führungsmotivation - 157

6.5 Messung einzelner Aspekte des Führungsverhaltens - 160

6.5.1 Führung und Einflussnahme - 161

6.5.2 Führung und Werte - 169

6.5.3 Führung und Emotionen - 174

6.5.4 Führung in bestimmten Situationen - 181

6.5.5 Hierarchische vs. Geteilte Führung - 188

6.6 Diagnose des Führungsstils - 193

6.6.1 Transaktionale Führung - 194

6.6.2 Transformationale Führung - 196

6.6.3 Full-Range-Leadership - 199

6.6.4 Charismatische Führung - 203 
6.6.5 Authentische Führung - 205

6.6.6 Beziehungsqualität von Führungskraft und

Mitarbeitenden - Leader-Member Exchange - 208

6.6.7 Ambidextre Führung - 213

Literatur - 215 
Die folgende „Toolbox“ besteht aus größtenteils frei verfügbaren und einsetzbaren Instrumenten. Diese bieten ein breites Repertoire an wissenschaftlichen, validierten Fragebögen und Skalen zur Erfassung verschiedener Aspekte von Führung. Auch wenn diese Sammlung keineswegs vollständig ist, so bietet sie doch einen guten Überblick über gängige und leistungsfähige Instrumente. Die Mehrzahl der Fragebögen und Skalen sind vollständig abgebildet, wodurch deutlich wird, dass viele Instrumente publiziert werden und damit auch für die breite nicht-akademische Öffentlichkeit frei verfügbar sind. Dies macht es möglich - wenn die entsprechende Statistik-Expertise vorhanden ist - eigene Untersuchungen $\mathrm{zu}$ konzipieren, ohne auf kommerzielle Verfahren mit teilweise sehr hohen Lizenzgebühren zurückzugreifen. Um weitere, nicht in diesem Buch dargestellte Merkmale von Führung zu entdecken, lohnt sich also eine eigene Recherche, z. B. über die Suchmaschine Google Scholar ( www.scholar.google.de).

\subsection{Die Toolbox im Überblick}

Die Toolbox orientiert sich inhaltlich und hinsichtlich ihres Aufbaus an den im $>$ Kap. 2 erläuterten Theorien und psychologischen Konstrukten der klassischen und aktuellen Führungsforschung. Auf die jeweiligen Theoriegrundlagen wird im Einzelnen verwiesen, wodurch den Leserinnen und Lesern eine Einordnung der Messinstrumente in die Führungsforschung ermöglicht wird. Den Anfang machen Messinstrumente zur Diagnose der Leistungsfähigkeit und Persönlichkeit von Führungskräften ( Abschn.6.2), dann folgen Verfahren zur Messung von Einstellungen ( Abschn. 6.3) und der Führungsmotivation ( Abschn.6.4). Schließlich folgen Fragebögen, die verschiedene Aspekte des Führungsverhaltens zum Gegenstand haben ( Abschn. 6.5). Der Diagnose von komplexen Verhaltensmustern bzw. Führungsstilen ist Abschn. 6.6 gewidmet.

\subsection{Diagnose der Leistungsfähigkeit und Persönlichkeit von Führungskräften}

Die eigenschaftsorientierten Führungstheorien ( Abschn. 2.2.1) sind u. a. der Frage nachgegangen, ob Intelligenz oder bestimmte Persönlichkeitseigenschaften dafür ausschlaggebend sind, dass man persönlichen und organisationalen Erfolg als Führungskraft hat. Zusammenhänge zwischen der Intelligenz und der Übernahme einer Führungsposition oder zwischen einer bestimmten Persönlichkeitsstruktur und dem Führungserfolg konnten auch tatsächlich nachgewiesen werden (Judge et al. 2002, 2004), sie 
sind jedoch geringer als dies Alltagstheorien nahelegen. Dennoch ist es, wie in $>$ Kap. 5 dargelegt, sinnvoll, sich mit der Intelligenz, der Persönlichkeitsstruktur und den Ausprägungen einzelner Persönlichkeitseigenschaften bei (potenziellen) Führungskräften zu beschäftigen und diese zu erfassen. Ziele können dabei sein, bei Nachwuchskräften globale Hinweise für eine generelle Führungseignung zu erhalten, validere Aussagen zur Passung von Personen für bestimmte situative Anforderungen (z. B. Vertrieb, Top Management) zu machen, oder Führungskräften eine persönliche Standortbestimmung $\mathrm{zu}$ ermöglichen und individuelle Entwicklungsfelder aufzuzeigen.

Emotionale vs. kognitive Intelligenz

Prädiktor "Intelligenz"

Allgemeiner Intelligenztest

Cattell-Horn-Carrol-Modell

Fluide und kristallisierte Intelligenz

\subsubsection{Die Intelligenz}

Ein Intelligenztest prüft die kognitive Leistungsfähigkeit einer Person und ist durchaus ein guter Prädiktor für generellen Berufserfolg (Hülsheger et al. 2007; Kramer 2009) und auch den Erfolg in einer Führungstätigkeit (Judge et al. 2004). Leistungsunterschiede im späteren Führungsalltag lassen sich also bis zu einem gewissen Grad durch Leistungsunterschiede im Test - z. B. über den ermittelten Intelligenzquotienten (IQ) - vorhersagen. Da Intelligenztests aber nicht geeignet sind, ein breites Spektrum an Führungskompetenzen oder Führungspotenzialen zu prüfen, finden sie in erster Linie Verwendung als „Filter" für die Vorauswahl und Eignungsdiagnostik bei Nachwuchsführungskräften. Unternehmen sollten sich hier aber bewusst sein, dass die emotionale „Intelligenz" [ $\bullet$ (George 2000; Goleman und Boyatzis 2008) neben den kognitiven Fähigkeiten entscheidend zu einem späteren Führungserfolg beiträgt und eine Vorselektion rein nach der kognitiven Leistungsfähigkeit auch zur Ablehnung evtl. sogar besser geeigneter Bewerberinnen und Bewerbern führen kann.

Für die Messung von Intelligenz gibt es - je nach Definition von Intelligenz (z. B. Cattell 1943; Spearman 1904; Wechsler 1972) - unterschiedliche Testinstrumente. Bekannt sind beispielsweise der Wechsler-Intelligenztest-für-Erwachsene (WIE, Aster et al. 2006), der Intelligenz-Struktur-Test 2000 R (IST 2000R, Amthauer et al. 2001) oder der online kostenlos zur Verfügung stehende Allgemeine Intelligenztest (AIT, Satow 2017).

Der im Folgenden vorgestellte AIT beruht auf den Modellen von Spearman (1904) und Cattell (1943). Spearman stellte fest, dass die Noten von Schülerinnen und Schülern in allen Fächern korrelieren und schloss daraus, dass dies an deren allgemeiner kognitiven Leistungsfähigkeit bzw. Intelligenz liegt, die er als "general factor (g-factor) “ bezeichnete. Cattell teilte den g-Faktor in einen ererbten Anteil (fluide Intelligenz) und einen durch Lernen erworbenen Anteil (kristallisierte Intelligenz). Die Fähigkeit logisch zu denken gehört zur fluiden Intelligenz, Sprach- 
kenntnisse sind Beispiele für die kristallisierte Intelligenz. Horn und Carroll entwickelten auf dieser Basis ein hierarchisches Strukturmodell für Intelligenz mit drei Ebenen (Cattell-HornCarrol-Modell (CHC), Carroll 1993, 2005). Der AIT erfasst die wichtigsten Intelligenzfaktoren dieses empirisch gut gestützten Modells. Laut Satow (2017, S. 5) umfasst die Allgemeine Intelligenz die „generelle kognitive Fähigkeit, Regeln und Muster $\mathrm{zu}$ analysieren und logisch korrekte Schussfolgerungen auch unter Einbeziehung erworbenen Wissens abzuleiten."

Im AIT (Satow 2017) werden das Sprachverständnis (die kristallisierte Intelligenz), das logisch-analytische Denken (die fluide Intelligenz), das räumlich-visuelle Denken sowie numerische Fähigkeiten gemessen.

Zum erworbenen Sprachverständnis gehören die Fähigkeit Sprachregeln $\mathrm{zu}$ verstehen und anzuwenden sowie kommunikative und kulturelle Fähigkeiten.

\section{? Beispielaufgabe}

Welches Wort passt zu der Liste: hier - damals - vielleicht: Antwortmöglichkeiten: a) warm, b) groß, c) jetzt, d) schön, e) laufen.

Das logisch-analytische Denken bedeutet, dass logisch korrekte Schussfolgerungen gezogen werden und neuartige abstrakte Probleme gelöst werden können.

\section{? Beispielaufgabe}

Kein Rechteck ist ein Kreis. Alle Quadrate sind Rechtecke.

Was folgt daraus?

Antwortmöglichkeiten a) Kein Quadrat ist ein Kreis. b) Alle Quadrate sind Vierecke. c) Kein Quadrat ist ein Viereck. d) Einige Vierecke sind Rechtecke.

Visuelle Regeln, Muster und Operationen erkennen, nachzuvollziehen und durchzuführen, ist Ausdruck des räumlich-visuellen Denkens.

\section{? Beispielaufgabe}

Welches Bild passt am besten in die Reihe? (• Abb. 6.1).

$\mathrm{Zu}$ den numerischen Fähigkeiten gehört das Erkennen, Nachvollziehen und Durchführen numerischer Regeln und Operationen - auch unter Anwendung erworbenen mathematischen Wissens.

Logisch-analytisches

Denken
Räumlich-visuelles Denken

Numerische Fähigkeiten 

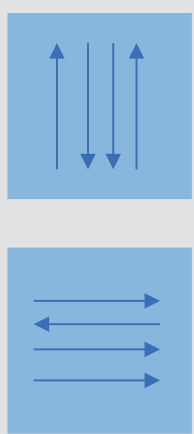

A
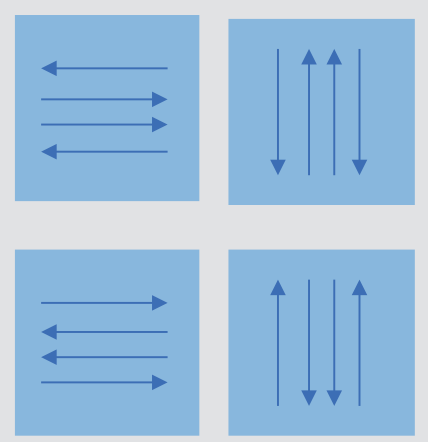

B

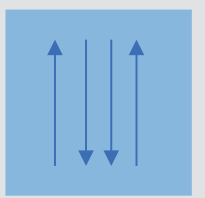

C
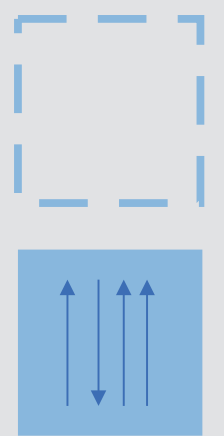

D

- Abb. 6.1 Beispielaufgabe - Visuelle Regeln, Muster und Operationen

\section{? Beispielaufgabe}

Ergänzen Sie folgende Zahlenfolge. Versuchen Sie dazu die Regeln zu erkennen, nach denen die Folge gebildet wurde: 20, 19, 21, 20, 22, ...

Antwortmöglichkeiten a) 11, b) 21, c) 31, d) 41, e) 51 .

Der Test eignet sich gut für die Personalauswahl bei mindestens 16 Jahre alten Personen, seine Bearbeitungsdauer beträgt etwa 90 Minuten (Satow 2017).

Allgemeiner Intelligenztest (AIT, Satow 2017).

Welcher Aspekt von Führung wird gemessen?

Was wird gemessen?

Für welche Unternehmen eignet sich die Skala besonders?

Für welche Führungskräfte eignet sich die Skala besonders?

Für welche Einsatzgebiete im Personalmanagement eignet sich die Skala besonders?
Kognitive Leistungsfähigkeit

Allgemeine Intelligenz:

- Sprachverständnis

- Logisch-analytisches Denken

- Räumlich-visuelles Denken

- Numerische Fähigkeiten

Unternehmen mit hohem Bewerbungsaufkommen und Rekrutierungsbedarf bei Nachwuchsführungskräften/Trainees

Nachwuchsführungskräfte:

- Kenntnis der eigenen kognitiven Leistungsfähigkeit/ Selbstreflektion

- Bewerbungstraining, Vorbereitung für das Assessment Center

- Eignungsdiagnostik bei Nachwuchsführungskräften

- Vorselektion von Bewerberinnen und Bewerbern 


\subsubsection{Die Persönlichkeit in ihrer Gesamtheit}

Erfolgreiche Führung hängt in erheblichem Maße von der Persönlichkeit der Führungskraft ab (Judge et al. 2002), daher bieten Persönlichkeitstests oftmals wertvolle ergänzende Informationen für die Eignungsdiagnostik bei Führungskräften ( Abschn. 5.1).

Was aber macht unsere Persönlichkeit aus? Nach der klassischen Definition von Gordon Allport, einem der Gründerväter der Persönlichkeitspsychologie, ist Persönlichkeit die dynamische Ordnung der psychophysischen Systeme eines Menschen, die seine einzigartigen Anpassungen an seine Umwelt bestimmen (Allport 1959). Einfacher ausgedrückt, ist Persönlichkeit die spezielle Art und Weise wie eine Person auf andere reagiert und mit anderen interagiert. Zwillingsstudien sollten entschlüsseln, ob Persönlichkeit vererbt und angeboren ist oder eher durch die Sozialisation, z. B. die Erziehung durch die Eltern, erworben wird. Die Studien konnten zeigen, dass wir unsere individuellen Wesenszüge zum größten Teil unseren Genen verdanken. Aber auch andere Faktoren prägen unsere Persönlichkeit, z. B. beeinflusst das Lebensalter und damit unsere Lebenserfahrung die Persönlichkeitseigenschaften (Wright 2013).

Generell kann die Persönlichkeit als Gesamtheit aller individuellen Eigenschaften aufgefasst werden, die dafür ausschlaggebend sind, wie ein Mensch auf verschiedene Situationen reagiert und sich verhält. Genau diese Grundannahme ist Basis des Assessment-Center-Ansatzes. Man beobachtet und analysiert die individuellen Reaktionen und Verhaltensweisen unterschiedlicher Bewerberinnen und Bewerber in bestimmten Testsituationen und schließt mittels eines interindividuellen Vergleichs auf deren Persönlichkeitsstruktur und Leistungsvermögen.

Persönlichkeitseigenschaften sind auch deshalb für die Eignungsdiagnostik besonders interessant, da sich die Persönlichkeit zwar im Erwachsenenalter noch verändern kann, die meisten Eigenschaften aber insgesamt zeitlich recht stabil sind (Roberts et al. 2006). Erfasst werden können Persönlichkeitseigenschaften mit verschiedenen Methoden. Einige Verfahren, wie die verbale Beschreibung der Persönlichkeit oder ihre Erfassung durch Zuordnung von Eigenschaften wie „dominant“ in Kategorien wie „trifft gar nicht zu“ oder "trifft stark $\mathrm{zu}^{\text {“ }}$ („Q-Sort-Methode, Block 1961), werden aber eher selten angewandt.

Am verbreitetsten ist die Bewertung von Einzelaussagen oder Eigenschaften mithilfe von Skalen und die Einordnung der individuellen Ergebnisse in eine geeignete Referenzgruppe (Hossiep und Mühlhaus 2015). Merkmale der Referenzgruppe
Definition von Persönlichkeit

Persönlichkeitseigenschaften sind zeitlich stabil

Standardmodell für die Persönlichkeitsmessung

Referenzgruppen 
Hauptdimensionen der Big Five sind z. B. das Alter, das Geschlecht und die Berufsgruppenzugehörigkeit. Der Abgleich individueller Persönlichkeitsprofile mit dem Profil einer Referenzgruppe erlaubt dann eine Prognose der individuellen Passung der Bewerberin bzw. des Bewerbers für eine bestimmte Tätigkeit oder eine Führungsaufgabe. Mithilfe standardisierter Fragebögen kann die Führungskraft eine Selbsteinschätzung abgeben, oder wird z. B. durch die oder den Vorgesetzte/n fremdbeurteilt. Als Standardmodell für die Messung von Persönlichkeit haben sich in der psychologischen Forschung die „Big Five“ durchgesetzt (McCrae und Costa 1987). Dieses Fünf-Faktoren-Modell erklärt die Persönlichkeitsunterschiede von Menschen anhand der Ausprägungen von fünf untereinander trennscharfen sowie zeitlich und kulturell stabilen Faktoren: Extraversion, Verträglichkeit, Gewissenhaftigkeit, Emotionale Stabilität und Offenheit für Erfahrungen.

Als Standardmodell für die Erfassung der Persönlichkeit wird in der Wissenschaft meist das sogenannte Big-5-Modell (- Abb. 6.2) zugrunde gelegt (Asendorpf und Neyer 2012).

Die fünf Hauptdimensionen Openness, Conscientiousness, Extraversion, Agreeableness und Neuroticism ergeben zusammen das Akronym OCEAN, weshalb es auch als OCEAN-Modell

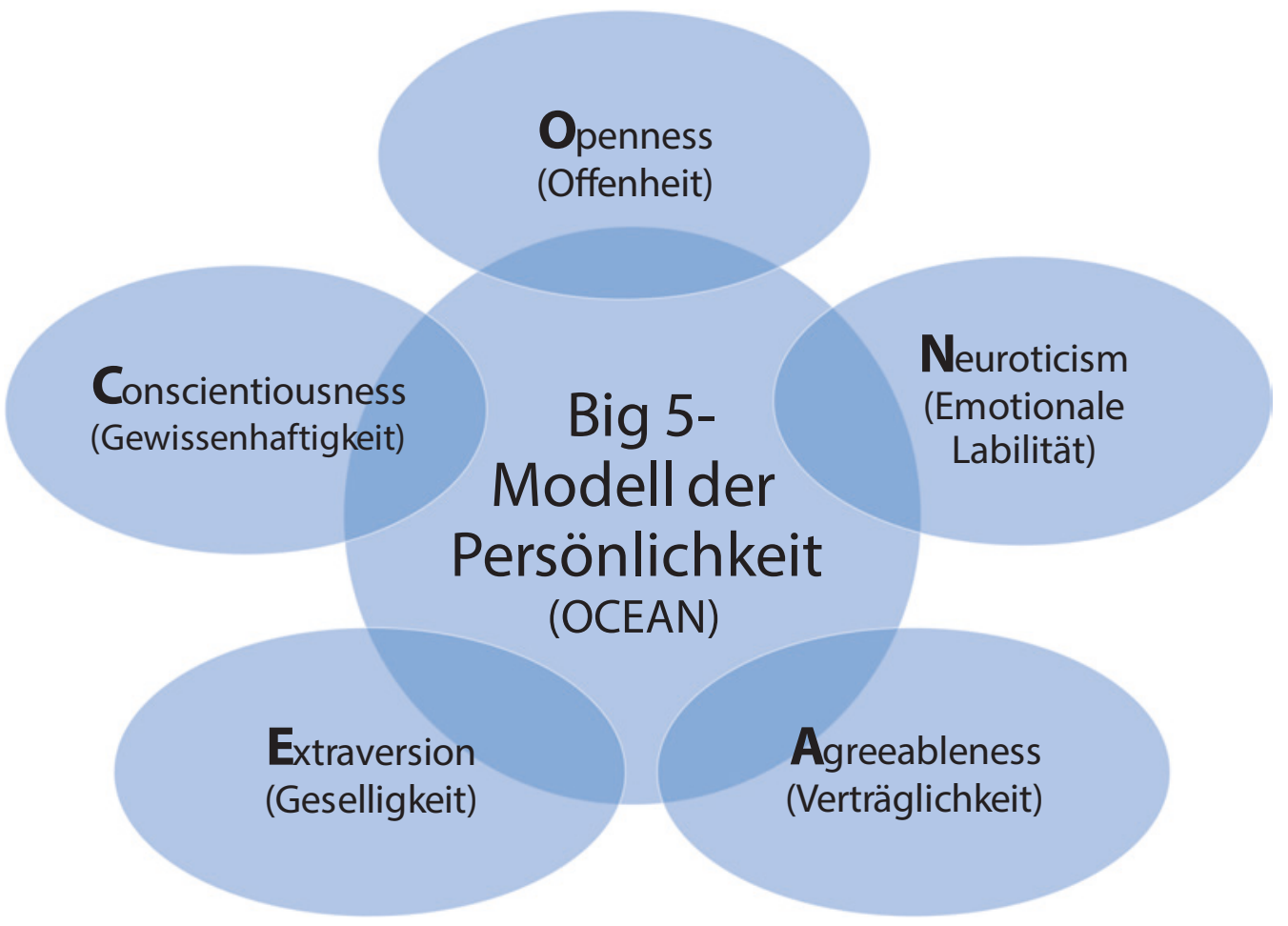

- Abb. 6.2 Das Big-Five Modell der Persönlichkeit (McCrae und John 1992) 
bezeichnet wird. Die Persönlichkeit jedes Menschen lässt sich anhand seiner individuellen Ausprägungen in den fünf Dimensionen beschreiben. Die Forschung hat gezeigt, dass die Big Five stabil, voneinander unabhängig und auf jeden Kulturkreis anwendbar sind.

- Openness: Personen mit hohen Werten bei Offenheit zeichnen sich durch eine hohe Wertschätzung für neue Erfahrungen aus, bevorzugen Abwechslung, sind wissbegierig, kreativ, phantasievoll und unabhängig in ihrem Urteil. Sie haben vielfältige kulturelle Interessen und interessieren sich für öffentliche Ereignisse.

- Conscientiousness: Mit der Skala Gewissenhaftigkeit kann man ordentliche, zuverlässige, hart arbeitende, disziplinierte, pünktliche, penible, ehrgeizige und systematische von leichtsinnigen, nachlässigen und gleichgültigen Personen unterscheiden.

- Extraversion: Personen mit hohen Werten bei Extraversion sind gesellig, aktiv, gesprächig, personenorientiert, herzlich, optimistisch und heiter. Sie mögen Anregungen und Aufregungen.

- Agreeableness: Personen mit hohen Werten bei der Verträglichkeit sind altruistisch, mitfühlend, verständnisvoll und wohlwollend. Sie neigen zu zwischenmenschlichem Vertrauen, zu Kooperation, zu Nachgiebigkeit, und sie haben ein starkes Harmoniebedürfnis.

- Neuroticism: Personen, die hier hohe Werte aufweisen neigen dazu, nervös, ängstlich, traurig, unsicher und verlegen $\mathrm{zu}$ sein und sich Sorgen um ihre Gesundheit zu machen. Sie haben unrealistische Ideen und sind weniger in der Lage, ihre Bedürfnisse zu kontrollieren und auf Stresssituationen angemessen $\mathrm{zu}$ reagieren.

Die weitverbreitetsten und anerkanntesten Möglichkeiten (Rauthmann 2017) zur Messung der Persönlichkeit auf Basis der Big Five ist einerseits das NEO Personality Inventory Revised (NEO-PI-R, Costa und McCrae 2008). Es besteht aus insgesamt 240 Items. Des Weiteren gibt es eine verschlankte Version mit 60 Items, das sogenannte NEO Five Factor Inventory (NEO-FFI, McCrae und Costa Jr 2004). Im Folgenden findet sich für jede Dimension des NEO-PI-R ein Beispielitem - die deutsche Fassung stammt von Ostendorf und Angleitner (2004).

\section{Fragebogen}

Beispielitems des NEO-PI-R nach Ostendorf und Angleitner (2004)

Skala „Offenheit (O)“:

„Ich habe eine sehr lebhafte Vorstellungskraft."

NEO Five Factor Inventory

NEO Personality Inventory Revised 
Reliabilität und Validität des NEO-FFI

Big-Five-Persönlichkeitstest
Skala "Gewissenhaftigkeit (C)“:

„Ich bin für meine Umsicht und meinen gesunden Menschenverstand bekannt."

Skala „Extraversion (E)“:

"Die meisten Menschen, die mir begegnen, sind mir wirklich sympathisch."

Skala „Verträglichkeit (A)“: „Im Hinblick auf die Absichten anderer bin ich eher zynisch und skeptisch."

Skala „Neurotizismus (N)": "Ich bin nicht leicht beunruhigt."

(Abdruck erfolgt mit freundlicher Genehmigung des Hogrefe Verlages. Das Testverfahren ist zu beziehen bei der Testzentrale, $\mathbf{w w w . t e s t z e n t r a l e . d e )}$

In der kürzeren Fassung, also dem NEO-FFI, werden die fünf Persönlichkeitsbereiche durch jeweils 12 Items repräsentiert. Der NEO-FFI weist eine gute Reliabilität auf (interne Konsistenzen der Skalen bei durchschnittlich $\alpha=, 80$ und Retest-Reliabilitäten zwischen $\mathrm{rtt}=, 71$ für Verträglichkeit und $\mathrm{rtt}=, 82$ für Extraversion). Die Konstruktvalidität des Verfahrens wurde faktorenanalytisch nachgewiesen, die Korrelationen zwischen Selbst- und Bekanntenbeurteilungen liegt zwischen $r=, 49$ bis $r=, 61$. Damit ist die Validität ebenfalls hoch.

Auch der im Folgenden ausführlich vorgestellte, online kostenlos zur Verfügung stehende Big-Five-Persönlichkeitstest (B5T) von Satow (2012) basiert auf dem Big-Five-Modell.

Der B5T enthält zu den Big Five folgende Skalen und Items (Satow 2012):

Offenheit: Menschen mit hohen Werten bei „Offenheit“ sind aufgeschlossen, neugierig und haben vielfältige Interessen, z. B. in kulturellen Bereichen. Sie sind kreativ und an Bildung interessiert.

- Ich will immer neue Dinge ausprobieren.

- Ich bin ein neugieriger Mensch.

- Ich reise viel, um andere Kulturen kennenzulernen.

- Am liebsten ist es mir, wenn alles so bleibt, wie es ist. (-)

- Ich diskutiere gerne.

- Ich lerne immer wieder gerne neue Dinge.

- Ich beschäftige mich viel mit Kunst, Musik und Literatur. 
- Ich interessiere mich sehr für philosophische Fragen. Ich lese viel über wissenschaftliche Themen, neue Entdeckungen oder historische Begebenheiten.

- Ich habe viele Ideen und viel Fantasie.

Gewissenhaftigkeit: Gewissenhafte Menschen arbeiten sorgfältig, sind zuverlässig, diszipliniert und ausdauernd und haben ein ausgeprägtes Verantwortungsbewusstsein.

- Ich bin sehr pflichtbewusst.

- Meine Aufgaben erledige ich immer sehr genau.

- Ich war schon als Kind sehr ordentlich.

- Ich gehe immer planvoll vor.

- Ich habe meine festen Prinzipien und halte daran auch fest.

- Auch kleine Bußgelder sind mir sehr unangenehm.

- Auch kleine Schlampereien stören mich.

- Ich achte sehr darauf, dass Regeln eingehalten werden.

- Wenn ich mich einmal entschieden habe, dann weiche ich davon auch nicht mehr ab.

- Ich mache eigentlich nie Flüchtigkeitsfehler.

Extraversion (Gegenteil: Introversion): Hier wird gemessen, wie gesellig Personen sind. Extraversion gilt als besonders relevante Persönlichkeitsdimension für Führung (Judge et al. 2002).

- Ich bin gerne mit anderen Menschen zusammen.

- Ich kann schnell gute Stimmung verbreiten.

- Ich bin unternehmungslustig.

- Ich stehe gerne im Mittelpunkt.

- Im Grunde bin ich oft lieber für mich allein. (-)

- Ich bin ein Einzelgänger. (-)

- Ich gehe gerne auf Partys.

- Ich bin in vielen Vereinen aktiv.

- Ich bin ein gesprächiger und kommunikativer Mensch.

- Ich bin sehr kontaktfreudig.

Verträglichkeit: Verträgliche Menschen sind freundlich, bescheiden und hilfsbereit. Sie arbeiten gut im Team, sind warmherzig und beliebt.

- Ich achte darauf, immer freundlich zu sein.

- Ich bin ein höflicher Mensch.

- Ich helfe anderen, auch wenn man mir es nicht dankt.

- Ich habe immer wieder Streit mit anderen. (-) 
- Ich bin ein Egoist. (-)

- Wenn mir jemand hilft, erweise ich mich immer als dankbar.

- Ich würde meine schlechte Laune nie an anderen auslassen.

- Es fällt mir sehr leicht, meine Bedürfnisse für andere zurückzustellen.

- Ich kann mich gut in andere Menschen hineinversetzen.

- Ich komme immer gut mit anderen aus, auch wenn sie nicht meiner Meinung sind.

Neurotizismus (Gegenteil: Emotionale Stabilität): Personen mit hohen Neurotizismuswerten sind nervös, ängstlich und reizbar. Sie lassen sich leicht verunsichern, sind besorgt und haben ein höheres Burn-Out-Risiko (z. B. Kim et al. 2009).

- Ich bin ein ängstlicher Typ.

- Ich fühle mich oft unsicher.

- Ich verspüre oft eine große innere Unruhe.

- Ich mache mir oft unnütze Sorgen.

- Ich grübele viel über meine Zukunft nach.

- Oft überwältigen mich meine Gefühle.

- Ich bin oft ohne Grund traurig.

- Ich bin oft nervös.

- Oft werde ich von meinen Gefühlen hin- und hergerissen.

- Ich bin mir in meinen Entscheidungen oft unsicher.

Motive als Grundlage für Motivation
Im B5T werden diese fünf Persönlichkeitsdimensionen noch durch drei weitere Dimensionen zu den Grundmotiven von Menschen ergänzt. Die Motive oder Grundbedürfnisse von Menschen sind in ihrer Persönlichkeit verwurzelt und ähnlich wie die Persönlichkeitseigenschaften zeitlich sehr stabil. Werden sie durch Anreize aktiviert, z. B. durch die Chance, einen höheren Status in einer Gruppe zu erlangen, so spricht man von Motivation. Ob jemand motiviert ist, hängt also davon $\mathrm{ab}$, inwieweit seine individuellen Grundbedürfnisse durch intrinsische oder extrinsische Anreize angesprochen werden. Die Kenntnis der Motive einer Person ist damit wichtig, um ihr Verhalten zu erklären und $\mathrm{zu}$ prognostizieren, oder kurz gesagt, sie zu motivieren.

Die Items $\mathrm{zu}$ Motiven decken die folgenden Bereiche ab: Interessen, Sehnsüchte, Visionen und Lebensträume sowie Motive als innere Kraftquelle. Der B5T erfasst folgende Grundmotive (Satow 2012): 
Bedürfnis nach Anerkennung und Leistung (Leistungsmotiv): Menschen mit einem ausgeprägten Bedürfnis nach Anerkennung und Leistung versuchen immer andere zu überflügeln und sind erst zufrieden, wenn sie ihre Ziele erreicht haben.

- Ich habe schon immer ein starkes Bedürfnis verspürt nach meinen eigenen Maßstäben der Beste zu sein.

- Ich habe schon immer ein starkes Bedürfnis nach Anerkennung und Bewunderung verspürt.

- Für mehr Anerkennung würde ich auf vieles verzichten.

- Am glücklichsten bin ich dann, wenn viele Menschen mich bewundern und das toll finden, was ich mache.

- Tief in meinem Innersten gibt es eine Sehnsucht danach der Beste sein zu wollen.

- Ich träume oft davon, berühmt zu sein.

Bedürfnis nach Macht und Einfluss (Machtmotiv): Personen mit einem starken Machtmotiv wollen Einfluss ausüben, gestalten und Verantwortung übernehmen.

- Ich träume oft davon, wichtige Entscheidungen für Politikerinnen und Politiker oder andere mächtige Menschen zu treffen.

- Wenn ich die Wahl hätte, würde ich in meinem Leben gerne weltbewegende Entscheidungen treffen.

- Tief in meinem Innersten gibt es eine Sehnsucht nach Einfluss und Macht.

- Für mehr Einfluss würde ich auf vieles verzichten.

- Am glücklichsten bin ich dann, wenn ich Verantwortung übernehmen kann und wichtige Entscheidungen treffen darf.

- Ich kann Menschen verstehen, die sagen, dass andere Dinge wichtiger sind als Einfluss und Politik. (-)

Bedürfnis nach Sicherheit und Ruhe (Sicherheitsmotiv): Personen, die ein ausgeprägtes Bedürfnis nach Sicherheit haben, streben nach (innerer) Ruhe und vermeiden Risiken.

- Ich habe schon immer ein starkes Bedürfnis nach Sicherheit und Ruhe verspürt.

- Wenn ich die Wahl hätte, würde ich ein Leben in Sicherheit und Frieden wählen.

- Für ein sicheres Leben ohne böse Überraschungen würde ich auf vieles verzichten. 
- Tief in meinem Innersten gibt es eine Sehnsucht nach Ruhe und Geborgenheit.

- Ich träume oft von einem ruhigen Leben ohne böse Überraschungen.

- Am glücklichsten bin ich dann, wenn ich mich geborgen fühle.

Der B5T enthält außerdem eine Skala zur Erfassung der Ehrlichkeit bei der Testbeantwortung. Hier wird nach menschlichen Schwächen gefragt, die eigentlich fast jeder bejahen muss, wenn er ehrlich antwortet (Satow 2012).

- Ich habe schon mal etwas unterschlagen oder nicht gleich zurückgegeben.

- Im privaten Bereich habe ich schon mal Dinge gemacht, die besser nicht an die Öffentlichkeit kommen sollten.

- Ich habe schon mal Dinge weitererzählt, die ich besser für mich behalten hätte.

- Ich habe schon mal über andere gelästert oder schlecht über sie gedacht.

Sollten viele dieser zuletzt genannten Items verneint werden, so besteht der Verdacht, dass der Teilnehmende sozial erwünscht geantwortet hat, also ein möglichst positives Bild seiner Persönlichkeit zeichnen will.

Für die Beantwortung der Items wurde generell eine vierstufige Likert-Skala gewählt, damit die Teilnehmenden nicht eine "neutrale“, mittlere Antwortkategorie wählen können. Insgesamt besitzt der Test eine hohe Skalen-Reliabilität und faktorielle Validität.

Big-Five-Persönlichkeitstest (B5T, Satow 2012)

\begin{tabular}{|c|c|}
\hline $\begin{array}{l}\text { Welcher Aspekt } \\
\text { von Führung } \\
\text { wird gemessen? }\end{array}$ & Persönlichkeitsstruktur und Grundmotive \\
\hline $\begin{array}{l}\text { Was wird } \\
\text { gemessen? }\end{array}$ & $\begin{array}{l}\text { Persönlichkeitsstruktur (Big Five): } \\
\text { - Offenheit } \\
\text { - Gewissenhaftigkeit } \\
\text { - Extraversion } \\
\text { - Verträglichkeit } \\
\text { - Neurotizismus (emotionale Labilität) } \\
\text { Grundmotive } \\
\text { - Leistungsmotiv } \\
\text { - Machtmotiv } \\
\text { - Sicherheitsmotiv }\end{array}$ \\
\hline
\end{tabular}




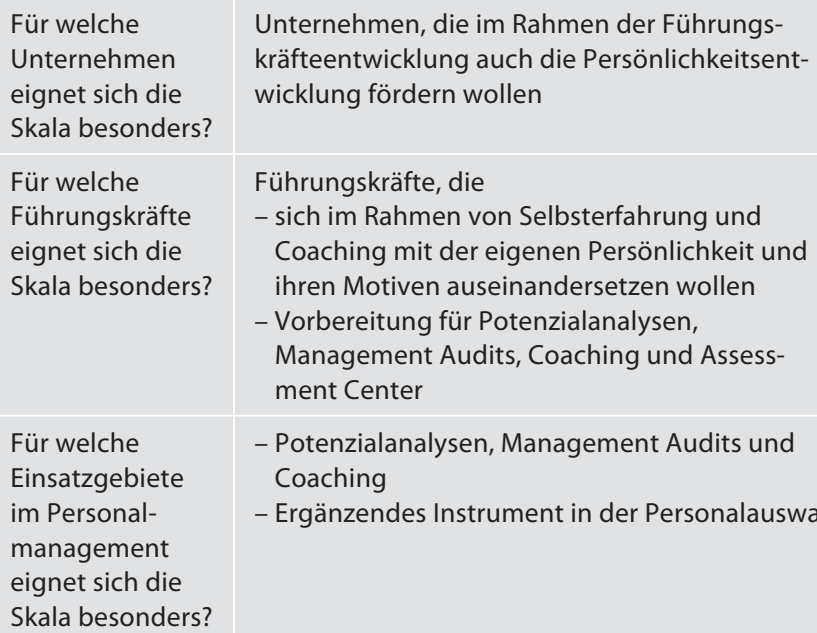

Neben diesem allgemeinen Persönlichkeitstest, können aber auch Fragebögen eingesetzt werden, die speziell die für Führung relevanten Persönlichkeitseigenschaften messen. So lässt sich mit dem Leadership Trait Questionnaire (LTQ) erfassen (Northouse 2015), wie die Führungskraft sich selbst wahrnimmt bzw. welche Eigenschaften ihr von Mitarbeitenden oder Kolleginnen und Kollegen zugeschrieben werden.

\section{Fragebogen}

Leadership Trait Questionnaire (LTQ) (Northouse 2015, eigene Übersetzung)

Anleitung: Der Zweck dieses Fragebogens ist es, für Führung relevante Persönlichkeitsmerkmale zu messen. Der Fragebogen sollte durch die Führungskraft und fünf Personen, die diese gut kennen (z. B. Mitarbeitende, Kolleginnen und Kollegen, Vorgesetzte, Freundinnen und Freunde, Familienmitglieder) ausgefüllt werden. Machen Sie fünf Kopien dieses Fragebogens. Dieser Fragebogen sollte von Ihnen und fünf Ihnen bekannten Personen (z. B. Mitbewohnerinnen und Mitbewohner, Mitarbeitende, Verwandte, Freundinnen und Freunde) ausgefüllt werden. Lassen Sie jede Person anhand der folgenden Skala angeben, inwieweit sie mit jeder der 14 folgenden Aussagen einverstanden oder nicht einverstanden ist. Vergessen Sie nicht, einen Bogen für sich selbst auszufüllen.

Kreuzen Sie jeweils an, inwieweit Sie den folgenden 14 Aussagen zustimmen.

Schlüssel: $1=$ starke Ablehnung, $2=$ Ablehnung, $3=$ neutral, $4=$ Zustimmung, $5=$ starke Zustimmung
Leadership Trait Questionnaire 
(Name der Führungskraft) ist...

1. redegewandt: kommuniziert erfolgreich mit anderen.

2. scharfsinnig: ist urteilsfähig und einfühlsam.

3. selbstvertrauend: glaubt an sich selbst und an seine/ihre Fähigkeiten.

4. selbstbewusst: ist selbstsicher und frei von Zweifeln.

5. beständig: hält - auch bei Widerständen - an Zielen fest.

6. entschlossen: hat einen festen Stand und handelt mit Bestimmtheit.

7. vertrauenswürdig: ist authentisch und weckt Vertrauen.

8. verlässlich: ist konsequent und zuverlässig.

9. freundlich: ist liebenswürdig und herzlich.

10. kontaktfreudig: spricht offen und kommt gut mit anderen aus.

11. gewissenhaft: ist gründlich, organisiert und beherrscht.

12. fleißig: ist ausdauernd, arbeitet hart.

13. sensibel: ist tolerant, taktvoll und mitfühlend.

14. empathisch: versteht andere, kann sich in andere hineinversetzen.

\section{Auswertung}

1. Tragen Sie die Antworten für die Teilnehmenden 1 bis 5 in die jeweiligen Spalten (siehe unten) ein.

2. Errechnen Sie für jede der 14 Aussagen den Durchschnittswert der 5 Teilnehmenden und tragen Sie sie in die Spalte Mittelwert ein.

3. Tragen Sie Ihre Selbsteinschätzung in die letzte Spalte ein.

\section{Auswertung anhand eines Beispiels}

\begin{tabular}{|c|c|c|c|c|c|c|c|c|}
\hline & & TN 1 & TN 2 & TN 3 & TN 4 & TN 5 & Mittelwert & Selbstbild FK \\
\hline 1. & Redegewandt & 4 & 4 & 3 & 2 & 4 & 3,4 & 4 \\
\hline 2. & Scharfsinnig & 2 & 5 & 3 & 4 & 4 & 3,6 & 5 \\
\hline 3. & Selbstvertrauend & 4 & 4 & 5 & 5 & 4 & 4,4 & 4 \\
\hline 4. & Selbstbewusst & 5 & 5 & 5 & 5 & 5 & 5 & 5 \\
\hline 5. & Beständig & 4 & 4 & 3 & 3 & 3 & 3,4 & 3 \\
\hline 6. & Entschlossen & 4 & 4 & 4 & 4 & 4 & 4 & 4 \\
\hline 7. & Vertrauenswürdig & 5 & 5 & 5 & 5 & 5 & 5 & 5 \\
\hline 8. & Verlässlich & 4 & 5 & 4 & 5 & 4 & 4,4 & 4 \\
\hline 9. & Freundlich & 5 & 5 & 5 & 5 & 5 & 5 & 5 \\
\hline 10. & Kontaktfreudig & 5 & 4 & 5 & 4 & 5 & 4,6 & 4 \\
\hline 11. & Gewissenhaft & 2 & 3 & 2 & 3 & 3 & 2,6 & 4 \\
\hline 12. & Fleißig & 3 & 3 & 3 & 3 & 3 & 3 & 4 \\
\hline 13. & Sensibel & 4 & 4 & 5 & 5 & 5 & 4,6 & 3 \\
\hline 14. & Empathisch & 5 & 5 & 4 & 5 & 4 & 4,6 & 3 \\
\hline
\end{tabular}




\section{Interpretation:}

Die Ergebnisse, die Sie mittels des LTQ erhalten haben, geben Aufschluss darüber, wie Sie sich selbst sehen und wie andere Sie als Führungskraft sehen. Das Diagramm ermöglicht es Ihnen zu sehen, wo Ihre Wahrnehmungen mit denjenigen anderer übereinstimmen und wo sie sich unterscheiden. Die Beispielbewertungen zeigen, wie die Führungskraft sich bei der Eigenschaft "redegewandt" selbst höher bewertet hat als die anderen Beurteilenden. Beim zweiten Merkmal "scharfsinnig", bewertete sich die Führungskraft selbst sogar wesentlich höher als sie durch andere bewertet wurde. Bei der Eigenschaft "selbstbewusst" stimmt das Selbstbild der Führungskraft mit dem Fremdbild überein. Bei diesem Fragebogen gibt es keine „Bestwerte“. Der Zweck des Instruments ist es, Ihnen eine Möglichkeit zu geben, Ihre Stärken und Schwächen zu beurteilen und Bereiche zu identifizieren, in denen Ihre eigene Wahrnehmung mit derjenigen anderer übereinstimmt und in denen es Diskrepanzen zwischen Selbst- und Fremdbild gibt.

Die errechneten Werte liefern Informationen, wie Sie von anderen gesehen werden, wie Sie selbst sich sehen und inwieweit Selbst- und Fremdbild übereinstimmen bzw. sich unterscheiden. Damit ermöglicht das Instrument Stärken und Schwächen auszuloten.

\subsubsection{Die Persönlichkeit im beruflichen Kontext}

Die Persönlichkeit determiniert neben der Fachkompetenz und der intellektuellen Leistungsfähigkeit bestimmte berufliche Erfolgskriterien. So sind z. B. bei Führungskräften persönliche Verhaltensdispositionen oft entscheidend für den Aufstieg oder das Scheitern. Das speziell für die berufliche Eignungsdiagnostik im Fach- und Führungskräftebereich entwickelte Bochumer Inventar zur berufsbezogenen Persönlichkeitsbeschreibung von Hossiep und Paschen (2003) erlaubt es, beruflich relevante Persönlichkeitsmerkmale von Fach- und Führungskräften über Fragebögen zur Selbst- und zur Fremdeinschätzung zu erfassen. Damit kann Aufschluss über das Leistungs-, Gestaltungs-, und die Führungsmotivation erhalten werden. Dies ist insbesondere deshalb interessant, weil der Test mit einer umfangreichen Datenbasis für relevante Referenzgruppen normiert wurde (Marcus 2004). Mithilfe des Verfahrens lassen sich Anknüpfungspunkte in Bezug auf kurz- oder langfristige Personalentwicklungsprozesse (z. B. Coachings, Trainings) gewinnen.

\section{Referenzgruppen}

Bochumer Inventar zur berufsbezogenen Persönlichkeitsbeschreibung 


\begin{tabular}{|c|c|c|c|c|c|c|}
\hline \multirow[b]{2}{*}{$\begin{array}{l}\text { Für einige bin ich ein unbequemer } \\
\text { Querdenker }\end{array}$} & \multicolumn{3}{|c|}{ Trifft voll zu } & \multicolumn{3}{|c|}{ Trifft überhaupt nicht zu } \\
\hline & 0 & ○ & 0 & $\circ$ & 0 & 0 \\
\hline $\begin{array}{l}\text { Für mich sind fachliche Kompetenzen } \\
\text { wichtiger als Führungsqualitäten }\end{array}$ & 0 & 0 & 0 & 0 & 0 & 0 \\
\hline $\begin{array}{l}\text { Es kommt vor, dass ich anderen } \\
\text { gegenüber sehr dominant bin }\end{array}$ & 0 & 0 & 0 & 0 & 0 & 0 \\
\hline
\end{tabular}

Kritik und praktische Anwendung des BIP
Insgesamt umfasst der Test für die Selbstbeschreibung 14 Skalen mit insgesamt 210 Aussagen zu den Bereichen

- berufliche Orientierung,

- Arbeitsverhalten,

- soziale Kompetenzen und

- psychische Konstitution (• Tab. 6.1).

Für die Fremdbeschreibung, z. B. durch Vorgesetzte, ist der Test auf 42 Aussagen beschränkt, die ebenfalls auf einer sechsstufigen Antwortskala beurteilt werden müssen.

Wenn auch aus Forschungssicht die hohen Interkorrelationen einiger Skalen kritisiert werden und - wie auch bei anderen Persönlichkeitstest - das Problem sozial erwünschter Antworten bei „durchschaubaren“ Fragen besteht (Hossiep und Mühlhaus 2015), so ist der BIP dennoch als Instrument für die Personal- und Führungskräfteentwicklung sehr gut geeignet. Auch in der Personalauswahl kann er verwendet werden, sollte allerdings aufgrund der großen Wahrscheinlichkeit von sozial erwünschten Antwortverhaltens nur als ergänzendes Instrument, z. B. als Grundlage für Interviews, eingesetzt werden. Mit dem BIP-6F (Hossiep et al. 2012) steht zudem eine kompaktere Version des BIP zur Verfügung, die sich z. B. in der Personalentwicklung für den Einsatz in Verhaltenstrainings oder Führungsseminaren eignet (- Tab. 6.2).

\footnotetext{
Bochumer Inventar zur berufsbezogenen Persönlichkeitsbeschreibung (BIP, Hossiep und Paschen 2003)

Welcher Aspekt Persönlichkeitsstruktur, bezogen auf den berufvon Führung wird lichen Kontext gemessen?
} 
6.2 Diagnose der Leistungsfähigkeit und Persönlichkeit von Führungskräften
Was wird
gemessen?
Persönlichkeitsstruktur:
- Berufliche Orientierung (Leistungsmotivation, Gestaltungsmotivation und Führungs- motivation),
- Arbeitsverhalten (Gewissenhaftigkeit, Flexibili- tät und Handlungsorientierung)
- Soziale Kompetenzen (Sensitivität, Kontakt- fähigkeit, Soziabilität, Teamorientierung und Durchsetzungsstärke),
- Psychische Konstitution (Emotionale Stabilität, Belastbarkeit und Selbstbewusstsein) nehmen eignet sich die Skala besonders?

Für welche Führungskräfte eignet sich die Skala besonders?

Für welche Einsatzgebiete im Personalmanagement eignet sich die Skala besonders?
Unternehmen, die im Rahmen von Führungskräfteauswahl und -entwicklung die Persönlichkeit von Kandidatinnen und Kandidaten ganzheitlich und unter Einsatz mehrerer Methoden erheben wollen. Der Test ist normiert für relevante Vergleichsgruppen (z. B. Fach- und Führungskräfte im Vertrieb, Geschäftsführer)

Führungskräfte, die

- sich im Rahmen von Selbsterfahrung und Coaching mit ihrer Persönlichkeitsstruktur im beruflichen Kontext auseinandersetzen wollen

- Vorbereitung für Potenzialanalysen, Management Audits, Coaching und Assessment Center

- Potenzialanalysen, Management Audits und Coaching

- Ergänzendes Instrument in der Personalauswahl

- Tab. 6.2 Beispielhafte Aussagen des Bochumer Inventars zur berufsbezogenen Persönlichkeitsbeschreibung - 6 Faktoren (BIP-6F) (Hossiep und Mühlhaus 2015)

\begin{tabular}{|l|l|l|l|l|l|}
\hline & Trifft voll zu & \multicolumn{3}{|c|}{ Trifft überhaupt nicht zu } \\
\hline $\begin{array}{l}\text { Mit ist es sehr wichtig, die } \\
\text { Richtung vorzugeben }\end{array}$ & 0 & 0 & 0 & 0 \\
\hline $\begin{array}{l}\text { Bei meinen Planungen überlasse } \\
\text { ich nichts dem Zufall }\end{array}$ & 0 & 0 & 0 & 0 \\
\hline $\begin{array}{l}\text { Ich stehe ungern im Mittelpunkt } \\
\text { der Aufmerksamkeit }\end{array}$ & 0 & 0 & 0 & 0 & 0 \\
\hline
\end{tabular}




\subsubsection{Einzelne Aspekte der Persönlichkeit}

Die Führungsforschung interessiert sich nicht nur für den Zusammenhang zwischen Führungserfolg und der Persönlichkeit in ihrer Gesamtheit (vgl. Abschn. 6.2.2 und 6.2.3). Auch einzelne Aspekte der Persönlichkeit wurden im Zusammenhang mit Führung erforscht. In den folgenden drei Kapiteln geht es zunächst um die positiven Seiten der Persönlichkeit von Führungskräften und zwar um die Vertrauenswürdigkeit sowie um die sogenannten Führungstugenden. Schließlich werden die „dunklen“ Seiten dargestellt, die oft auch als Dunkle Triade der Führung bezeichnet werden: die machiavellistische Führung, die narzisstische Führung und die psychopathische Führung.

Nicht nur in schwierigen Führungssituationen wie Unternehmenskrisen oder bei großen Veränderungen, kommt es darauf an, dass die Mitarbeitenden ihrer Führungskraft vertrauen. Schottländer (1957) hat Vertrauen als den Glauben an das Gute im Menschen definiert. Führungskräfte müssen wohlwollend, kompetent, berechenbar und integer sein, damit ihnen Vertrauen geschenkt wird. In Abschn. „Vertrauenswürdigkeit“ wird eine Skala zur Messung der Vertrauenswürdigkeit von Führungskräften vorgestellt. Auch die Beschäftigung mit dem Thema Vertrauen hat eine lange Tradition - bereits in der Antike wurde darüber nachgedacht, welche Tugenden eine herausragende und nach ethischen Maßstäben handelnde Führungspersönlichkeit auszeichnen. Die Klugheit, die Tapferkeit, die Mäßigung und die Gerechtigkeit - wurden sofern sie zusammenwirken - als Kardinaltugenden bezeichnet. Warum sie heute noch relevant sind und wie man sie messen kann, wird in Abschn. „Führungstugenden“ beschrieben. Abschn. „Die Dunkle Triade: Machiavellistische Führung, Narzisstische Führung und Psychopathische Führung " konzentriert sich dann auf die Untugenden in der Führung. Es werden Instrumente zur Messung von machiavellistischer, narzisstischer und psychopathischer Führung vorgestellt.

\section{Vertrauenswürdigkeit}

In turbulenten und veränderungsreichen Zeiten, aber auch ganz allgemein, ist es für Führungskräfte wichtig das Vertrauen ihrer Mitarbeitenden zu gewinnen. Worauf aber basiert die Überzeugung oder die Entscheidung von Mitarbeitenden, einer Führungskraft zu vertrauen? Die Entstehung von Vertrauen wurde zunächst mit der Wahrnehmung von Wohlwollen (Strickland 1958), Ehrlichkeit (Larzelere und Huston 1980) und Kompetenz (Butler 1991) in Verbindung gebracht.

Vertrauen entwickelt sich langfristig

Was ist Vertrauen?
Und welche Konsequenzen hat Vertrauen für das Verhalten von Mitarbeitenden? Mit eine der meistzitiertesten Definitionen von Vertrauen stammt von Mayer et al. (1995). Sie sehen es als wesentliche Eigenschaft von Vertrauen an, dass die Bereitschaft 
besteht, ein persönliches Risiko einzugehen, indem man anderen etwas offenbart, das auch gegen einen verwendet werden könnte. Man bietet eine „Angriffsfläche“, weil man dem Gegenüber vertraut, dass es diese Schwachstelle nicht zu seinem Vorteil nutzen wird und sich kooperativ verhalten wird. Beispiele aus der Arbeitswelt sind: der Führungskraft Fehler eingestehen, auf Risiken hinweisen, die man mitverantwortet, das eigene Unvermögen oder die eigene Unsicherheit bekennen. Es liegt auf der Hand, dass derartige Verhaltensweisen nicht nur die Grundlage für eine gelebte Fehlerkultur, die Sicherung von Qualität und eine ethische Unternehmenskultur sind, sondern generell über den Führungserfolg und den nachhaltigen Erfolg von Unternehmen entscheiden. Um Mitarbeitende erfolgreich zu führen, ist Vertrauen wesentlich. Dabei kann Vertrauen nicht kurzfristig aufgebaut oder von oben „verordnet“ werden (Eberl 2003). Denn Vertrauen entwickelt sich langfristig und kann zudem sehr schnell verspielt werden. Wie aber gelingt es Führungskräften, Vertrauen zu erzeugen?

Auch wenn eine Reihe von Faktoren vorgeschlagen wurde, die dafür verantwortlich sind, ob einer Führungskraft vertraut werden kann, sehen Dietz und Den Hartog (2006) die folgenden vier Eigenschaften einer Person als zentral für ihre Vertrauenswürdigkeit an:

- Wohlwollen drückt sich bei einer Führungskraft dadurch aus, dass sie gutartige Motive verfolgt, dass sie einen freundlichen Umgang pflegt und für das persönliche Wohlergehen anderer Sorge trägt.

- Kompetenz bedeutet, dass die Führungskraft in der Lage ist, aufgrund ihrer Fähigkeiten und ihres Wissens ihre Aufgabe zu erfüllen.

- Integrität bedeutet, dass sich die Führungskraft an gegenseitig anerkannte Prinzipien hält, zu denen auch Ehrlichkeit und faire Behandlung gehören und dass sie nicht „scheinheilig“ oder „doppelzüngig“ ist.

- Berechenbarkeit bedeutet, dass ihr Verhalten eine Regelmäßigkeit aufweist und nicht widersprüchlich ist.

Vertrauen ist eine wesentliche Voraussetzung, um ein Team auf Dauer leistungsfähig zu machen. Nur wenn ein Team der Führungskraft vertraut, wird es die Handlungen, Entscheidungen und Ziele der Führungskraft akzeptieren und sich anstrengen, die gemeinsamen Ziele zu erreichen (Dirks 2000). Wenn ein Team an der Verlässlichkeit der Führungskraft zweifelt (z. B. in Bezug auf versprochene Belohnungen) oder sie verdächtigt, gegen die Interessen der Teammitglieder $\mathrm{zu}$ handeln, wird das Team den Erwartungen nicht gerecht werden. Gillespie und Mann (2004) haben herausgefunden, dass v. a. drei Verhaltensweisen seitens einer Führungskraft wichtig sind, damit die Teammitglieder ihr Vertrauen schenken: a) die Mitglieder
Eigenschaften einer vertrauenswürdigen Führungskraft

Verhaltensweisen, um Vertrauen zu gewinnen 


\section{Leadership Trust Inventory}

Behavioural Trust Inventory um Rat bitten, wenn eine Entscheidung getroffen wird, b) eine gemeinsame Vision kommunizieren und c) dass die Mitglieder eine ähnliche Wertorientierung wie die Führungskraft haben, bzw. die gleichen Werte vertreten.

Um die Vertrauenswürdigkeit in der FührungskraftMitarbeitende-Beziehung näher analysieren zu können, haben Jonge und Scherm (2015) das Leadership Trust Inventory entwickelt. Die Skala wird von den Mitarbeitenden ausgefüllt, um zu erfassen, ob sie ihrer Führungskraft vertrauen.

\section{Fragebogen}

Auszug aus dem Leadership Trust Inventory (Felfe 2015)

Meine Vorgesetzte/mein Vorgesetzter ...

... verhält sich wertschätzend im Umgang mit mir.

... würde mich nicht absichtlich kränken.

... wird von Mitarbeitenden, Kolleginnen und Kollegen aufgrund ihres/seines Könnens geschätzt.

... kennt sich aus.

... achtet immer darauf, dass der äußere Schein gewahrt bleibt. (-)

... wirkt im menschlichen Kontakt sehr berechnend. (-)

Auch Gillespie (2003; aus Dietz und Den Hartog 2006) hat einen Fragebogen, das Behavioural Trust Inventory, entworfen (- Tab. 6.3), der das Vertrauen der Mitarbeitenden in ihre Führungskraft erfasst. Gillespies Konzept zufolge gewinnt eine Führungskraft das Vertrauen ihrer Mitarbeitenden, wenn sie sich ihnen gegenüber wohlwollend zeigt, Kompetenz ausstrahlt und sich integer und berechenbar verhält.

- Tab. 6.3 Behavioural Trust Inventory (Gillespie 2003, eigene Übersetzung)

Wie sehr sind Sie bereit...

... auf die arbeitsbezogenen Entscheidungen Ihrer Führungskraft zu vertrauen?

... auf die aufgabenbezogenen Kompetenzen und Fähigkeiten Ihrer Führungskraft zu vertrauen?

... davon abhängig zu sein, dass Ihre Führungskraft sich um eine für Sie wichtige Angelegenheit kümmert?

... sich darauf zu verlassen, dass ihre Führungskraft Ihre Arbeit bei anderen richtig darstellt?

... davon abhängig zu sein, dass Ihre Führungskraft Sie in schwierigen Situationen unterstützt?

... Ihre persönlichen Gefühle mit Ihrer Führungskraft zu teilen?

... Ihrer Führungskraft persönliche Angelegenheiten anzuvertrauen, die sich auf Ihre Arbeit auswirken?
Worauf zielt die Frage ab:

Kompetenz, Berechenbarkeit

Kompetenz, Berechenbarkeit

Wohlwollen, Kompetenz, Berechenbarkeit

Wohlwollen, Kompetenz, Berechenbarkeit

Wohlwollen, Kompetenz, Berechenbarkeit

Wohlwollen, Kompetenz, Integrität

Wohlwollen, Kompetenz, Integrität 
- Tab. 6.3 Fortsetzung

Wie sehr sind Sie bereit...

... ehrlich anzusprechen, was Sie selbst von Ihrer Arbeit halten, sogar negative Gefühle und Frustration?

... arbeitsbezogene Probleme oder Schwierigkeiten mit Ihrer Führungskraft zu diskutieren, wenn diese möglicherweise gegen Sie verwendet werden könnten?

... Ihre persönlichen Überzeugungen mit Ihrer Führungskraft zu teilen?

\section{Worauf zielt die Frage ab:}

Wohlwollen, Kompetenz, Integrität

Wohlwollen, Kompetenz, Integrität

Wohlwollen, Integrität

\section{Behavioural Trust Inventory (Gillespie 2003)}

\begin{tabular}{l|l}
$\begin{array}{l}\text { Welcher Aspekt von Führung } \\
\text { wird gemessen? }\end{array}$ & $\begin{array}{l}\text { Vertrauenswürdigkeit des } \\
\text { unmittelbaren Vorgesetzten }\end{array}$ \\
\hline $\begin{array}{l}\text { Welche Dimensionen enthält } \\
\text { die Skala? }\end{array}$ & - Wohlwollen \\
& - Kompetenz \\
& - Berechenbarkeit \\
& - Integrität
\end{tabular}

Für welche Unternehmen eignet sich die Skala besonders?

Für welche Führungskräfte eignet sich die Skala besonders?

Für welche Einsatzgebiete im Personalmanagement eignet sich die Skala besonders?
Unternehmen, die ihre Führungskultur, den Umgang mit Fehlern und das Teamklima verbessern wollen

Unmittelbarer Vorgesetzte/r in einem Team

- Coaching

- Führungskräfteentwicklung

- Teamentwicklung

\section{Führungstugenden}

Seit den Führungsskandalen in den USA bei Enron, WorldCom und Tycon (Johnson 2003) oder jüngst in Deutschland bei VW und Audi, seit dem Versagen vieler US-Finanzinstitutionen im Jahr 2007/2008 und den anhaltenden Bedenken hinsichtlich eines moralisch vertretbaren Handelns in der Politik, beschäftigen sich Praxis und Medien immer intensiver mit der Frage: Wie soll ethisches Führungsverhalten konkret aussehen (Clinard und Yeager 2011)? Auch die Wissenschaft diskutiert das Thema und liefert gute Argumente für mehr Ethik in der Führung: So soll ethische Führung die Leistung der Mitarbeitenden positiv beeinflussen und bei diesen zu proaktivem Verhalten führen (Brown et al. 2005; Brown und Treviño 2006).

Die menschliche Natur weist aber Abgründe auf und oft wird Wasser gepredigt und Wein getrunken: So ist es denkbar, dass Führungskräfte sich in ihren Organisationen durchaus ethisch korrekt geben und ihre Mitarbeitenden zu ethischem Handeln ermahnen, während sie selbst, z. B. im Privaten,

Anspruch und Wirklichkeit von ethischer Führung 
Kardinaltugenden: Klugheit, Tapferkeit, Mäßigung und Gerechtigkeit
Leadership Virtues

Questionnaire unethisch handeln. Man denke z. B. an Verfehlungen religiöser oder politischer Führungspersönlichkeiten.

Riggio et al. (2010) haben eine Skala für ethisches Führungsverhalten entwickelt, die sich weniger auf konkrete ethische Verhaltensweisen bezieht, sondern sich auf die dahinterliegenden charakterlichen Elemente stützt. Eine ethische Führungskraft muss demnach die vier Kardinaltugenden Klugheit, Tapferkeit, Mäßigung und Gerechtigkeit besitzen, die bereits in den Texten von Platon, Aristoteles und Thomas von Aquin beschrieben wurden.

So ist die Tugend der Klugheit notwendig, um in komplexen Situationen Entscheidungen $\mathrm{zu}$ treffen, die dazu beitragen, Schaden $\mathrm{zu}$ minimieren und gleichzeitig den größtmöglichen Nutzen zu stiften (Riggio et al. 2010). Klugheit ist nach Aristoteles die Fähigkeit, auf der Grundlage von Erfahrungen, Reflexion und Lernprozessen das Richtige zu tun. Ohne Klugheit kann Tapferkeit in Tollkühnheit ausarten, Mäßigung kann zum Fanatismus werden, und Gerechtigkeit kann sich in Gnadenlosigkeit verwandeln. Die Klugheit ist damit Bedingung für die anderen drei Kardinaltugenden Standhaftigkeit, Mäßigung und Gerechtigkeit. Standhaftigkeit bedeutet, dass Führungskräfte angesichts von Widerständen konsequent bleiben und Rückgrat beweisen. Mäßigung ist nicht nur die Fähigkeit, die eigenen Emotionen zu kontrollieren, sondern bedeutet auch, demütig zu sein und sich z. B. nicht allzu sehr auf das zu konzentrieren, was man nicht erreichen kann, also seine eigenen Schwächen zu erkennen und diese zu akzeptieren. Bei der Gerechtigkeit unterscheidet Aristoteles zwischen dem Befolgen von Gesetzen und der Fairness; wenn sich Führungskräfte z. B. auf Kosten anderer bereichern oder ihnen Rechte verweigern, handeln sie ebenfalls ungerecht und unethisch, auch wenn sie nicht unbedingt gegen Gesetze verstoßen.

Bei der Messung der Tugenden stellt sich die durchaus philosophische Frage, ob es möglich ist, sich hier auf die Bewertungen der Mitarbeitenden $\mathrm{zu}$ verlassen, da eigentlich nur wirklich tugendhafte Personen die Tugenden anderer beurteilen können (Riggio et al. 2010). Riggio et al. (2010) konnten in ihrer Forschung allerdings starke Interkorrelationen ihres Konstrukts mit anderen Messgrößen für "gute“ Führung nachweisen, sodass die Bewertung durch Mitarbeitende durchaus legitim ist.

Der Leadership Virtues Questionnaire basiert auf der Annahme, dass sich Führungskräfte, deren persönliche Eigenschaften und Handlungen mit jeder der oben genannten vier Kardinaltugenden übereinstimmen, ethisch verhalten und dass deren unmittelbar unterstellte Mitarbeitende dies durchaus zutreffend einschätzen können. 


\section{Fragebogen}

Leadership Virtues Questionnaire (Riggio et al. 2010, eigene Übersetzung)

\begin{tabular}{|c|c|c|c|c|}
\hline Nie & & Manchmal & & Häufig \\
\hline 1 & 2 & 3 & 4 & 5 \\
\hline
\end{tabular}

Meine Führungskraft ...

\section{Klugheit}

1. macht das, was er/sie in einer gegebenen Situation tun sollte.

2. berücksichtigt nicht sorgfältig alle verfügbaren Informationen bevor er/sie eine wichtige Entscheidung trifft, die Auswirkungen auf andere hat. (-)

3. stürzt sich tollkühn in eine Situation ohne die Folgen seines/ihres Handelns zu bedenken. (-)

4. sucht nicht in einer Vielzahl von Quellen nach Informationen, sodass die beste Entscheidung getroffen werden kann. (-)

5. betrachtet ein Problem von allen Seiten und erzielt damit die beste Entscheidung für alle Parteien.

\section{Tapferkeit}

1. würde eher seinen/ihren Job riskieren als etwas Unrechtes zu tun.

2. würde Schwierigkeiten haben, für seine/ihre Überzeugung gegenüber Freundinnen und Freunden einzustehen, die nicht die gleichen Ansichten teilen. (-)

3. scheitert daran, die moralisch beste Entscheidung in einer gegebenen Situation zu treffen. (-)

4. würde zögern, ethische Standards durchzusetzen, wenn es um einen guten Freund geht. (-)

5. ignoriert seine/ihre „innere Stimme, wenn es um die Entscheidung geht, wie es weitergehen soll. (-)

\section{Mäßigung}

1. scheint allzu besorgt um seine/ihre persönliche Macht zu sein. (-)

2. scheint nicht allzu sehr besorgt um seine/ihre eigenen Verdienste.

3. möchte alles wissen, was in seinem/ihrem Organisationsbereich vor sich geht, bis hin zum Micromanagement. (-)

\section{Gerechtigkeit}

1. würdigt andere, wie es ihm/ihr gebührt. 
2. zeigt Respekt für alle Menschen.

3. würde die Lorbeeren anderer für sich reklamieren. (-)

4. respektiert die Rechte und Würde anderer.

5. würde Beförderungen aufgrund der Verdienste des $/ r$ Kandidaten/in fällen.

6. behandelt andere nicht so, wie er/sie selbst behandelt werden möchte. $(-)$

Leadership Virtues Questionnaire (Riggio et al. 2010)

Welcher Aspekt von Führung wird gemessen?

Ethische Führung, basierend auf den vier Kardinaltugenden

Welche Dimensionen enthält die Skala?

- Klugheit

- Tapferkeit

- Mäßigung

- Gerechtigkeit

Für welche Unternehmen eignet sich die Skala besonders?

Unternehmen in einem Prozess der Neudefinition von Führungskultur, z. B. nach Skandalen

Für welche Führungskräfte eignet sich die Skala besonders?

Führungskräfte, die ihr Führungsverhalten reflektieren und sich weiterentwickeln wollen

Für welche Einsatzgebiete im

- Führungsfeedback

Personalmanagement eignet

- Organisationsentwicklung/ sich die Skala besonders?

Cultural Change

- Führungskräfteentwicklung

- Führungskräftetraining

- Coaching

\section{Die Dunkle Triade: Machiavellistische Führung, Narzisstische Führung und Psychopathische Führung}

I) Ein Narzisst, ein Psychopath und ein Machiavellist treffen sich in einer Bar. Der Barkeeper fragt: „Wer von Euch dreien hat die dunkelste Persönlichkeit?". Der Narzisst antwortet: „Ich!“, der Psychopath sagt: „Das ist mir egal.“ Und der Machiavellist erwidert: „Es ist derjenige, den ich bestimme.“ (Chopra 2013)

Auch wenn narzisstisches, psychopathisches und machiavellistisches Führungsverhalten unterschiedliche Ausprägungen und unterschiedliche Ursprünge haben, so gibt es doch auch einige Gemeinsamkeiten - Führungskräfte, die einen solchen „Führungsstil“ zeigen, haben einen sozial bösartigen Charakter mit Verhaltenstendenzen zur Selbstdarstellung, emotionaler Kälte, Doppelzüngigkeit und Aggressivität (Paulhus und Williams 2002). Einen solchen Chef wünscht man sich eher nicht. 


\section{- Machiavellistische Führung}

Niccolo Machiavelli (1469-1527) war florentinischer Politiker und Staatsphilosoph. Sein berühmtestes Werk hat den Titel „Il Principe“ (zu Deutsch: Der Fürst), und war ein „Lehrbuch“ für die damaligen Regenten (Machiavelli 2013). Machiavelli bricht darin mit der bisherigen Tradition der sogenannten „Fürstenspiegel“" und deren moralischem Ansatz. Er entwickelt darin die Grundsätze einer Staatsräson, nach der Herrscher mitunter die Gesetze der traditionellen Moral verletzen müssen bzw. das tun müssen, was notwendig ist, um ihre politischen Ziele zu erreichen und den Staat zu erhalten („Staatsräson“).

Obwohl dies nicht notwendigerweise unethisches, rücksichtsloses und amoralisches Verhalten bedeutet, wird der Begriff „machiavellistisch“ heute abwertend gebraucht, um ein Führungsverhalten zu beschreiben, bei dem der Zweck, nämlich der persönliche Nutzen, die Mittel heiligt. Mit anderen Worten: Eine machiavellistische Führungskraft ist misstrauisch, versucht Situationen und Menschen so gut wie möglich unter ihre Kontrolle zu bringen und sie hat keinerlei Skrupel, unethisch zu handeln oder anderen zu schaden, um ihre Ziele zu erreichen. Machiavellistische Führungskräfte haben ein negatives Menschenbild, sie sehen andere Menschen als schwach, fehlbar, leichtgläubig und unaufrichtig an. Sie agieren nicht auf Augenhöhe, sondern manipulieren andere Menschen, z. B. ihre Mitarbeitenden, wie Objekte.

Basierend auf der Forschung von Christie und Geis (1970) können machiavellistische Führungskräfte folgendermaßen charakterisiert werden:

- Sie lassen sich emotional nicht auf zwischenmenschliche Beziehungen ein, weil es einfacher ist andere $\mathrm{zu}$ manipulieren, wenn man zu diesen keine persönliche Bindung aufgebaut hat und sie als Objekte und nicht als Mitmenschen sieht.

- Bei ihren Interaktionen mit anderen nehmen sie eher eine utilitaristische Perspektive ein, als eine moralische, da sie die herkömmliche Moral nicht interessiert.

- Eine erfolgreiche Manipulation ihrer Mitmenschen ist abhängig von einer präzisen Analyse ihrer Bedürfnisse und einer realistischen Einschätzung der Situation im Allgemeinen. Aus diesem Grund sind machiavellistische Führungskräfte nicht unbedingt psychisch pathologisch.

- Sie können sich für Ideologien wenig begeistern, da sie ihren Fokus darauf richten, ihre Ziele zu erreichen, anstatt sich mit möglicherweise hinderlichen Weltanschauungen und Wertvorstellungen auseinanderzusetzen.

Grundsätze einer Staatsräson

Der Zweck heiligt die Mittel

Merkmale einer machiavellistischen Führungskraft

Persönlichkeitsskala 
der die machiavellistische Persönlichkeit misst. Eine methodisch fundiertere Weiterentwicklung stellt die von Dahling et al. (2009) entworfene Machiavellistische Persönlichkeitsskala dar, bei der auch neuere Erkenntnisse bspw. aus den Bereichen Vertrauen, Ethik und Unternehmenspolitik, berücksichtigt wurden.

\section{Fragebogen}

Machiavellistische Persönlichkeitsskala (MPS) nach Dahling et al. (2009, eigene Übersetzung)

Stimme über-

haupt nicht zu
Neutral

4
Stimme vollkommen zu

7

\section{Misstrauen gegenüber anderen}

1. Personen sind nur durch ihren persönlichen Nutzen motiviert.

2. Ich binde mich nicht gerne an Gruppen, weil ich anderen nicht vertraue.

3. Teammitglieder fallen sich gegenseitig ständig in den Rücken, um weiter zu kommen.

4. Wenn ich eine Schwäche in der Arbeit zeige, werden andere dies ausnützen.

5. Andere Leute überlegen ständig, wie sie Gelegenheiten auf meine Kosten ausnutzen können.

\section{Amoralität}

1. Ich würde mich unethisch verhalten, wenn ich glaube, dass es mir hilft, erfolgreich zu sein.

2. Ich würde die Bemühungen anderer sabotieren, wenn diese meine eigenen Ziele gefährden.

3. Ich würde betrügen, wenn die Wahrscheinlichkeit gering ist, erwischt zu werden.

4. Ich glaube, unaufrichtig zu sein, ist notwendig, um einen Wettbewerbsvorteil gegenüber anderen zu behalten.

5. Der einzige triftige Grund mit anderen zu reden ist Informationen zu erhalten, die ich zu meinem Vorteil nutzen kann.

\section{Wunsch nach Kontrolle}

1. Ich erteile in zwischenmenschlichen Situationen gerne Anweisungen.

2. Ich genieße es, Kontrolle über die Situation zu haben.

3. Ich genieße es, die Kontrolle über andere Personen zu haben.

\section{Wunsch nach Status}

1. Status ist ein gutes Zeichen für den Erfolg im Leben.

2. Reichtum anzuhäufen ist ein wichtiges Ziel für mich.

3. Ich möchte eines Tages reich und einflussreich sein. 


\begin{tabular}{|c|c|}
\hline $\begin{array}{l}\text { Welcher Aspekt von Führung } \\
\text { wird gemessen? }\end{array}$ & $\begin{array}{l}\text { Machiavellistische Führungs- } \\
\text { persönlichkeit }\end{array}$ \\
\hline $\begin{array}{l}\text { Welche Dimensionen enthält } \\
\text { die Skala? }\end{array}$ & $\begin{array}{l}\text { - Misstrauen gegenüber anderen } \\
\text { - Amoralität } \\
\text { - Wunsch nach Kontrolle } \\
\text { - Wunsch nach Status }\end{array}$ \\
\hline $\begin{array}{l}\text { Für welche Unternehmen eignet } \\
\text { sich die Skala besonders? }\end{array}$ & $\begin{array}{l}\text { Unternehmen, die ihre Führungs- } \\
\text { kultur reflektieren, entwickeln, } \\
\text { verändern wollen }\end{array}$ \\
\hline $\begin{array}{l}\text { Für welche Führungskräfte } \\
\text { eignet sich die Skala besonders? }\end{array}$ & $\begin{array}{l}\text { Führungskräfte, die ihr } \\
\text { Menschenbild und ihre eigenen } \\
\text { Einstellungen reflektieren wollen }\end{array}$ \\
\hline $\begin{array}{l}\text { Für welche Einsatzgebiete im } \\
\text { Personalmanagement eignet } \\
\text { sich die Skala besonders? }\end{array}$ & $\begin{array}{l}\text { Entwicklung von Führungskultur } \\
\text { (Führungstrainings, Coaching, } \\
\text { Compliance, Selbstreflexion, } \\
\text { Persönlichkeitsentwicklung) }\end{array}$ \\
\hline
\end{tabular}

\section{- Narzisstische Führung}

Das narzisstische Führungskonzept hat eine lange Geschichte. Erstmals wurde Narzissmus im Jahr 1898 in der psychologischen Literatur eingeführt. Havelock Ellis (1898) nutzte den Begriff „narcissus-like“, um eine Tendenz des sich Verlierens in Selbstbewunderung zu beschreiben. Kurze Zeit später schrieb der Deutsche Paul Näcke (1899) eine Zusammenfassung von Ellis' Artikel und verwendete erstmalig den Begriff Narzissmus. Dieser bezog sich hier auf eine sexuelle Perversion bzw. Geschlechtsverirrung, bei der eine Person ihren eigenen Körper als sexuelles Objekt behandelt. Freud wurde auf diese Publikation aufmerksam und führte in der Folge den Narzissmus als metapsychologisches Konstrukt ein. Aus seiner Perspektive ist Narzissmus u. a. der Ursprung und Energielieferant für die Entwicklung des eigenen Egos (Raskin und Terry 1988).

Im Kontext von Führung wird mit Narzissmus ein Syndrom bezeichnet, das mit Arroganz, Selbstverliebtheit, Anspruchsdenken und einem zerbrechlichen Selbstwertgefühl einhergeht und sich in starken Bedürfnissen nach Ansehen (z. B. Prestige, Status, Aufmerksamkeit, Bewunderung) und Macht manifestieren. In vielen Fällen werden diese Bedürfnisse auf Kosten von Mitarbeitenden erreicht, v. a. dann, wenn sich die Führungskraft gegenüber Mitarbeitenden launisch, feindselig, unfair, egoistisch und manipulierend verhält (Yukl 2010). Auch wenn bei Narzissten nicht die einfühlsame Sorge um die von ihnen geführten Mitarbeitenden oder Organisationen im Vordergrund steht, so besitzen sie doch das Charisma und die visionäre Kraft, die für eine effektive Führung unerlässlich sind (Rosenthal und Pittinsky 2006). So zeigen Untersuchungen,
Verständnis von Narzissmus

Merkmale einer narzisstischen Führungskraft 
Narcissistic Personality Inventory dass viele mächtige und extrem erfolgreiche Führungspersönlichkeiten, z. B. U.S. Präsidenten und CEOs von Computerund Softwareunternehmen, narzisstische Züge aufweisen (Chatterjee und Hambrick 2007; Deluga 1997).

Raskin und Terry (1988) entwickelten für die Messung von Narzissmus mittels Selbsteinschätzung das Narcissistic Personality Inventory, das die sieben Komponenten Autorität, Exhibitionismus, Überlegenheit, Eitelkeit, Ausnutzen anderer, Anspruchshaltung und Unabhängigkeit umfasst.

\section{Fragebogen \\ Narcissistic Personality Inventory nach Raskin und Terry (1988, eigene Übersetzung)}

\begin{tabular}{c|c|c}
$\begin{array}{c}\text { Stimme } \\
\text { ganz und } \\
\text { gar nicht zu }\end{array}$ & Neutral & $\begin{array}{c}\text { Stimme voll } \\
\text { und ganz zu }\end{array}$ \\
\hline
\end{tabular}

1

2

3

4

5

\section{Autorität}

1. Ich würde es vorziehen, Führungskraft zu sein.

2. Ich sehe mich selbst als gute Führungskraft.

3. Ich werde erfolgreich sein.

4. Andere Personen scheinen immer meine Autorität zu erkennen.

5. Ich habe ein natürliches Talent, Menschen zu beeinflussen.

6. Ich bin durchsetzungsfähig.

7. Ich habe gerne Autorität über andere.

8. Ich bin eine geborene Führungsperson.

\section{Unabhängigkeit}

9. Ich bin selten von jemand anderem abhängig, um etwas zu schaffen.

10. Ich übernehme gerne Verantwortung für das Treffen von Entscheidungen.

11. Ich bin fähiger als andere Personen.

12. Ich kann mein Leben so leben, wie ich es will.

13. Ich weiß immer genau, was ich tue.

14. Ich werde eine große Persönlichkeit sein.

\section{Überlegenheit}

15. Ich bin eine außerordentliche Persönlichkeit.

16. Ich weiß, dass ich gut bin, weil es mir ständig alle sagen.

17. Ich erhalte gerne Komplimente.

18. Ich denke, ich bin etwas Besonderes.

19. Ich wünschte, jemand würde eines Tages meine Biographie schreiben. 


\section{Exhibitionismus}

20. Ich habe eine Neigung anzugeben, wenn sich eine Möglichkeit dazu bietet.

21. Bescheidenheit passt nicht zu mir.

22. Es ärgert mich, wenn andere Personen nicht bemerken wie ich aussehe, wenn ich ausgehe.

23. Ich stehe gerne im Mittelpunkt.

24. Ich würde fast alles machen bei einer Mutprobe.

25. Ich stehe wirklich gerne im Mittelpunkt.

26. Ich mag neue Mode und bin Trendsetter.

\section{Ausnutzen anderer}

27. Ich kann in Personen wie in einem Buch lesen.

28. Ich kann jeden glauben machen, was ich will.

29. Es fällt mir leicht, andere zu manipulieren.

30. Ich kann mich normalerweise aus allem herausreden.

31. Jeder hört gerne meine Geschichten.

\section{Eitelkeit}

32. Ich betrachte gerne meinen Körper.

33. Ich schaue mich gerne im Spiegel an.

34. Ich zeige gerne meinen Körper.

\section{Anspruchshaltung}

35. Ich bin solange nicht zufrieden bis ich bekomme, was ich verdiene.

36. Ich erwarte sehr viel von anderen Menschen.

37. Ich möchte in den Augen der Welt etwas bedeuten.

38. Ich habe einen großen Willen zur Macht.

39. Ich bestehe darauf, den Respekt zu bekommen, der mir zusteht.

40. Wenn ich die Welt regieren würde, wäre sie ein viel besserer Ort.

Narcissistic Personality Inventory (Raskin und Terry 1988)

\begin{tabular}{l|l}
$\begin{array}{l}\text { Welcher Aspekt von Führung } \\
\text { wird gemessen? }\end{array}$ & Narzisstische Führung \\
\hline $\begin{array}{l}\text { Welche Dimensionen enthält } \\
\text { die Skala? }\end{array}$ & $\begin{array}{l}\text { - Autorität } \\
\text { - Unabhängigkeit } \\
\end{array}$ \\
& - Überlegenheit \\
& - Exhibitionismus \\
& - Ausnutzen anderer \\
& - Eitelkeit \\
\hline $\begin{array}{l}\text { Für welche Unternehmen eignet } \\
\text { sich die Skala besonders? }\end{array}$ & - Anspruchshaltung \\
\hline
\end{tabular}


Psychopathie - die

dunkelste Dimension der

Dunklen Triade

"Helle" Seiten der

Psychopathie

Taktiken psychopathischer Führungskräfte
Für welche Führungskräfte eignet sich die Skala besonders?

Für welche Einsatzgebiete im Personalmanagement eignet sich die Skala besonders?
- Top Management

- Obere Hierarchieebenen

Selbstreflektion und Coaching für Führungskräfte im oberen Management, z. B. Kontrastierung zu ethischer Führung

\section{- Psychopathische Führung}

I) "Not all psychopaths are in prison. Some are in the Boardroom." (Hare 2002)

Die wohl finsterste Dimension der dunklen Triade ist die psychopathische Führung. Im Vergleich zu Narzissten und Machiavellisten tendieren Psychopathen noch mehr zu Schikane, Tyrannei und Mobbing (Baughman et al. 2012). Psychopathen sind außerdem unberechenbar - bei ihnen kann es jederzeit zu einem cholerischen Ausbruch kommen. Sie lassen sich als kalt, gefühllos, manipulativ und gleichzeitig erlebnishungrig charakterisieren. Als Führungskräfte können sie sich nur schwer bis gar nicht in andere Personen einfühlen. Beispiele aus der Populärkultur für solche Persönlichkeiten sind bspw. der gefühlskalte Drogenboss Tuco Salamanca aus der Fernsehserie „Breaking Bad“ oder der Joker - gespielt von Heath Ledger - im Film „The Dark Knight“ (Furtner 2017).

Im Unternehmenskontext weisen laut Babiak et al. (2010) etwa $4 \%$ der Führungskräfte in den Top-Führungsebenen psychopathische Züge auf. Man findet psychopathische Persönlichkeiten eher in privaten Unternehmen und weniger im öffentlichen Dienst, in sozialen oder medizinischen Berufen. Im Idealfall finden Psychopathen einen Job, in dem sie ohne Aufsicht überwiegend alleine arbeiten können und kaum Regeln befolgen müssen (Externbrink et al. 2018).

Warum aber werden sie überhaupt eingestellt? Neben ihrer dunklen Seite besitzen Psychopathen oft auch wünschenswerte Eigenschaften wie Charme und Durchsetzungsfähigkeit und sie beherrschen alle Register des Eindrucksmanagements. Die oft innerhalb eines kurzen Zeitraums stattfindende Eignungsdiagnostik, z. B. mittels Interviews, erlaubt es nicht, alle Facetten der Persönlichkeit von Bewerberinnen und Bewerbern zu enthüllen. Eine Meta-Studie von Landay et al. (2019) zeigt sogar, dass eine leicht psychopathische Persönlichkeit die Chancen verbessert, in die Chefetage aufzusteigen - allerdings ohne langfristigen Erfolg. Ein weiteres Ergebnis dieser Studie ist, dass weibliche Führungskräfte mit psychopathischen Zügen weniger toleriert werden als Männer.

Die Case Study von Boddy (2017) beschreibt die verheerenden Konsequenzen, wenn ein psychopathischer CEO "an die Macht“ gelangt - und eben nicht alleine, sondern mit einem Team arbeitet: Die Mitarbeiterfluktuation nimmt zu, der Umsatz und die Mitarbeiterbindung gehen zurück, das kreative Verhalten und die Innovationskraft nehmen ebenfalls ab. Das liegt v. a. auch daran, 
dass sich psychopathische Führungskräfte nicht nur sogenannter „weicher Taktiken, wie z. B. Einschmeicheln und Argumentieren, sondern auch "harten Taktiken“ bedienen, wie bspw. der direkten Manipulation und des Aufzwingens des eigenen Willens. Durch geschickte Beeinflussungstechniken und die Ausübung von Druck führen sie nicht nur Verhaltensänderungen herbei, sondern wirken auch auf Überzeugungen, Einstellungen, Bedürfnisse und Werte ein, um ihre persönlichen Ziele zu erreichen (Jonason et al. 2012).

Um alle drei Dimensionen der dunklen Triade - den Narzissmus, den Machiavellismus und die Psychopathie praktikabel abbilden zu können, entwickelten Jones und Paulhus (2014) aus bestehenden Skalen eine Kurzskala, die Short Dark Triad Skala. In der folgenden Tabelle werden die Items zur Messung psychopathischer Führung vorgestellt:

\section{Fragebogen}

Psychopathie-Items der Short Dark Triad (SD3) Skala nach Jones und Paulhus (2014, eigene Übersetzung)

\begin{tabular}{c|c|c|c|c|}
$\begin{array}{c}\text { Stimme ganz } \\
\text { und gar } \\
\text { nicht zu }\end{array}$ & $\begin{array}{c}\text { Stimme } \\
\text { nicht zu }\end{array}$ & Teils/teils & Stimme zu & $\begin{array}{c}\text { Stimme voll } \\
\text { und ganz zu }\end{array}$ \\
\hline
\end{tabular}

\begin{tabular}{|l|l|l|l|l|}
\hline 1 & 2 & 3 & 4 & 5 \\
\hline
\end{tabular}

1. Ich mag es, mich an Autoritäten zu rächen.

2. Ich meide gefährliche Situationen. (-)

3. Rache muss schnell und schmerzhaft sein.

4. Leute sagen oft, dass ich außer Kontrolle bin.

5. Ich kann zu anderen wirklich gemein sein.

6. Leute, die sich mit mir anlegen, bereuen es immer.

7. Ich bin noch niemals mit dem Gesetz in Konflikt geraten. (-)

8. Ich genieße es, Sex mit Personen zu haben, die ich kaum kenne.

9. Ich würde alles sagen, um zu bekommen, was ich will.

Short Dark Triad-Skala (SD3, Jones und Paulhus 2014) Welcher Aspekt von Führung
wird gemessen?
Welche Dimensionen enthält
die Skala?

Für welche Unternehmen und Führungskräfte eignet sich die Skala besonders?

Für welche Einsatzgebiete im Personalmanagement eignet sich die Skala besonders?
Short Dark Triad Skala 
Das "dreckige Dutzend“ eine kompakte Messmethode

\section{- Das „dreckige Dutzend"}

Jonason und Webster (2010) haben eine kompakte Messmethode mit lediglich 12 Items zur Erfassung der dunklen Seite der menschlichen Natur entwickelt und validiert. Sie nennen dieses Instrument das „dreckige Dutzend“. Generell gibt es einen Trend in der psychologischen Diagnostik, prägnante Messungen für die wichtigsten Persönlichkeitsmerkmale zu erstellen. Knackige Messmethoden sind attraktiv, weil sie weniger Zeit in Anspruch nehmen als umfangreiche Persönlichkeitsinventare, indem sie redundante Items eliminieren und so die Ermüdung und Frustration der Teilnehmenden reduzieren.

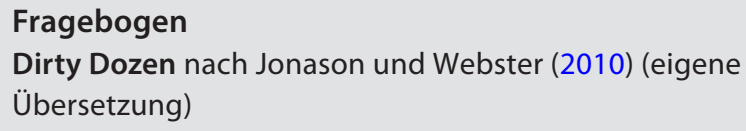

Stimme voll und ganz zu

9

\section{Machiavellismus}

1. Ich neige dazu, andere zu manipulieren, um meinen Willen durchzusetzen.

2. Ich habe getäuscht oder gelogen, um meinen Willen durchzusetzen.

3. Ich habe Schmeicheleien benutzt, um meinen Willen durchzusetzen.

4. Ich neige dazu, andere für mein eigenes Ziel auszunutzen.

\section{Psychopathie}

1. Ich neige dazu, keine Skrupel zu haben.

2. Ich neige dazu, mich nicht mit der Moral meines Handelns zu beschäftigen.

3. Ich neige dazu, gefühllos oder unsensibel zu sein.

4. Ich neige dazu, zynisch zu sein.

\section{Narzissmus}

1. Ich neige dazu, zu wollen, dass andere mich bewundern.

2. Ich neige dazu, zu wollen, dass andere auf mich schauen.

3. Ich neige dazu, nach Prestige oder Status zu streben.

4. Ich neige dazu, von anderen besondere Gefälligkeiten zu erwarten.

Dirty Dozen (Jonason und Webster 2010) 


\begin{tabular}{|c|c|}
\hline $\begin{array}{l}\text { Welche Dimensionen enthält } \\
\text { die Skala? }\end{array}$ & $\begin{array}{l}\text { - Machiavellismus } \\
\text { - Psychopathie } \\
\text { - Narzissmus }\end{array}$ \\
\hline $\begin{array}{l}\text { Für welche Unternehmen eignet } \\
\text { sich die Skala besonders? }\end{array}$ & $\begin{array}{l}\text { - Dynamisches Umfeld } \\
\text { - Intensiver Wettbewerb }\end{array}$ \\
\hline $\begin{array}{l}\text { Für welche Führungskräfte } \\
\text { eignet sich die Skala besonders? }\end{array}$ & $\begin{array}{l}\text { - Top Management } \\
\text { - Obere Hierarchieebenen }\end{array}$ \\
\hline $\begin{array}{l}\text { Für welche Einsatzgebiete im } \\
\text { Personalmanagement eignet } \\
\text { sich die Skala besonders? }\end{array}$ & $\begin{array}{l}\text { Selbstreflektion und Coaching } \\
\text { für Führungskräfte im oberen } \\
\text { Management, z. B. Kontrastierung } \\
\text { zu ethischer Führung }\end{array}$ \\
\hline
\end{tabular}

\subsection{Diagnose von Einstellungen}

Mit Einstellung ist in der Psychologie die Bereitschaft einer Person gemeint, in bestimmter, meist positiver oder negativer Weise auf einen Reiz zu reagieren. Der Reiz kann dabei vielgestaltig sein. Es kann sich z. B. um eine bestimmte Person, eine Personengruppe aber auch eine Situation, ein Objekt oder lediglich eine Vorstellung handeln. Und auch die Reaktion kann sich auf verschiedenen Ebenen abspielen: der kognitiven Ebene (z. B. indem sich eine Überzeugung verfestigt), der Gefühlsebene (z. B. indem man sich ärgert) oder der Verhaltensebene (z. B. indem man sich bei der Arbeit anstrengt) (Six 2014).

Im Folgenden werden einige Messinstrumente vorgestellt, die die Einstellung der Mitarbeitenden gegenüber der Führung oder Einstellungen der Führungskräfte selbst erheben können. - Abschn. 6.3.1 stellt eine Skala zum Vertrauen in die Führungskraft bzw. zur Loyalität von Mitarbeitenden gegenüber der Führungskraft vor. In $>$ Abschn.6.3.2 geht es um die Feedbackorientierung von Führungskräften, die ebenfalls Einstellungskomponenten z. B. Verantwortungsübernahme - enthält. Ein Instrument zur Messung der Selbstwirksamkeitsüberzeugung von Führungskräften, also der Einschätzung der eigenen Möglichkeiten, neue oder schwierige Anforderungssituationen aufgrund eigener Fähigkeiten bewältigen zu können, wird in $\mathbf{A b s c h n . 6 . 3 . 3 ~ p r a ̈ s e n t i e r t . ~}$

\subsubsection{Vertrauen und Loyalität gegenüber der Führungskraft}

Besonders heikle Situationen, wie bspw. ein anstehender Personalabbau, stellen Führungskräfte vor die Herausforderung, das Vertrauen ihrer Mitarbeitenden weiterhin aufrecht zu erhalten. Norman et al. (2010) fanden heraus, dass eine offene und ehrliche Kommunikationspolitik sowie Fähigkeiten aus der positiven Psychologie seitens der Führungskraft das Vertrauen der Mitarbeitenden in die Führung in derartigen Situationen steigern können. Unabhängig davon, ob
Positive Auswirkungen von Vertrauen 
Trust in/Loyalty to the Leader Scale

die Unternehmenssituation schwierig ist oder nicht, sind Mitarbeitende zufriedener im Job und zeigen mehr Commitment gegenüber ihrer Organisation, wenn sie ihrer Führungskraft vertrauen können. Diese Vertrauensbeziehung bestärkt die Mitarbeitenden zudem darin, ihre Aufgaben engagierter anzugehen und unterstützendes Verhalten gegenüber Kolleginnen und Kollegen zu zeigen (Yang und Mossholder 2010).

Um das Vertrauen und die Loyalität von Mitarbeitenden gegenüber ihrer Führungskraft zu erfassen, haben Podsakoff et al. (1990) drei Items aus den Skalen von Cook und Wall (1980) mit drei neuen Items kombiniert, um ein ökonomisches und übersichtliches Messinstrument zu entwickeln. Die ersten drei Items zielen mit den Themen Fairness, Verlässlichkeit und Integrität auf die vermutete Vertrauenswürdigkeit der Führungskraft ab, die restlichen Items reflektieren die Loyalität der Mitarbeitenden gegenüber ihrer Führungskraft.

\section{Fragebogen}

Trust in/Loyalty to the Leader Scale nach Podsakoff et al. (1990, eigene Übersetzung)

\section{Stimme \\ über- \\ haupt \\ nicht zu}

1
Neutral

Stimme vollkommen zu

5

1. Ich bin sehr zuversichtlich, dass mich meine Führungskraft immer fair behandeln wird.

2. Meine Führungskraft würde nie versuchen, einen Vorteil zu erlangen, indem sie/er Mitarbeitende täuscht.

3. Ich habe vollstes Vertrauen in die Integrität meiner Führungskraft.

4. Ich empfinde eine starke Loyalität gegenüber meiner Führungskraft.

5. Ich würde meine Führungskraft in fast jeder Notsituation unterstützen.

6. Ich habe ein gespaltenes Loyalitätsverhältnis zu meiner Führungskraft. (-)

Trust in/Loyalty to the Leader Scale (Podsakoff et al. 1990)

Welcher Aspekt von Führung wird gemessen?

Welche Dimensionen enthält die Skala?
Vertrauen in die Führungskraft und Loyalität gegenüber der Führungskraft

Vertrauen/Loyalität 
Für welche Unternehmen eignet sich die Skala besonders?

Für welche Führungskräfte eignet sich die Skala besonders?

Für welche Einsatzgebiete im Personalmanagement eignet sich die Skala besonders?
- Innovative Unternehmen in dynamischem Umfeld

- Unternehmen mit hoher Fluktuation

Führungskräfte, die sich selbst und ihr Verhältnis zu Mitarbeitenden reflektieren wollen

- Mitarbeiterbindung/Commitment erhöhen

- Feedbackkultur fördern

- Kooperation verbessern

- Mitarbeiterzufriedenheit erhöhen

\subsubsection{Feedbackorientierung}

Heute schlagen Arbeitnehmerinnen und Arbeitnehmer den Nutzen von Feedback Berufspfad ein, der am meisten Weiterentwicklung und Erfolg verspricht, unabhängig vom Unternehmen. Wenn Unternehmen talentierte Mitarbeitende anwerben und an sich binden wollen, müssen sie also Entwicklungsmöglichkeiten schaffen und vielfältige Karrierepfade bieten (Linderbaum und Levy 2010). Im Rahmen der Mitarbeiter- und Führungskräfteentwicklung ist Feedback ein immer wichtiger werdendes Tool. Feedback wirkt nicht nur motivations- und leistungssteigernd (London 2003), es reduziert Unsicherheit, liefert Orientierung über Zielfortschritt und -erreichung und verstärkt das Gefühl, kompetent zu sein. In der Personalarbeit wird Feedback daher sogar häufiger zur Mitarbeiterentwicklung eingesetzt als zur reinen Leistungsbewertung (Levy und Williams 2004).

Um wirksam Feedback geben zu können und eine positive Haltung gegenüber dem Feedback und dem Feedbackgebenden sicherzustellen, müssen Führungskräfte sensibel sein: Welche Einstellungen haben die einzelnen Mitarbeitenden zu Feedback, wie reagieren sie auf Feedback und wie nutzen sie dieses im Alltag (Ilgen et al. 1979)? Um diese feedbackspezifischen individuellen Unterschiede in der Feedbackorientierung zu ermitteln, haben Linderbaum und Levy (2010) die Feedback Orientation Scale (FOS) entwickelt.

Die FOS hilft zu erkennen, wie offen oder empfänglich ein Mitarbeitender oder eine Führungskraft für Feedback und damit verbundene Entwicklungsmaßnahmen ist (Linderbaum und Levy 2010).

\section{Fragebogen}

Feedback Orientation Scale (FOS) nach Linderbaum und Levy (2010, eigene Übersetzung)

Stimme ganz und gar nicht zu
Neutral

3
Feedback Orientation Scale
Stimme voll und ganz zu

$\mid$

$\mid$

2




\section{Nützlichkeit}

1. Feedback trägt zu meinem Erfolg in der Arbeit bei.

2. Um meine Fähigkeiten bei der Arbeit zu entwickeln, bin ich auf Feedback angewiesen.

3. Feedback ist entscheidend, um die Arbeitsleistung zu verbessern.

4. Feedback von Vorgesetzten kann mir helfen im Unternehmen weiter zu kommen.

\section{Verantwortungsübernahme}

5. Es liegt in meiner Verantwortung erhaltenes Feedback umzusetzen, um meine Leistung zu verbessern.

6. Ich bin dafür verantwortlich, angemessen auf Feedback zu reagieren.

7. Erst wenn ich auf Feedback reagiert habe, ist die Sache für mich abgeschlossen.

8. Wenn ich von meinem Vorgesetzten Feedback erhalte, bin ich dafür verantwortlich, darauf einzugehen.

9. Ich fühle mich verpflichtet, aufgrund von Feedback etwas zu verändern.

\section{Soziale Wahrnehmung}

10. Ich achte darauf, was andere Personen von mir denken.

11. Durch Feedback wird mir bewusster, was andere Personen über mich denken.

12. Feedback hilft mir, den Eindruck, den ich auf andere mache, zu steuern.

13. Ich nutze Feedback, um einen guten Eindruck bei anderen zu hinterlassen.

\section{Feedbackselbstvertrauen}

14. Ich bin selbstbewusst im Umgang mit Feedback.

15. Im Vergleich zu anderen kann ich besser mit Feedback umgehen.

16. Ich glaube, dass ich die Fähigkeit habe, wirksam mit Feedback umzugehen.

17. Sowohl auf positives als auch auf negatives Feedback kann ich selbstsicher reagieren.

18. Ich weiß, dass ich mit dem Feedback, das ich erhalte, umgehen kann.

Linderbaum und Levy (2010) gehen davon aus, dass es einen deutlichen Zusammenhang zwischen der individuellen Feedbackorientierung und dem Erfolg von Trainingsoder Coaching-Maßnahmen gibt. Obwohl die individuelle Feedbackorientierung grundsätzlich relativ stabil ist, kann sie durch gezielte Interventionen wie Coaching beeinflusst 
werden. In der HR-Praxis von Unternehmen kann es daher sinnvoll sein, die Skala z. B. in Potenzialanalysen oder Assessment Centern einzusetzen. Aber auch Führungskräften hilft es, mehr über ihre eigene oder die Feedbackorientierung ihrer Mitarbeitenden zu erfahren. Einerseits können sie dadurch bspw. ein besseres Verständnis gewinnen, warum sie selbst nie Feedback erhalten. Andererseits hilft es ihnen, wenn z. B. ein Mitarbeitender nur ein geringes Feedbackselbstvertrauen hat, dies bei Rückmeldungen adäquat berücksichtigen zu können.

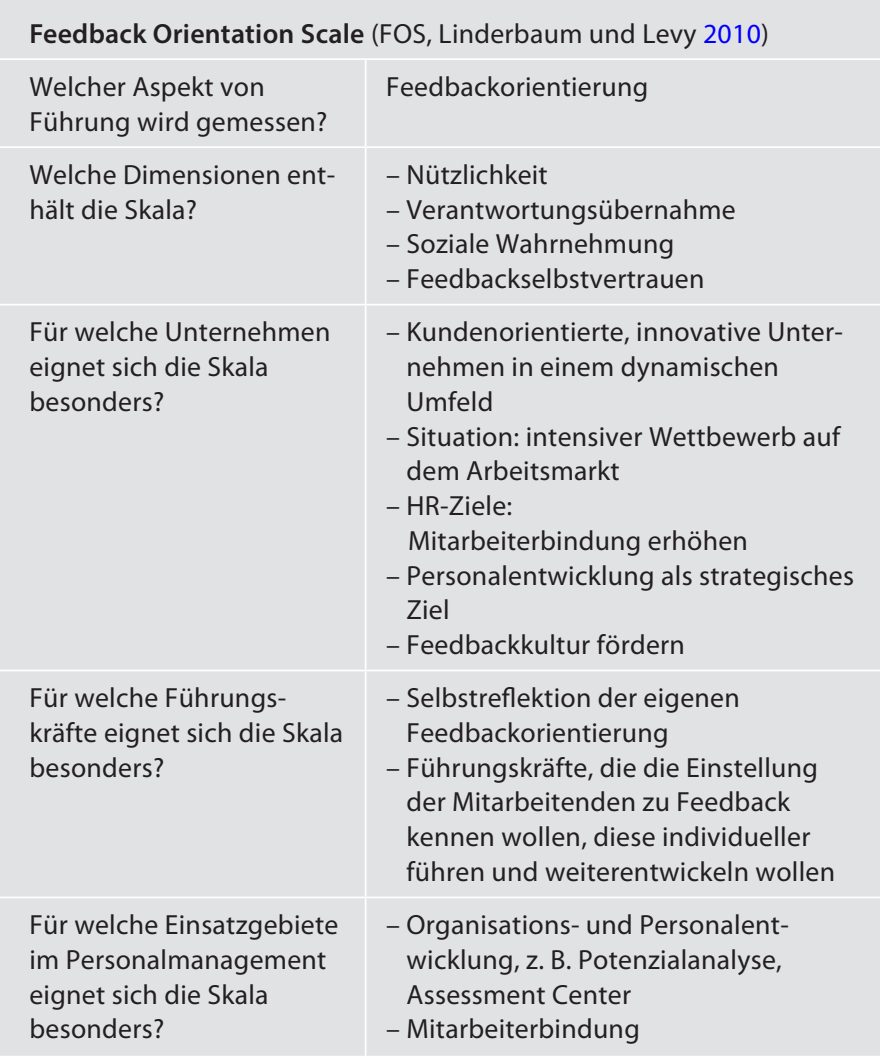

\subsubsection{Selbstwirksamkeitsüberzeugung}

Um aktuellen Anforderungen als Führungskraft gerecht zu werden, reicht es nicht Wissen und Fähigkeiten im eigenen Tätigkeitsfeld zu haben. Sie müssen auch über sogenannte Selbstkonzepte verfügen, Notwendigkeit von Selbstkonzepten also entsprechende psychologische Ressourcen, um dieses Wissen und diese Fähigkeiten in dynamischen und sich verändernden Kontexten auch nutzen zu können (Hannah et al. 2009). Eines dieser Selbstkonzepte ist die Selbstwirksamkeitsüberzeugung, die das Vertrauen in die eigene Kompetenz ausdrückt. Personen mit ausgeprägter Selbstwirksamkeitsüberzeugung glauben daran, dass 
Positive Auswir-

kungen der Selbstwirksamkeitsüberzeugung von Führungskräften

Leader Efficacy

Questionnaire sie aufgrund eigener Kompetenzen bestimmte, auch schwierige Aufgaben bewältigen oder Ziele erreichen können. Diese Personen sind der Meinung, dass es an ihnen liegt, gezielt Einfluss zu nehmen (internaler locus-of-control) und dass sie weder Opfer der Umstände noch anderer Personen sind, die sie nicht kontrollieren können. Die Selbstwirksamkeitsüberzeugung wird u. a. dadurch positiv beeinflusst, dass man motivierenden Zuspruch bekommt, dass man selbst schwierige Aufgaben löst oder miterlebt, wie andere dies tun (Bandura 1977).

Es hat sich gezeigt, dass die Selbstwirksamkeitsüberzeugung von Führungskräften nicht nur deren Commitment zum eigenen Unternehmen steigert, sondern dass auch deren Führungsleistung (z. B. Streben nach Verbesserung, Vorantreiben von Veränderungsprozessen) von den Mitarbeitenden positiver wahrgenommen wird (Paglis und Green 2002). Des Weiteren haben Villanueva und Sánchez (2007) herausgefunden, dass Führungskräfte, die Vertrauen in ihre eigenen Führungsqualitäten haben, auch dazu beitragen, die kollektive Selbstwirksamkeit der Mitarbeitenden zu erhöhen. Eben diese führt dann letztlich auch zu einer höheren allgemeinen Gruppenleistung. Diese Zusammenhänge zeigen, wie wichtig und wertvoll diese Eigenschaft bei Führungspersonen für Unternehmen ist.

Um dieses Konstrukt zu fassen, haben Hannah und Avolio (2013) den Leader Efficacy Questionnaire (LEQ) mit 22 Items entwickelt. Sie bilden dabei einerseits das Vertrauen einer Führungskraft in ihre eigene Führungskompetenz $\mathrm{ab}$ und andererseits inwieweit die Führungskraft überzeugt ist, dass Kolleginnen und Kollegen, Vorgesetzte und ihr sonstiges Umfeld sie bei ihrer Führungsaufgabe unterstützen. ${ }^{1}$ Die persönliche Selbstwirksamkeit ist also nur eine Seite der Medaille, Führungskräfte müssen nicht nur von sich selbst überzeugt sein, sondern auch davon, dass ihre Leistung als Führungskraft vom Kontext unterstützt wird. Der LEQ erfasst beides. Der vollständige Fragebogen kann auf $\downarrow$ www.mindgarden.com ${ }^{2}$ erworben werden.

\section{Fragebogen}

Leader Efficacy Questionnaire (LEQ) - 3 Beispielitems

(Hannah und Avolio 2013, eigene Übersetzung)

\section{Instruktion:}

Denken Sie an sich selbst als Führungskraft in Ihrem Unternehmen und geben Sie für jede der folgenden Aussagen Ihr persönliches Selbstvertrauen an. Ein Wert von 100

1 Eine ausführliche theoretische Herleitung des Fragebogens kann in dem Artikel von Hannah et al. (2012) nachgelesen werden.

2 Detaillierte Informationen finden Sie hier: $>$ https://www.mindgarden. com/115-leader-efficacy-questionnaire (zuletzt geprüft am 10.08.2019). 
entspricht 100 \% Selbstvertrauen, während ein Wert von 0 kein Selbstvertrauen bedeutet. Diese Umfrage ist vertraulich und wird nur für Ihre eigene Entwicklung verwendet. Bitte antworten Sie ganz offen und ehrlich.
Überhaupt
Mittelmäßig
Vollkommen

nicht

0

50

100

Als Führungskraft kann ich...

... meine Mitarbeitenden aktivieren, damit sie ihr Bestes geben.

... mich darauf verlassen, dass meine Organisation mir benötigte Ressourcen zur Verfügung stellt, um effektiv zu sein.

... bestimmen, welcher Führungsstil in einer gegebenen Situation erforderlich ist.

Leader Efficacy Questionnaire (LEQ, Hannah und Avolio 2013)

Welcher Aspekt von Führung wird gemessen?

Welche Dimensionen enthält

die Skala?

Für welche Unternehmen eignet sich die Skala besonders?

Für welche Führungskräfte eignet sich die Skala besonders?

Für welche Einsatzgebiete im Personalmanagement eignet sich die Skala besonders?
Selbstwirksamkeitsüberzeugung

- Leader Action Self-Efficacy (Handlungsselbstwirksamkeit der Führungskraft)

- Leader Self-Regulation Efficacy (Selbstregulierungswirksamkeit der Führungskraft)

- Leader Means Efficacy (Wirksamkeit des Umfelds der Führungskraft)

Unternehmen im Wandel, z. B. in disruptiven Transformationsprozessen

Führungskräfte, die Veränderungsprozesse bewältigen müssen

- Change-Management

- Führungskräfteentwicklung

- Potenzialanalysen

- 360-Grad-Feedback

\subsection{Diagnose der Führungsmotivation}

Kark und van Dijk (2007) gehen davon aus, dass die Motivation Ideales Selbst vs. zu führen entweder affektiv oder sozial-normativ ausgeprägt sein kann. Das bedeutet, es gibt Führungskräfte, die ihre FührungsPflicht-Selbst aufgabe genießen und sich selbst als "geborene" Führungskraft sehen (affektiv) und diejenigen, die aus einem Gefühl von Verantwortung und Pflicht führen (sozial-normativ) (Chan und Drasgow 2001). Kark und van Dijk (2007) unterscheiden 
Führungsmotivation beeinflussen

Hamburger Führungsmotivationsinventar auch Führungskräfte mit „Promotionszielen“ von Führungskräften mit „Präventionszielen“. Während erstere das „ideale Selbst" darstellen und Hoffnungen, Wünsche und Ambitionen beinhalten, stellen Präventionsziele das „Pflicht-Selbst“ dar und umfassen Aufgaben, Verpflichtungen und Verantwortlichkeiten. Führungskräfte, die auf einen Aufstieg hoffen und offen für Veränderungen sind, tendieren dazu affektiv motiviert $\mathrm{zu}$ sein. Es wird ihnen ein transformationaler ( Abschn. 2.2.2) oder charismatischer Führungsstil ( Abschn. 2.2.1) zugeschrieben. Setzen Führungskräfte jedoch auf Pflichterfüllung und sind ihnen Werte wie Sicherheit und Tradition wichtig, so gehen Kark und van Dijk (2007) von einer sozial-normativen Führungsmotivation aus. Diese spiegelt sich in einem kontrollierenden und eher transaktionalen Führungsstil ( $\triangle$ Abschn. 2.2.2) wider.

Wie wichtig persönliche Werte sind, zeigen auch die Ergebnisse von Clemmons und Fields (2011), die eine Studie im militärischen Kontext durchgeführt haben. Sie kommen zu dem Schluss, dass Werte der Selbstentfaltung wie bspw. das Verlangen nach Macht und Leistung, sowohl stark mit der affektiven als auch der sozial-normativen Führungsmotivation verknüpft sind.

Unternehmen können sich nun die Frage stellen, ob es sinnvoll wäre, die Führungsmotivation ihrer Führungskräfte beeinflussen $\mathrm{zu}$ wollen bzw. ob dies überhaupt möglich wäre. Techniken der Verhaltensmodellierung (z. B. Videos von erwünschtem Führungsverhalten bzw. Rollenbildern) wären denkbar, um das individuelle Führungspotential weiterzuentwickeln und die Identität als Führungskraft zu stärken (Waldman et al. 2013). Man sollte sich allerdings bewusstmachen, dass es sich aus ethischer Perspektive je nach Ausprägung der Verhaltungsmodellierung um eine Gratwanderung handelt.

Das individuelle Führungsmotiv kann mithilfe des Hamburger Führungsmotivationsinventars (FÜMO) - entwickelt von Felfe et al. (2012) - gemessen werden. Es wird also gemessen, welchen Antrieb ein Individuum hat, eine Führungskarriere einzuschlagen und entsprechend Führungsverantwortung zu übernehmen. Das FÜMO besteht aus 28 Skalen, folglich handelt es sich hier um einen sehr ausführlichen Fragebogen, für den bis zu 25 Minuten Bearbeitungszeit eingeplant werden sollten. Im Folgenden finden Sie fünf Beispielitems:

\section{Fragebogen}

Beispielitems des Hamburger Führungsmotivationsinventars

(FÜMO) nach Felfe et al. (2012)

Skala "Streben nach Einfluss":

"Ich empfinde es als angenehm, in meinem Umfeld die Kontrolle über Ereignisse zu haben." 


\section{Skala "Vermeidung von Kontrollverlust":}

„Wenn andere auf mich angewiesen sind, habe ich große Bedenken, einen Fehler zu machen."

\section{Skala "Streben nach Erfolg":}

„Es macht mir Spaß zu zeigen, dass ich etwas kann."

\section{Skala „Vermeidung von Misserfolg":}

"Ich vermeide Konkurrenzsituationen, um nicht als Verlierer hervorzugehen."

\section{Skala "Streben nach Akzeptanz":}

„Mir ist es wichtig, zu allen eine gute Beziehung zu pflegen."

(Abdruck erfolgt mit freundlicher Genehmigung des Hogrefe Verlages. Das Testverfahren ist zu beziehen bei der Testzentrale $\boldsymbol{\sim}$ www.testzentrale.de)

Hamburger Führungsmotivationsinventar(FÜMO, Felfe et al. 2012)

Welcher Aspekt von

Führung wird gemessen?

Welche Dimensionen enthält die Skala?

Für welche Unternehmen eignet sich die Skala besonders?

Für welche Führungskräfte eignet sich die Skala besonders?

Für welche Einsatzgebiete im Personalmanagement eignet sich die Skala besonders?
Führungsmotivation

- Basismotive (Macht-, Leistungs- und Anschlussmotiv)

- Führungsmotiv (affektiv, kalkulativ, normativ)

- Führungsaffine Interessenfelder (Gestaltung, Autonomie, Verantwortung, Bestätigung, Mentoring, Wachstum)

- Motivationshindernisse (Vermeidung von Führung, Bedingtes Führungsmotiv, Work-Life-Conflict)

Unternehmen, die ihre Karriere-/Laufbahnplanung professionalisieren wollen oder Talentmanagement einführen wollen (Potenziale frühzeitig erkennen)

- Führungskräfte vor dem nächsten Karriereschritt

- Führungskräfte, die sich neu orientieren wollen

- Führungskräfte, die ihre motivationalen Potenziale und Hindernisse erkennen und verbessern wollen

- Führungskräfteentwicklung

- Potenzialanalyse

- Trainings

- Coachings 


\subsection{Messung einzelner Aspekte des Führungsverhaltens}

Im folgenden Kapitel werden Messinstrumente für einzelne Aspekte des Führungsverhaltens vorgestellt. Zunächst steht das Einfluss- und Kommunikationsverhalten der Führungskraft im Fokus, das für den Führungserfolg entscheidend ist. Hier kann in einer Messung die Selbstwahrnehmung der Führungskraft zu ihrem eigenen Kommunikationsstil mit der Fremdeinschätzung durch ihre Mitarbeitenden kontrastiert werden. Ebenso wichtig wie Kommunikation ist das Repertoire von Einflussstrategien, das eine Führungskraft besitzt. Ob dieses ausreichend groß ist, kann durch den Einsatz eines Messinstruments sichtbar gemacht werden, das aus der Außenperspektive danach fragt, inwieweit Führungskräfte bestimmte Einflussstrategien anwenden ( Abschn. 6.5.1).

Weitere Instrumente zielen auf in der Gesellschaft verankerte Werte und Normen für gute Führung ab. Hier geht es zunächst um einen respektvollen Umgang von Führungskräften mit ihren Mitarbeitenden, aber auch um die Verwirklichung und das Vorleben moralisch-ethischer Prinzipien durch Führungskräfte ( Abschn. 6.5.2).

Die emotionale Seite der Führung ist Gegenstand zweier weiterer Messinstrumente. Hier interessieren z. B. die Fähigkeiten von Führungskräften zur Steuerung und Neubewertung ihrer eigenen Emotionen bzw. zur Unterdrückung von unerwünschten Gefühlen. Despotische Führung löst allemal sehr negative Gefühle aus, allerdings bei den Mitarbeitenden. Ein Fragebogen zur despotischen Führung kann helfen, solche Führungskräfte zu identifizieren ( Abschn. 6.5.3).

Und schließlich werden einige Messinstrumente präsentiert, die sich mit Führung in bestimmten Situationen beschäftigen. Mithilfe eines Selbstbewertungsinstruments zum situativen Führen können Führungskräfte selbst evaluieren, ob sie in der Lage sind, ihren Führungsstil an die Situation anzupassen und die ganze Bandbreite möglicher Verhaltensweisen auszuschöpfen. Krisensituationen und extrem gefährliche Führungssituationen erfordern besondere Kompetenzen. Ob diese vorhanden sind, kann mit einem Instrument zur Messung der Führungseffektivität bei der Situationsbeurteilung und Entscheidungsfindung in Krisen gemessen werden. Eine große Herausforderung stellt auch die Führung altersgemischter Teams und der Umgang mit älteren oder auch ganz jungen Mitarbeitenden dar, hierzu wird ebenfalls ein Messinstrument vorgestellt ( Abschn. 6.5.4).

Mit einem Instrument zur Messung der individuellen Wahrnehmung der eigenen Situation als Vorgesetzte/r oder Untergebene/r können Unternehmen ihre Hierarchisierung messen und mehr darüber erfahren wie Führungskräfte und 
Mitarbeitende ihre Rollen erleben. Die geteilte Führung stellt das Gegenteil zur klassischen, von der Hierarchie geprägten Rollenverteilung in Untergebene und Vorgesetzte, dar. Hierzu wird ein Fragebogen beschrieben, mit dem die Bereitschaft von Teammitgliedern zur Teilhabe an der Führung gemessen werden kann $(\triangleright$ Abschn. 6.5.5).

\subsubsection{Führung und Einflussnahme}

\section{- Kommunikationsverhalten der Führungskraft}

Dass Kommunikation für jedes Unternehmen und jede Arbeitsbeziehung von großer Bedeutung ist, wird niemand abstreiten. Gerade der Wille mit Mitarbeitenden zu kommunizieren, ist ein wesentlicher Pfeiler für die eigene Führungswirksamkeit (Hackman und Johnson 2013). Und trotzdem kommt es immer wieder zu Situationen in denen missverständlich oder gar nicht kommuniziert wird. Vries et al. (2010) haben herausgefunden, dass vor allem eine unterstützende, zuversichtliche und präzise Art des Kommunizierens seitens der Führungskraft hilfreich ist, wenn Mitarbeitende neue Erkenntnisse gewinnen sollen. Dabei gilt es aber immer auf die Vielfältigkeit der Mitarbeiterschaft (z. B. Bildungshintergrund, Kultur, Alter, Betriebszugehörigkeit, usw.) und die daraus resultierenden Bedürfnisse zu achten (Blessin und Wick 2015), denn ein „alter Hase“ im Unternehmen benötigt sicherlich andere Informationen als der frischgebackene Universitätsabsolvent.

Um einen besseren Einblick zu gewinnen, wie eine Führungskraft ihre eigene Kommunikation mit ihren Mitarbeitenden einschätzt (SR - self-rating) und wie diese dann tatsächlich von den Mitarbeitenden (OR - other rating) wahrgenommen wird, entwickelten Schneider et al. (2015) den Perceived Leadership Communication Questionnaire. Auf einer fünfstufigen Likert Skala werden die einzelnen Items, die jeweils für die Fremd- und Eigenwahrnehmung formuliert sind, bewertet.

\begin{tabular}{|c|c|c|c|c|}
\hline \multicolumn{5}{|c|}{$\begin{array}{l}\text { Fragebogen } \\
\text { Perceived Leadership Communication Questionnaire von } \\
\text { Schneider et al. }(2015)^{3}\end{array}$} \\
\hline $\begin{array}{l}\text { Stimme } \\
\text { ganz und } \\
\text { gar nicht zu }\end{array}$ & & Neutral & & $\begin{array}{l}\text { Stimme } \\
\text { voll und } \\
\text { ganz zu }\end{array}$ \\
\hline 1 & 2 & 3 & 4 & 5 \\
\hline
\end{tabular}

3 Die deutsche Version findet sich auf der ResearchGate-Seite des Erstautors Frank Schneider.
Kommunikationsbedürfnisse der Mitarbeitenden beachten

Perceived Leadership Communication Questionnaire 
SR - Ich bin sensibel für die Bedürfnisse anderer.

OR - Meine Führungskraft ist sensibel für die Bedürfnisse anderer

SR - Für meine Mitarbeitenden nehme ich mir gerne Zeit.

OR-Meine Führungskraft scheint sich gerne Zeit für mich zu nehmen

SR - Ich bin zufrieden damit, wie meine Kommunikation mit meinen Mitarbeitenden läuft.

OR - Ich bin zufrieden, wie die Kommunikation zwischen meiner Führungskraft und mir läuft

SR - Meine Mitarbeitenden und ich haben ein gemeinsames Verständnis davon, wie wir unsere Ziele erreichen wollen.

OR - Meine Führungskraft und ich haben ein gemeinsames Verständnis davon, wie wir unsere Ziele erreichen wollen

SR - Meine Mitarbeitenden und ich können offen miteinander sprechen.

OR-Meine Führungskraft und ich können offen miteinander sprechen

SR - Gerade wenn es Probleme gibt, sprechen wir umso ausführlicher miteinander, um die Probleme zu lösen.

OR - Gerade wenn es Probleme gibt, sprechen meine Führungskraft und ich umso ausführlicher miteinander, um die Probleme zu lösen

Perceived Leadership Communication Questionnaire (Schneider et al. 2015)

Welcher Aspekt von
Führung wird gemessen?
Welche Dimensionen ent-
hält diese Skala?
Für welche Unternehmen
eignet sich die Skala
besonders?

Für welche Führungskräfte eignet sich die Skala besonders?

Für welche Einsatzgebiete im Personalmanagement eignet sich die Skala besonders? Kommunikationsverhalten der
Führungskraft

Unternehmen,

- die ihre Kommunikationskultur verbessern wollen

- die sich in tiefgreifenden Veränderungsprozessen befinden, z. B. im Rahmen einer Fusion

- Führungskräftenachwuchs

- Führungskräfte, die eine Krise meistern müssen

- Führungskräfte, die ihr Selbst- und Fremdbild abgleichen möchten

- Führungsfeedback im Rahmen der Führungskräfteentwicklung

- Evaluation und Entwicklung der Führungskultur, z. B. im Rahmen von Change Management 


\section{- Einflussverhalten}

Einflussnahme ist ein wichtiges, wenn nicht das wichtigste Werkzeug einer Führungskraft, um Leistung erbringen zu können. Damit eine Führungskraft überhaupt effektiv sein kann, muss sie andere dahingehend beeinflussen, dass diese ihre Aufgaben erledigen, Vorschläge unterstützen und getroffene Entscheidungen umsetzen. Die konkreten Strategien und Vorgehensweisen, die angewandt werden, um die eigenen Mitarbeitenden zu beeinflussen, können sich von Führungskraft zu Führungskraft jedoch stark unterscheiden (Kipnis et al. 1980; Yukl et al. 2008).

Grundsätzlich lassen sich Beeinflussungstaktiken nach ihrem Zweck und ihrem zeitlichen Rahmen klassifizieren. Die auf eine unmittelbare Erfüllung konkreter Aufgaben abzielenden Einflusstaktiken (proaktive Taktiken) können von Taktiken des längerfristigen Impression-Management unterschieden werden, bei denen die Führungskraft Einfluss auf ihre Mitarbeitenden ausübt, indem sie ein vorteilhaftes Bild von sich selbst kreiert und vermittelt. Hier soll auf die Qualität der Beziehung zum Mitarbeitenden Einfluss genommen werden, die Erreichung konkreter arbeitsbezogener Zielsetzungen steht nicht im Vordergrund (Gardner und Martinko 1988; Wayne und Ferris 1990).

Taktiken des Impression Managements sind:

- Selbstbeschreibung (z. B. der eigenen Persönlichkeit, Motivation)

- Beschreibungen der eigenen Organisation oder des eigenen Organisationsbereichs

- Demonstrieren von Konformität der eigenen Meinung mit derjenigen der Zielgruppe

- Erklärungen (z. B. zu eigenen Handlungen)

- Entschuldigungen und Rechtfertigungen (z. B. zu eigenen Handlungen)

- Selbstlob (z. B. in Bezug auf Projekte, Leistungen)

- Lob der Zielgruppe (z. B. der Mitarbeitenden)

- Gefälligkeiten für die Zielgruppe (z. B. die Mitarbeitenden)

Proaktive Einflusstaktiken auf Mitarbeitende - aber auch andere Stakeholder - sind nach Yukl und Falbe (1990) und Yukl et al. (2008) diese elf Einflusstaktiken:

- Druck ausüben: Die Führungskraft stellt Forderungen, droht oder schüchtert ein, um die Zielperson zu überzeugen, einen Auftrag auszuführen oder ein Ziel zu unterstützen.

- Sich auf „höhere Instanzen“ berufen: Die Führungskraft versucht, die Zustimmung der Zielperson zu erlangen, indem sie z. B. höhere Hierarchieebenen einbezieht oder auf diese verweist.

- Auf Tauschbeziehung verweisen: Die Führungskraft verspricht der Zielperson ausdrücklich oder implizit, dass sie Belohnungen oder Vorteile erhält, wenn sie einer Anfrage nachkommt, oder sie erinnert an eine vorherige Gefälligkeit, die erwidert werden soll.
Beeinflussungstaktiken sind abhängig von ihrem Zweck und ihrem zeitlichen Rahmen

Taktiken des Impression

Managements

Proaktive Einflusstaktiken 
- Koalitionen bilden: Die Führungskraft sucht die Hilfe anderer, um die Zielperson dazu zu bringen, etwas zu tun, oder sie benutzt die Unterstützung anderer als Argument.

- Liebenswürdigkeit zeigen: Die Führungskraft versucht, die Zielperson in eine gute Stimmung zu bringen oder positiv über sie oder ihn zu denken, bevor sie darum bittet, etwas zu tun.

- Inspirierend appellieren: Die Führungskraft versucht Begeisterung für ihre Vorschläge zu erzeugen, indem sie emotional an die Werte und Ideale der Zielperson appelliert oder deren Vertrauen in die eigene Kompetenz stärkt.

- Rational argumentieren: Die Führungskraft setzt logische und fachliche Argumente ein, um die Zielperson zu überzeugen, dass eine Idee oder eine Aufgabe realisierbar ist und wahrscheinlich zur Zielerreichung führt.

- Rat einholen: Die Führungskraft bezieht die Zielperson in Entscheidungen oder die Planung ein, wie vorgeschlagene Aufgaben oder Strategien umgesetzt werden können.

- Unterstützung anbieten: Die Führungskraft bietet Unterstützung oder notwendige Ressourcen an, wenn die Zielperson für ein Vorhaben stimmt oder eine vorgeschlagene Veränderung mitträgt.

- Vorteile in Aussicht stellen: Die Führungskraft erklärt, dass die Durchführung einer Anfrage oder die Unterstützung eines Vorhabens der Zielperson persönlich zugutekommen wird oder dazu beiträgt, die Karriere der Zielperson voranzutreiben.

- Persönliche Bitten aussprechen: Die Führungskraft bittet die Zielperson, eine Anfrage auszuführen oder einen Vorschlag aus Freundschaft zu unterstützen, oder bittet um einen persönlichen Gefallen.

Kulturelle Unterschiede der Einflusstaktiken
Influence Behavior

Questionnaire
Interessanterweise werden je nach Kultur unterschiedliche Einflussstrategien bevorzugt. Amerikanische Führungskräfte beispielsweise nutzen am häufigsten die Beratung mit ihren Mitarbeitenden oder führen sachlich-rationale Argumente an, um Commitment bei ihren Mitarbeitenden zu erzeugen (Yukl und Falbe 1990; Yukl et al. 1996). Schmidt und Yeh (1992) zeigten, dass die beliebtesten Einflussstrategien von Führungskräften in Australien, Großbritannien, Japan und Taiwan sich ähneln. Sie bevorzugen es, ihre Mitarbeitenden durch Fakten, Daten und logische Argumente zu überzeugen.

Die Forschung hat jedoch gezeigt, dass eine Kombination rationaler (z. B. Tauschangebot oder logische Argumente) und weicher Einflusstaktiken (z. B. um Rat fragen oder sich einschmeicheln) wirksamer ist, als nur auf der rational-sachlichen Ebene versuchen $\mathrm{zu}$ überzeugen. Am erfolgreichsten ist die Kombination zweier weicher Einflusstaktiken (z. B. Wertschätzung zeigen und emotional begeistern) und am wenigsten erfolgreich die Kombination zweier harter Einflusstaktiken (z. B. Druck ausüben und höhere Instanzen einschalten) (Blickle 2004).

Yukl et al. (2008) haben eine erweiterte Version des Influence Behavior Questionnaires (IBQ) entwickelt und evaluiert. Der 
IBQ misst die elf proaktiven Taktiken, die Führungskräfte verwenden, aus Sicht ihrer „Zielpersonen“, z. B. der Mitarbeitenden:

\section{Fragebogen}

Influence Behavior Questionnaire nach Yukl et al. (2008, eigene Übersetzung)

\section{Instruktion}

Name der Person, deren Einflussverhalten beschrieben wird:

Dieser Fragebogen dient dazu, mehr über die unterschiedlichen Wege zu lernen, wie Menschen in Ihrem Unternehmen andere Personen beeinflussen. Bitte beschreiben Sie, wie die oben genannte Person verschiedene Verhaltensweisen nutzt, um Sie zu beeinflussen. Bitte wählen Sie jeweils eine der folgenden Antwortmöglichkeiten aus und notieren Sie die entsprechende Nummer auf der dafür vorgesehenen Linie.

1. Ich kann mich nicht daran erinnern, dass er/sie jemals diese Taktik bei mir angewandt hat.

2. Er/Sie wendet diese Taktik nur sehr selten bei mir an.

3. Er/Sie wendet gelegentlich diese Taktik bei mir an.

4. Er/Sie wendet diese Taktik immer mal wieder bei mir an.

5. Er/Sie wendet diese Taktik sehr häufig bei mir an.

Sollte eine der genannten Antwortmöglichkeiten nicht auf Sie zutreffen, so nutzen Sie bitte ebenfalls Antwortalternative 1.

\section{Sachliche Argumentation}

Diese Person...

_ 1. setzt Fakten und Logik ein, um überzeugend Vorschläge zu machen oder etwas zu erreichen.

_ 2. legt deutlich dar, warum eine Anforderung oder eine Veränderung notwendig ist, um ein Aufgabenziel zu erreichen.

_ 3. legt dar, warum ein vorgeschlagenes Projekt oder eine Veränderung zweckmäßig und kosteneffizient wäre.

_ 4. informiert bzw. bringt Beweise, um zu zeigen, dass ein Vorschlag oder eine Veränderung erfolgversprechend ist.

\section{Tauschangebote}

\section{Diese Person...}

_ 5. bietet Ihnen etwas, das Sie wollen, als Gegenleistung für Ihre Hilfe bei einer Aufgabe oder einem Projekt.

_ 6. bietet an im Gegenzug etwas für Sie zu tun, wenn Sie einer Aufforderung nachkommen.

7. bietet als Gegenleistung für Ihre Hilfe und Unterstützung an, eine bestimmte Aufgabe für Sie zu erledigen oder Ihnen einen Gefallen zu tun.

8. bietet Ihnen für die Zukunft einen Gefallen als Gegenleistung an, wenn Sie ihm/ihr jetzt helfen. 


\section{Wecken von Begeisterung}

Diese Person...

_ 9. erklärt, dass ein Vorschlag oder eine Veränderung eine Möglichkeit ist, etwas wirklich Spannendes und Lohnenswertes zu tun.

_ 10. vermittelt eine klare und begeisternde Vision davon, was durch ein vorgeschlagenes Projekt oder eine Veränderung erreicht werden könnte.

_ 11. spricht über Ideale und Werte, wenn er/sie etwas Neues oder eine Veränderung vorschlägt.

_ 12. hält eine inspirierende Rede oder Präsentation, um Begeisterung für einen Vorschlag oder eine Veränderung zu wecken.

\section{Legitimation}

Diese Person...

_ 13. erklärt, dass seine/ihre Forderung oder sein/ihr Vorschlag mit den offiziellen Regeln und Richtlinien im Einklang steht.

_ 14. erklärt, dass eine Forderung oder ein Vorschlag mit einer vorausgegangenen Vereinbarung oder einem Vertrag in Einklang steht.

_ 15. belegt, dass eine Forderung berechtigt ist, indem er/sie auf Dokumente wie Aufträge, Handbücher, Satzungen, Statuten oder offizielle Verträge verweist.

_ 16. erklärt, dass eine Forderung oder ein Vorschlag früheren Fällen und gängiger Praxis entspricht.

\section{Aufzeigen persönlichen Nutzens}

Diese Person...

_ 17. erklärt, wie die Aufgabe, die Sie machen sollen, Ihre Karriere fördern könnte.

_ 18. beschreibt, wie Sie profitieren könnten, wenn Sie eine Aufgabe oder Tätigkeit übernehmen (z. B. neue Fähigkeiten erlernen, wichtige Leute treffen, Ihr Ansehen steigern).

_ 19. zeigt auf, wie eine vorgeschlagene Tätigkeit oder Veränderung Ihnen helfen könnte, ein persönliches Ziel zu erreichen.

_ 20. erklärt, warum eine vorgeschlagene Tätigkeit oder Veränderung gut für Sie wäre.

\section{Ausüben von Druck}

Diese Person...

_ 21. verlangt, dass Sie einer Aufforderung nachkommen.

_ 22. nutzt Drohungen und Warnungen, um Sie dazu zu bringen, etwas zu tun. 
23. überprüft immer wieder, ob Sie einer Aufforderung nachgekommen sind.

_ 24. versucht Sie unter Druck zu setzen, damit Sie einer Aufforderung nachkommen.

\section{Unterstützungsangebote}

Diese Person...

_ 25. bietet Hilfe bei einer Aufgabe an, von der er/sie will, dass Sie sie ausführen.

_ 26. bietet an Ressourcen bereitzustellen, die Sie benötigen, um eine Aufgaben für ihn/sie auszuführen.

_ 27. bietet an zu zeigen, wie eine Aufgabe auszuführen ist, die Sie für ihn/sie erledigen sollen.

_ 28. bietet Ihnen jegliche Unterstützung an, die Sie benötigen, um eine Aufgabe zu erledigen.

\section{Zeigen von Wertschätzung}

Diese Person...

_ 29. sagt, dass Sie die besonderen Fähigkeiten oder das besondere Wissen haben, die für das Erledigen einer Aufgabe notwendig sind.

_ 30. lobt Ihre bisherigen Leistungen und Erfolge, wenn er/ sie Sie bittet, eine Aufgabe zu erledigen.

_ 31. lobt Ihr Können oder Wissen, wenn er/sie Sie darum bittet, etwas zu tun.

— 32. sagt, dass Sie die qualifizierteste Person für eine Aufgabe sind, von der er/sie möchte, dass Sie sie übernehmen.

\section{Einholen von Rat}

Diese Person...

_ 33. bittet Sie, Vorschläge zu machen, wie Sie ihm/ihr helfen könnten, ein Aufgabenziel zu erreichen oder ein Problem zu lösen.

_ 34. zieht Sie hinzu, um Ihre Ideen zu einer vorgeschlagenen Tätigkeit oder Veränderung, die Sie unterstützen oder umsetzen sollen, zu erfahren.

_ 35. ermutigt Sie Bedenken zu einer vorgeschlagenen Tätigkeit oder Veränderung, die Sie unterstützen oder ausführen sollen, zu äußern.

_ 36. bittet Sie um Vorschläge, einen Plan oder Vorschlag zu verbessern, den Sie unterstützen oder an dessen Ausführung sie beteiligt sein sollen.

\section{Persönliche Bitten}

Diese Person...

_ 37. appelliert an Ihre Freundschaft, wenn er/sie Sie bittet, etwas zu erledigen. 
_ 38. sagt, dass er/sie Sie um einen Gefallen bitten muss, bevor er/sie erzählt, worum es geht.

_ 39. bittet Sie als Freund/in ihm/ihr einen Gefallen zu tun.

_ 40. bittet um Ihre Hilfe als einen persönlichen Gefallen.

\section{Einsetzen von Verbündeten}

Diese Person...

_ 41. erwähnt die Namen von anderen Personen, die einen Vorschlag gutheißen, wenn er/sie darum bittet, diesen zu unterstützen.

_ 42. holt andere, die Ihnen erklären, warum sie einen Vorschlag oder eine Veränderung unterstützen, für die er/sie Ihre Unterstützung möchte.

_ 43. bringt jemanden zur Unterstützung mit, wenn er/sie Sie trifft, um eine Anfrage oder einen Vorschlag zu machen.

_ 44. bittet jemanden, den Sie respektieren, Sie zu beeinflussen, damit Sie eine Aufgabe erledigen oder einen Vorschlag unterstützen.

\begin{tabular}{|c|c|}
\hline $\begin{array}{l}\text { Welcher Aspekt von Führung } \\
\text { wird gemessen? }\end{array}$ & $\begin{array}{l}\text { Einflussverhalten von Führungs- } \\
\text { kräften }\end{array}$ \\
\hline $\begin{array}{l}\text { Welche Dimensionen enthält } \\
\text { diese Skala? }\end{array}$ & $\begin{array}{l}\text { - Sachliche Argumentation } \\
\text { - Tauschangebote } \\
\text { - Wecken von Begeisterung } \\
\text { - Legitimation } \\
\text { - Aufzeigen persönlichen } \\
\text { Nutzens } \\
\text { - Ausüben von Druck } \\
\text { - Unterstützungsangebote } \\
\text { - Zeigen von Wertschätzung } \\
\text { - Einholen von Rat } \\
\text { - Persönliche Bitten } \\
\text { - Einsetzen von Verbündeten }\end{array}$ \\
\hline $\begin{array}{l}\text { Für welche Unternehmen eignet } \\
\text { sich die Skala besonders? }\end{array}$ & $\begin{array}{l}\text { - Konzerne } \\
\text { - Öffentlicher Dienst }\end{array}$ \\
\hline $\begin{array}{l}\text { Für welche Führungskräfte } \\
\text { eignet sich die Skala besonders? }\end{array}$ & $\begin{array}{l}\text { Führungskräfte, die ihre eigenen } \\
\text { Einflusstaktiken reflektieren und } \\
\text { weiterentwickeln wollen }\end{array}$ \\
\hline $\begin{array}{l}\text { Für welche Einsatzgebiete im } \\
\text { Personalmanagement eignet } \\
\text { sich die Skala besonders? }\end{array}$ & $\begin{array}{l}\text { - Coaching } \\
\text { - Mentoring } \\
\text { - Förderung von Führungsnach- } \\
\text { wuchs } \\
\text { - Frauenförderung }\end{array}$ \\
\hline
\end{tabular}




\subsubsection{Führung und Werte}

\section{- Respektvolle Führung}

Ein respektvolles Miteinander ist essentiell im Alltag und vor allem auch im Arbeitskontext, schließlich ist es die Grundlage für sachliche Dialoge und das Lösen von Konflikten. Seitens der Wissenschaft gibt es zur respektvollen Führung noch kaum Forschungsergebnisse. Dies ist besonders vor dem Hintergrund verwunderlich, dass Mitarbeitende zunehmend den Mangel an Respekt und das Fehlen ehrlicher Wertschätzung beklagen (Miller 2001). Erste Studien haben aber herausgefunden, dass Mitarbeitende ein stärkeres Commitment gegenüber ihrem Arbeitgeber zeigen und sich an die Regeln der Organisation halten, wenn die eigene Führungskraft einen respektvollen Umgang pflegt (Boezeman und Ellemers 2008; DeCicco et al. 2006).

Da respektvolle Führung von großer Bedeutung für Mitarbeitende ist und sich positiv auf ein Unternehmen auswirken kann, haben van Quaquebeke und Eckloff (2010) basierend auf Mitarbeiterinterviews ein Inventar entwickelt, das Verhaltensweisen beschreibt, die diese als Zeichen für respektvolle Führung sehen. Insgesamt ergaben sich 19 verschiedene Kategorien für respektvolles Führungsverhalten, die 149 Verhaltensweisen beinhalten. Ein Jahr später wurde zusätzlich eine Kurzversion, die Respectful Leadership Scale mit 12 Items von van Quaquebeke (2011) veröffentlicht, die gerade für den Unternehmensalltag eine ökonomische Alternative zur Vollversion darstellt.

\section{Fragebogen \\ Respectful Leadership Scale (van Quaquebeke 2011, eigene Übersetzung)}

\section{Stimme ganz \\ und gar \\ nicht zu}

Neutral

3
Stimme voll und ganz zu

2
4

Meine Führungskraft ...

1. ... vertraut auf meine Fähigkeit, selbständig und eigenverantwortlich gute Leistungen zu erbringen.

2. ... äußert Kritik sachlich und konstruktiv.

3. ... erkennt mich als vollwertiges Gegenüber an.

4. ... erkennt meine Arbeit an.

5. ... ist aufrichtig interessiert an meiner Meinung und Einschätzung.

6. ... behandelt mich höflich.

7. ... versucht mich nicht für seine/ihre Fehler verantwortlich zu machen.

8. ... setzt sich gegenüber Dritten vorbehaltlos für mich und meine Arbeit ein.

Forschungspotential zu

respektvoller Führung

Respectful Leadership Scale 
Moralisch-ethische

Prinzipien als Grundlage ethischer Führung

Doppelte Verantwortung für Führungskräfte
9. ... stellt mir alle Informationen zur Verfügung, die für mich relevant sind.

10. ... nimmt mich und meine Arbeit ernst.

11. ... agiert offen und ehrlich mit mir.

12. ... behandelt mich fair.

\section{- Ethische Führung}

Aufgrund von verschiedenen Skandalen in Wirtschaft und Politik, hat das Interesse an ethischer Führung sowohl in der Praxis als auch in der Wissenschaft in den letzten Jahren erheblich zugenommen. Man spricht von ethischer Führung, wenn das Handeln von Führungskräften von moralisch-ethischen Prinzipien geprägt ist. Ethische Führung verwirklicht dann nicht nur die Humanverantwortung von Führung im Unternehmen, sondern trägt auch dazu bei, einen nachhaltigen wirtschaftlichen Erfolg sicherzustellen (Kerschreiter und Eisenbeiss 2015).

Führungskräfte tragen eine doppelte Verantwortung: Einerseits müssen von der Unternehmung vorgegebene Ziele erreicht werden, andererseits soll für Mitarbeitende eine gute Arbeitsund Lebensqualität realisiert werden. Ethische Grundsätze der Führung liefern hier eine Richtschnur für das Handeln innerhalb dieses Spannungsfeldes, das zudem von Machtasymmetrie zwischen Führungskraft und Mitarbeitenden geprägt ist. Denn die Führungskraft kann auf Machtpotentiale zurückgreifen, die einem Mitarbeitenden nicht zugänglich sind bzw. nicht zustehen (Kuhn und Weibler 2003). 
Brown et al. (2005) konzipieren ethische Führung auf Basis der sozialen Lerntheorie. Diese besagt, dass man sich Verhalten in erster Linie durch soziale Interaktionen aneignet. Das bedeutet, dass der Geführte neues Verhalten von seiner Führungskraft erlernt, die als Modell oder Vorbild dient (Bandura 1991). Folglich definieren Brown und Kollegen ethische Führung als a) angemessenes Verhalten der Führungskraft bzgl. Kommunikation und Handlungen (z. B. Ehrlichkeit, Fairness und Fürsorge) und b) einer Verstärkung angemessenen Verhaltens gegenüber anderen durch kommunikativen Austausch, Feedback und Belohnungen (Brown et al. 2005). Zusammenfassend ist das Ziel von ethischem Führungsverhalten, Mitarbeitenden ethisches Verhalten näher zu bringen, sodass sie dieses Verhalten selbst annehmen.

Zur Erfassung ethischer Führung haben Brown et al. (2005), basierend auf der beschriebenen Definition, die Ethical Leadership Scale (ELS) entwickelt. Das Antwortformat wird mit einer fünfstufigen Likert-Skala ( $1=$ nie bis $5=$ immer $)$ abgebildet.

\section{Fragebogen}

Ethical Leadership Scale (ELS) (Brown et al. 2005; deutsche Übersetzung nach Rowold et al. 2009)

\begin{tabular}{|c|c|c|c|c|}
\hline Nie & & Manchmal & & Immer \\
\hline 1 & 2 & 3 & 4 & 5 \\
\hline
\end{tabular}

Meine Führungskraft ...

\section{Ethische Mitarbeiterführung}

1. ... hört auf das, was Mitarbeitende zu sagen haben.

2. ... denkt an die Interessen der Mitarbeitenden.

3. ... trifft faire und ausgewogene Entscheidungen.

4. ... ihr/ihm kann vertraut werden.

5. ... beurteilt Erfolge nicht nur nach den Ergebnissen, sondern auch danach, wie sie erreicht werden.

\section{Ethisches Rollenmodell}

1. ... führt ihr/sein Leben in einer ethischen Art und Weise.

2. ... diskutiert Geschäftsethiken und -werte mit Mitarbeitenden.

3. ... gibt Beispiele, wie Dinge aus ethischer Sicht richtig gemacht werden sollten.

4. ... wenn sie/er Entscheidungen fällt, fragt sie/er: „Wie kann ich bei dieser Entscheidung das Richtige tun?"
Definition ethischer Führung

Ethical Leadership Scale 
Ethical Leadership at Work Questionnaire
Ein alternatives Erhebungsinstrument zu ethischer Führung haben Kalshoven et al. (2011) mit dem Ethical Leadership at Work Questionnaire (ELW) vorgestellt. Der ELW weist sieben ethische Führungsverhaltensdimensionen auf (Mitarbeiterorientierung, Fairness, Teilen von Macht, Nachhaltigkeit, ethische Anleitung, Rollenklärung und Integrität), besitzt gute psychometrische Eigenschaften und eine hohe Konstruktvalidität. Das Antwortformat wird mit einer fünfstufigen LikertSkala $\left(1=\right.$ „stimme gar nicht $\mathrm{zu}^{\prime \prime}$ bis $5=$,stimme völlig $\left.\mathrm{zu}^{\prime}\right)$ abgebildet.

\section{Fragebogen}

Ethical Leadership at Work Questionnaire (ELW) (Kalshoven et al. 2011, eigene Übersetzung)

\begin{tabular}{|c|c|c|c|c|}
\hline $\begin{array}{c}\text { Stimme } \\
\text { gar nicht } \\
\text { zu }\end{array}$ & & Neutral & & $\begin{array}{l}\text { Stimme } \\
\text { völlig zu }\end{array}$ \\
\hline 1 & 2 & 3 & 4 & 5 \\
\hline
\end{tabular}

Meine Führungskraft ...

\section{Mitarbeiterorientierung}

1. ... interessiert sich dafür, wie ich mich fühle und wie es mir geht.

2. ... nimmt sich Zeit für den persönlichen Kontakt.

3. ... achtet auf meine persönlichen Bedürfnisse.

4. ... nimmt sich Zeit, um über arbeitsbezogene Empfindungen zu sprechen.

5. ... ist aufrichtig bestrebt, meine persönliche Entwicklung zu fördern.

6. ... hat Verständnis für mich, wenn ich Probleme habe.

7. ... kümmert sich um seine/ihre Mitarbeitenden.

\section{Fairness}

8. ... macht mich verantwortlich für Probleme, auf die ich keinen Einfluss habe.

9. ... macht mich verantwortlich für Arbeiten, über die ich keine Kontrolle hatte.

10. ... macht mich verantwortlich für Dinge, die nicht meine Schuld sind.

11. ... verfolgt den eigenen Erfolg auf Kosten anderer.

12. ... konzentriert sich hauptsächlich auf die Erreichung der eigenen Ziele.

13. ... manipuliert Untergebene.

\section{Teilen von Macht}

14. ... ermöglicht es Untergebenen, kritische Entscheidungen zu beeinflussen. 
15. ... erlaubt es anderen nicht, an der Entscheidungsfindung teilzuhaben.

16. ... holt Ratschläge von Untergebenen bezüglich der Unternehmensstrategie ein.

17. ... überdenkt Entscheidungen auf der Grundlage von Empfehlungen derjenigen, die ihm Bericht erstatten.

18. ... delegiert herausfordernde Aufgaben an Untergebene.

19. ... erlaubt mir, eine Schlüsselrolle bei der Festlegung meiner eigenen Leistungsziele zu spielen.

\section{Nachhaltigkeit}

20. ... möchte umweltfreundlich arbeiten.

21. ... ist aufmerksam für Nachhaltigkeitsthemen.

22. ... fördert das Recycling von Gegenständen und Materialien in unserer Abteilung.

\section{Ethische Anleitung}

23. ... erläutert anschaulich integritätsbezogene Verhaltenskodizes.

24. ... erklärt, was von den Mitarbeitenden in Bezug auf ein integres Verhalten erwartet wird.

25. ... verdeutlicht Integritätsrichtlinien.

26. ... stellt sicher, dass die Mitarbeitenden die Integritätsrichtlinien einhalten.

27. ... klärt die möglichen Folgen eines etwaigen unethischen Verhaltens von mir und meinen Kolleginnen und Kollegen.

28. ... regt die Diskussion über Integritätsthemen unter den Mitarbeitenden an.

29. ... lobt Mitarbeitende, die sich entsprechend den Integritätsrichtlinien verhalten.

\section{Rollenklärung}

30. ... legt die Leistungserwartungen der einzelnen Gruppenmitglieder fest.

31. ... erklärt, was von jedem Gruppenmitglied erwartet wird.

32. ... erklärt, was von mir und meinen Kolleginnen und Kollegen erwartet wird.

33. ... klärt Prioritäten.

34. ... klärt, wer wofür verantwortlich ist.

\section{Integrität}

35. ... hält seine/ihre Versprechen.

36. Man kann sich darauf verlassen, dass er/sie die Dinge tut, die er/sie sagt.

37. Man kann sich darauf verlassen, dass er/sie seinen Verpflichtungen nachkommt.

38. ... hält immer sein/ihr Wort. 
Ethical Leadership at Work Questionnaire (ELW, Kalshoven et al. 2011)

\begin{tabular}{|c|c|}
\hline $\begin{array}{l}\text { Welcher Aspekt von Führung } \\
\text { wird gemessen? }\end{array}$ & Ethische Führung \\
\hline $\begin{array}{l}\text { Welche Dimensionen enthält } \\
\text { die Skala? }\end{array}$ & $\begin{array}{l}\text { ELS: } \\
\text { - Ethische Mitarbeiterführung } \\
\text { - Ethisches Rollenmodell } \\
\text { ELW: } \\
\text { - Mitarbeiterorientierung } \\
\text { - Fairness } \\
\text { - Teilen von Macht } \\
\text { - Nachhaltigkeit } \\
\text { - Ethische Anleitung } \\
\text { - Rollenklärung } \\
\text { - Integrität }\end{array}$ \\
\hline $\begin{array}{l}\text { Für welche Unternehmen eignet } \\
\text { sich die Skala besonders? }\end{array}$ & $\begin{array}{l}\text { Unternehmen mit hoher } \\
\text { Reputation und gesellschaftlicher } \\
\text { Vorbildfunktion (z. B. NGOs) }\end{array}$ \\
\hline $\begin{array}{l}\text { Für welche Führungskräfte } \\
\text { eignet sich die Skala besonders? }\end{array}$ & $\begin{array}{l}\text { Führungskräfte aller Hierarchie- } \\
\text { stufen und Branchen }\end{array}$ \\
\hline $\begin{array}{l}\text { Für welche Einsatzgebiete im } \\
\text { Personalmanagement eignet } \\
\text { sich die Skala besonders? }\end{array}$ & $\begin{array}{l}\text { - Transformation von Führungs- } \\
\text { kultur } \\
\text { - Sensibilisierung für das } \\
\text { Führungsverhalten in der } \\
\text { Personalentwicklung }\end{array}$ \\
\hline
\end{tabular}

\subsubsection{Führung und Emotionen}

Ambiguität von Emotionen

Aspekte emotionaler Intelligenz

\section{- Emotionale Führung}

Von der Antike bis zur Aufklärung wurde geglaubt, dass Emotionen einen Gegensatz zur Vernunft bilden und als Leidenschaften („Passion“) zu werten sind, denen der Mensch mehr oder weniger ausgeliefert ist, die also von selbst kommen und gehen (Solomon 1983). Mittlerweile ist bekannt, dass Individuen ihre Gefühle kontrollieren können. Um zu beeinflussen, welche Gefühle sie wann haben möchten, wenden sie eine Vielzahl von Strategien an (Gross 1998). Aber nicht nur die eigenen Gefühle können gesteuert werden. So sprechen bspw. charismatische Führungskräfte erfolgreich die Emotionen der Mitarbeitenden an, um ihre Vision zu vermitteln und ihre Mitarbeitenden $\mathrm{zu}$ motivieren (House et al. 1991; Shamir et al. 1993).

Insgesamt gilt, dass Führungskräfte, die Emotionen in geeigneter Weise einsetzen, um wirksamer zu kommunizieren oder die sich ihrer eigenen und der Gefühle anderer bewusster sind, als fähiger eingestuft werden (Goleman 2000). Umgekehrt kann Emotionalität, z. B. das Zeigen negativer Gefühle, auch den Führungserfolg schwächen. In einer Untersuchung von Lewis (2000) wurde z. B. festgestellt, dass es in Bezug auf die 
Wahrnehmung von Emotionalität bei einer Führungskraft und der Einschätzung der Wirksamkeit ihres Führungshandelns auch geschlechtsabhängige Unterschiede gibt. So werden weibliche Führungskräfte als weniger effektiv eingestuft, wenn sie Traurigkeit oder Wut zum Ausdruck bringen, während Männer nur als weniger effektiv gelten, wenn sie Traurigkeit zeigen. Daher ist es für den Führungserfolg wichtig, Emotionen regulieren zu können. Dies ist auch ein Teil der sogenannten Emotionalen Intelligenz, die folgende Aspekte umfasst:

- Die eigenen Emotionen kennen und akzeptieren: Dies ist eine Grundvoraussetzung für ein tiefergehendes Verständnis des eigenen Verhaltens und für die Selbstregulation auf der Gefühlsebene.

- Die eigenen Emotionen beeinflussen und in die Tat umsetzen: Dies erlaubt situationsangemessenes oder zielkonformes Verhalten, z. B. in belastenden Situationen Ruhe zu bewahren oder schädliche Impulse zu unterdrücken.

- Die Emotionen anderer erkennen und dadurch in der Lage sein, sie - sowohl im positiven als auch negativen Sinne - zu beeinflussen.

- Beziehungen zu anderen Menschen erfolgreich gestalten: Auch dies setzt einen kompetenten Umgang mit den Gefühlen anderer voraus und ist eine Voraussetzung für die Akzeptanz als Führungskraft.

Mayer et al. (2002) haben einen Test zur Messung der „Emotionalen Intelligenz" entwickelt, den MSCEIT ${ }^{\mathrm{TM}}$ (MayerSalovey-Caruso Emotional Intelligence Test ${ }^{\mathrm{TM}}$ ), der wie folgt aufMayer-Salovey-Caruso Emotional Intelligence gebaut ist (- Abb. 6.3) und der auch als deutschsprachige Version Test $^{\mathrm{TM}}$ vorliegt (Steinmayr et al. 2011).

GESAMT-

ERGEBNIS

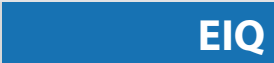

Emotional Intelligence Quotient

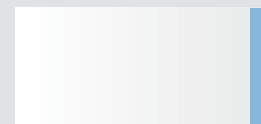

BEREICHE

anderen Eindrücken vergleichen
und ihre Wechselbeziehung mit
Gedanken verstehen

DIMENSIONEN

\section{Erfahrungsbasierte Emotionale Intelligenz}

Emotionen erkennen, sie mit anderen Eindrücken vergleichen

Gedanken verstehen

Emotionen
nutzen

\section{Strategische \\ Emotionale Intelligenz}

Emotionen deuten können, ihre Auswirkungen auf Beziehungen verstehen und wissen, wie man sie steuern kann

Emotionen
verstehen

Emotionen regulieren

- Abb. 6.3 Aufbau des Mayer-Salovey-Caruso Emotional Intelligence Test ${ }^{\mathrm{TM}}$ 
Der MSCEIT ${ }^{\mathrm{TM}}$ enthält Fragen zur Fähigkeit Emotionen wahrzunehmen, zu nutzen, zu verstehen und zu regulieren. Im Folgenden werden zwei Beispiele für Fragen dargestellt (Mayer et al. 2002, eigene Übersetzung):

\section{Fragebogen \\ Beispielfrage aus dem Teilbereich 3 des MSCEIT ${ }^{\mathrm{TM}}$ Verständnis von Emotionen \\ Tom fühlte sich unruhig und war etwas gestresst, als er über all die Arbeit nachdachte, die er zu erledigen hatte. Als sein Vorgesetzter ihm ein zusätzliches Projekt übergab, fühlte er sich . (Wählen Sie die beste Alternative aus.)}
a) überwältigt
b) deprimiert
c) beschämt
d) selbstbewusst
e) nervös

\section{Beispielfrage aus dem Teilbereich 4 des MSCEIT ${ }^{\mathrm{TM}}$ - Umgang mit Emotionen \\ Debbie ist gerade aus dem Urlaub zurückgekommen. Sie fühlte sich ruhig und zufrieden. Wie gut würde jede der folgenden Handlungen ihre Stimmung aufrechterhalten?}

\section{Aktion 1: Sie begann zu Hause eine Liste der Dinge zu erstellen, die sie tun musste.}

sehr unwirksam 1

Aktion 2: Sie begann darüber nachzudenken, wo und wann sie ihren nächsten Urlaub machen würde.

sehr unwirksam 1

Kritik des MSCEIT ${ }^{\mathrm{TM}}$

Emotion Regulation Questionnaire
Wenngleich dieses Testverfahren sich in der Praxis durchsetzen konnte, hat es seitens der Wissenschaft einige Kritik hinsichtlich seiner Güte erfahren, u. a. wird die Konstruktion des Tests als zu wenig dokumentiert und nachvollziehbar bewertet (Burk und Amelang 2015).

Gross und John (2003) entwickelten ein anderes Verfahren, den Emotion Regulation Questionnaire (ERQ), der die Fähigkeit zur Emotionsregulation erfasst. Hier stehen zwei kognitive Strategien, die Neubewertung und die Unterdrückung von Emotionen im Fokus. Bei der kognitiven Neubewertung geht es darum, emotionsauslösende Reize dahingehend neu zu interpretieren, dass sich deren emotionale Auswirkung verändert (Lazarus und Alfert 1964). Ein Beispiel hierfür wäre die Situation eines Bewerbungsgesprächs. Hier könnte eine Bewerberin das Gespräch nicht als Stresssituation interpretieren, in der sie und 
ihre Kompetenzen auf dem Prüfstand stehen, sondern umgekehrt als Bewährungssituation für das Unternehmen, bei dem sie sich bewirbt. Diese Umdeutung kann in der Folge zu einer geringeren emotionalen Belastung und folglich einer besseren Leistung führen. Bei der Anwendung der Unterdrückungsstrategie wird der eigene emotionale Ausdruck bewusst unterdrückt (Gross 1998). Ein passendes Beispiel hierfür ist das Pokerface schließlich möchte man den anderen Spielerinnen und Spielern nichts über das eigene Blatt verraten (Gross und John 2003). Auch in Führungssituationen kann es wichtig sein, spontane emotionale Regungen wie Enttäuschung, Wut und Angst zu unterdrücken.

\section{Fragebogen}

Emotion Regulation Questionnaire (ERQ) von Gross und John (2003) nach der deutschsprachigen Übersetzung von Abler und Kessler (2009)

Emotion Regulation Questionnaire (ERQ) von Gross und John (2003) nach der deutschsprachigen Übersetzung von Abler und Kessler (2009)

\section{Instruktion}

Wir möchten Ihnen gerne einige Fragen zu Ihren Gefühlen stellen. Uns interessiert, wie Sie Ihre Gefühle unter Kontrolle halten, bzw. regulieren. Zwei Aspekte Ihrer Gefühle interessieren uns dabei besonders. Einerseits ist dies Ihr emotionales Erleben, also was Sie innen fühlen. Andererseits geht es um den emotionalen Ausdruck, also wie Sie Ihre Gefühle verbal, gestisch oder im Verhalten nach außen zeigen. Obwohl manche der Fragen ziemlich ähnlich klingen, unterscheiden sie sich in wesentlichen Punkten.

Bitte beantworten Sie die Fragen, indem Sie folgende Antwortmöglichkeiten nutzen.

\begin{tabular}{|c|c|c|c|c|c|c|}
\hline $\begin{array}{c}\text { Stimme ganz } \\
\text { und gar } \\
\text { nicht zu }\end{array}$ & & & Neutral & & & $\begin{array}{l}\text { Stimme } \\
\text { voll und } \\
\text { ganz zu }\end{array}$ \\
\hline 1 & 2 & 3 & 4 & 5 & 6 & 7 \\
\hline
\end{tabular}

\section{Neubewertung}

1. Wenn ich mehr positive Gefühle (wie Freude oder Heiterkeit) empfinden möchte, ändere ich, woran ich denke.

2. Wenn ich weniger negative Gefühle (wie Traurigkeit oder Ärger) empfinden möchte, ändere ich, woran ich denke.

3. Wenn ich in eine stressige Situation gerate, ändere ich meine Gedanken über die Situation so, dass es mich beruhigt.

4. Wenn ich mehr positive Gefühle empfinden möchte, versuche ich über die Situation anders zu denken. 
5. Ich halte meine Gefühle unter Kontrolle, indem ich über meine aktuelle Situation anders nachdenke.

6. Wenn ich weniger negative Gefühle empfinden möchte, versuche ich über die Situation anders zu denken.

\section{Unterdrückung}

7. Ich behalte meine Gefühle für mich.

8. Wenn ich positive Gefühle empfinde, bemühe ich mich, sie nicht nach außen zu zeigen.

9. Ich halte meine Gefühle unter Kontrolle, indem ich sie nicht nach außen zeige.

10. Wenn ich negative Gefühle empfinde, sorge ich dafür, sie nicht nach außen zu zeigen.

\section{- Despotische Führung}

Emotion Regulation Questionnaire (ERQ, Gross und John 2003)

Welcher Aspekt von Führung Emotionsregulation

wird gemessen?

Welche Dimensionen enthält - Neubewertung

die Skala? - Unterdrückung

Für welche Unternehmen - Unternehmen in Krisensituationen

eignet sich die Skala $\quad$ - Unternehmen in denen die

besonders? $\quad$ Regulierung von Emotionen wichtig ist, z. B. Einsatzorganisationen wie Feuerwehr, Armee, Polizei, Krankenhäuser

Für welche Führungs- $\quad$ Führungskräfte, die in Krisenkräfte eignet sich die Skala situationen besonnen reagieren besonders? müssen

Für welche Einsatzgebiete im - Führungskräfteentwicklung Personalmanagement eignet - Coaching sich die Skala besonders? - Mentoring

Führungskräfte, die feindselige verbale und nonverbale Verhaltensweisen aus Sicht der Untergebenen an den Tag legen, werden als despotisch bezeichnet. Im Englischen wird in diesem Kontext auch von sogenannter "abusive supervision“ gesprochen, also der herabwürdigenden Kontrolle (Tepper 2000). Sollten Sie bereits ähnliche Aussagen, wie die folgenden, zu hören bekommen haben, hatten Sie bereits Kontakt mit einer derartigen Führungskraft:

॥ „Wie, Du gehst schon nach Hause? Es ist gerade mal 19 Uhr! Wie praktisch, dass jetzt die anderen für Dich ackern. Am besten Du machst gleich Urlaub und kommst nicht wieder." 
„Können Sie denn gar nichts richtigmachen? Manchmal glaube ich, Sie stellen sich absichtlich so dumm an. Sie brauchen gar nicht so schauen. Es wäre besser, Sie würden einfach zu Hause bleiben - hier richten Sie nur Schaden an."

„Seit Du hier arbeitest, gibt es nur noch Ärger!"

Absichtliche Feindseligkeit oder auch demonstrative Gleichgültigkeit gegenüber Mitarbeitenden sind typische Verhaltensweisen von despotischen Führungskräften.

Es überrascht wenig, dass in Studien nachgewiesen werden konnte, dass diese Art der Führung mit schlechten Leistungen der Mitarbeitenden zusammenhängt. Dieser Zusammenhang ist sogar noch stärker, wenn die Arbeit für die Mitarbeitenden eine große persönliche Bedeutung besitzt (Aryee et al. 2008; Harris et al. 2007). Es ist zudem wahrscheinlicher, dass das mittlere Management ebenfalls zu herabwürdigender Kontrolle neigt, wenn das Top Management dies vorlebt. Dabei wird die Kreativität der Mitarbeitenden im Keim erstickt (Liu et al. 2012). Eine derartige Führung kann sich aber nicht nur auf den Beruf, sondern auch auf das Privatleben der Geführten auswirken: Konflikte zwischen dem Arbeits- und Familienleben entstehen, die psychische Belastung steigt und die persönliche Lebenszufriedenheit sinkt dramatisch (Tepper 2000).

Spätestens, wenn das Privatleben durch die eigene Führungskraft schädlich beeinflusst wird, sollten sich Mitarbeitende gut überlegen, ob dieser Job noch der Richtige für sie ist. In jedem Falle können Betroffene einzelne Vorfälle dokumentieren und sich z. B. dem Betriebsrat oder Ombudspersonen anvertrauen.

Um despotische Führungskräfte aus der Perspektive von Mitarbeitenden identifizieren zu können, hat Tepper (2000) im Rahmen einer Langzeitstudie 15 Abusive Supervision Items zur Messung dieses Führungsstils entwickelt (deutsche Übersetzung nach Felfe 2015).

\section{Fragebogen}

Abusive Supervision Items nach Tepper (2000) (deutsche Übersetzung nach Felfe 2015)

\section{Instruktion}

Bitte beantworten Sie folgende Fragen ehrlich und spontan.

Es gibt keine richtigen oder falschen Antworten.

Die Kennzeichnung von 1 bis 5 bedeutet Folgendes:

1. Ich kann mich nicht erinnern, dass er/sie sich mir gegenüber jemals so verhalten hat.

2. Er/sie verhält sich sehr selten so mir gegenüber.

3. Er/sie verhält sich gelegentlich so mir gegenüber.
Negative Auswirkungen despotischer Führung

Abusive Supervision Items 
4. Er/sie verhält sich mäßig oft so mir gegenüber.

5. Er/sie verhält sich oft so mir gegenüber.

Meine Führungskraft ...

\section{Beleidigend-erniedrigend}

1. ... macht sich über mich lustig.

2. ... sagt mir, dass meine Gedanken oder Gefühle dumm sind.

3. ... erniedrigt mich vor anderen.

4. ... erinnert mich an vergangene Fehler und Misserfolge.

5. ... gibt anderen gegenüber negative Kommentare über mich ab.

6. ... lässt nicht zu, dass ich Umgang mit meinen Kolleginnen und Kollegen habe.

7. ... sagt mir, dass ich unfähig sei.

\section{Unaufrichtig-unfair}

8. ... spricht nicht mit mir.

9. ... dringt in meine Privatsphäre ein.

10. ... gibt mir keine Anerkennung für aufwendige Arbeiten.

11. ... beschuldigt mich wegen Dingen, um sich selbst Peinlichkeiten zu ersparen.

12. ... bricht seine/ihre Versprechen.

13. ... lässt seinen/ihren Ärger an mir aus, wenn er/sie wegen anderer Dinge wütend ist.

14. ... ist unhöflich mir gegenüber.

15. ... lügt mich an.

\section{Abusive Supervision (Tepper 2000)}

Welcher Aspekt von Führung Despotische Führung wird gemessen?

Welche Dimensionen enthält - Beleidigend-erniedrigend die Skala?

- Unaufrichtig-unfair

Für welche Unternehmen eignet sich die Skala besonders?

Unternehmen, die ihre Führungskultur verändern wollen

Für welche Führungskräfte eignet sich die Skala besonders?

Für alle Führungskräfte zur Unterstützung von Selbstreflektion und Selbstmanagement

Für welche Einsatzgebiete im Personalmanagement eignet sich die Skala besonders?

Reflektion und Austausch mit Führungskräften und Geführten über Führung und Führungsverhalten, z. B. im Rahmen von Trainings und Coaching 


\subsubsection{Führung in bestimmten Situationen}

\section{- Situationsspezifisches Führungsverhalten}

Der Frage, wie man als Führungskraft die Mitarbeitenden als Menschen nicht aus den Augen verliert und gleichzeitig die anstehenden Aufgaben nicht vernachlässigt, geht der Ansatz der situationsspezifischen Führung nach. Anders als frühere Führungstheorien, die postulierten, dass ganz bestimmte Verhaltensweisen oder Persönlichkeitsmerkmale (z. B. autoritäres Auftreten oder Charisma) den Führungserfolg sicherstellen, geht die situative Führung nach Hersey und Blanchard (1976) davon aus, dass eine gegebene Situation zunächst analysiert und dann passend darauf reagiert werden muss. Jede Führungssituation ist also anders und sollte in Abhängigkeit vom „Reifegrad“ eines Mitarbeitenden unterschiedlich angegangen werden, um die gewünschten Ergebnisse zu erzielen ( Abschn. 2.1.3). Aus wissenschaftlicher Perspektive werden bei diesem Ansatz häufig konzeptionelle Widersprüche und Unklarheiten bemängelt (z. B. Bass und Bass 2008; Graeff 1997), Praktikerinnen und Praktiker hingegen schätzen den Ansatz des situativen Führens, da er intuitiv einleuchtet, scheinbar einfach anzuwenden ist und als relevant für das tägliche Führen wahrgenommen wird (Avery und Ryan 2002).

Hersey und Blanchard (1976) entwickelten ein Selbstbewertungsinstrument für Führungskräfte (engl. Leadership Effectiveness and Adaptability Description ${ }^{4}$ ) bestehend aus 20 Situationen, um die Bandbreite von Führungsstil und Anpassungsfähigkeit der Anwenderin oder des Anwenders zu bewerten. Exemplarisch finden sich hier drei Situationen:

Fragebogen

Leadership Effectiveness and Adaptability Description

(LEAD) (Hersey und Blanchard 1976, eigene Übersetzung)

Instruktion:

Lesen Sie sich jede Situation durch. Umranden Sie den

Buchstaben, der Ihr Vorgehen am besten beschreiben würde.

\section{Situationen}

Ihre Mitarbeitenden reagieren in letzter Zeit nicht auf Ihre freundliche Ansprache und die offensichtliche Sorge um ihr Wohlergehen. Die Leistung Ihrer Mitarbeitenden nimmt rapide ab.
Jede Führungssituation ist individuell

Leadership Effectiveness and Adaptability Description

4 Der gesamte Fragebogen kann unter $\boldsymbol{~ h t t p s : / / d e . s c r i b d . c o m / ~ k o s t e n - ~}$ pflichtig gedownloaded werden. 
a) Sie betonen die Anwendung einheitlicher Vorgehensweisen und die Notwendigkeit, die Aufgaben zu erledigen.

b) Sie bieten an, die Thematik zu diskutieren, drängen sich aber nicht auf.

c) Sie sprechen mit Ihren Mitarbeitenden und legen anschließend Ziele fest.

d) Sie greifen absichtlich nicht ein.

Sie denken über eine Veränderung nach. Ihre Mitarbeitenden haben eine gute Erfolgsbilanz und respektieren die Notwendigkeit der Veränderung.

a) Sie erlauben der Abteilung, sich an der Entwicklung der Veränderung zu beteiligen, und sind nicht zu direktiv.

b) Sie kündigen Veränderungen an und setzen diese dann unter strenger Aufsicht um.

c) Sie erlauben der Abteilung ihre eigene Neuausrichtung zu formulieren.

d) Sie nehmen die Empfehlungen der Abteilungen auf, aber steuern die Veränderung.

Ihre Mitarbeitenden, die normalerweise Verantwortung übernehmen, reagieren nicht auf Ihre jüngste Neudefinition von Standards.

a) Sie erlauben der Abteilung sich bei der Neudefinition von Standards einzubringen und üben keine Kontrolle aus.

b) Sie definieren die Standards neu und überprüfen diese auch genau.

c) Sie vermeiden eine Konfrontation, indem Sie keinen Druck ausüben; Sie ziehen sich zurück.

d) Sie integrieren die Empfehlungen der Abteilung, aber achten darauf, dass die neuen Standards auch erfüllt werden.

Leadership Effectiveness and Adaptability Description (LEAD, Hersey und Blanchard 1976)

Welcher Aspekt von Führung wird gemessen?

Welche Dimensionen enthält diese Skala?

Für welche Unternehmen eignet sich die Skala besonders?
Situationsspezifisches Führungsverhalten

Keine - stattdessen 20 verschiedene Führungssituationen

Unternehmen mit homogener Führungskultur, die ihre Führungskräfte für situationsangemessenes, flexibles Führungsverhalten sensibilisieren wollen 
Für welche Führungskräfte eignet sich die Skala besonders?

Für welche Einsatzgebiete im Personalmanagement eignet sich die Skala besonders?
- Führungskräfte, die sich und ihre Anpassungsfähigkeit verbessern wollen

- Führungskräfte, die ihren Entwicklungspfad planen möchten

- Führungskräfte, die verschiedene Führungsstrategien reflektieren wollen

- Coaching

- Mentoring

- Führungstrainings

\section{- Entscheidungsverhalten der Führungskraft in Krisen und Leadership in Extremis}

Während einer Krise, die die öffentliche Gesundheit und Sicherheit betrifft, wie bspw. Flugzeugabstürze, Hurrikans oder terroristische Anschläge, besteht ein besonderes Bedürfnis nach wirkungsvoller Führung. Innerhalb kürzester Zeit müssen Entscheidungen getroffen werden, auch wenn Unsicherheit und Zeitnot die Situation beherrschen (Hannah et al. 2010; Pearson und Clair 1998). Beispiele aus der Geschichte (z. B. Hurrikan Katrina, 9/11 oder die Finanzkrise 2008) oder die Covid-19-Pandemie zeigen, dass ineffektive Führung in Krisen manchmal Todesfälle zur Folge haben kann, oder zumindest immense Kosten oder einen Reputationsschaden - wie im folgenden Beispiel - verursachen kann.

\section{Die „Belgienkrise“ der Coca-Cola-Company (Fiederer und Ternès 2017)}

Ein perfektes Beispiel ist die „Belgienkrise", die die Coca-Cola Company vor einigen Jahren durchlaufen hat. Die belgischen Gesundheitsbehörden erhielten immer häufiger Beschwerden darüber, dass Kinder nach dem Konsum von Coca-Cola krank wurden. Die Beschwerden bezogen sich darauf, dass die Dosen und das Getränk "seltsam" rochen und schmeckten. Die Coca-Cola Company wies die Beschwerden als "rein psychologisch“ zurück.

Technische Analysen ergaben, dass an der Qualität der Produkte tatsächlich nichts auszusetzen war. Daher musste das Problem „in den Köpfen“ der Verbraucherinnen und Verbraucher liegen. Als die Führungskräfte von Coca-Cola erkannten, dass technische Informationen oder "Fachchinesisch" die Verbraucherinnen und Verbraucher nicht davon überzeugten, sich nicht mehr krank zu fühlen, standen sie vor einer ausgewachsenen Krise. Darüber hinaus wurde der belgische Gesundheitsminister über die verzögerte Reaktion von Coca-Cola so wütend, dass er anordnete alle Dosen von Coca-Cola aus den Regalen aller Geschäfte in ganz Belgien zu nehmen. 
Leadership in extremis

Notwendigkeit von MultiTasking in Krisen
Und um sich von der Krise zu distanzieren, stellte McDonald's, einer der größten Partner von Coca-Cola, die Belieferung mit Cola in allen Filialen ein.

Aufgrund seines schlechten Umgangs mit der Krise wurde der CEO von Coca-Cola, M. Douglas Ivester, entlassen. Dies reichte aber nicht aus, um den weltweiten Schaden am Ruf von Coca-Cola ungeschehen zu machen.

Wenn es um weit mehr als das Bewältigen einer Unternehmenskrise geht, wird von Leadership in extremis gesprochen. Es geht dabei um die Führung in Situationen, in denen die Gefahr physischer Beeinträchtigungen jederzeit realistisch ist, z. B. in Gefechtssituationen bei militärischen Konflikten, bei Katastrophen oder im Extremsport. Hier vertrauen die Geführten darauf, dass das Führungsverhalten und die Entscheidungen der Führungsperson den Ausgang der kritischen Situation wesentlich beeinflussen (Beyer 2010). Ihr Handeln entscheidet nicht nur über Erfolg oder Misserfolg, sondern über Verwundungen, in besonders kritischen Lagen über Leben oder Tod (Kolditz 2005, 2006). Die Führungspersonen sind gefordert, in komplexen, dynamischen und unklaren Situationen aus einer auf sie einwirkenden Informationsflut die entscheidungsrelevanten Informationen herausfiltern. Damit dies gelingt und auch auf spontane Lageänderungen intuitiv reagiert werden kann, ist die durch Ausbildung und Vorbereitung geförderte "Situation Awareness“eine extreme Sensibilisierung der Wahrnehmung und Interpretation von Reizen aus der Umgebung - Voraussetzung (Dixon 2014; Dixon et al. 2017). Trotz Müdigkeit, Stress oder Angst muss die Führungskraft dabei Ruhe bewahren und diese auch ausstrahlen. Dies kann durchaus bedeuten, dass sie Vertrauen erzeugt, indem sie durch die Kontrolle der eigenen Ängste überzeugend eine Rolle spielt und nur äußerlich ein Bild abgibt, das von ihrem inneren Befinden abweicht (Dixon 2014). Dieses Vertrauen und eine schnelle und klare Kommunikation („Sense-Giving“) sind die Grundlagen für die Zusammenarbeit und die Nutzung der kognitiven, psychischen und physischen Ressourcen der Gruppenmitglieder und stärken den Glauben daran, dass eine Mission oder das Überstehen einer existenzbedrohenden Situation von Erfolg gekrönt sein wird (Holenweger et al. 2017).

Aber auch in nicht unmittelbar lebensbedrohlichen Situationen wie Unternehmenskrisen sind Führungskräfte dazu aufgerufen, vieles gleichzeitig zu erledigen. Hierzu zählt die Aufklärung Beteiligter und Betroffener über die Situation, die Vermittlung von Hoffnung und Entschlossenheit gegenüber der Öffentlichkeit sowie das Motivieren und Koordinieren der Mitarbeitenden (Mitroff 2004). 
Die zwei grundlegenden Verhaltensweisen, die essentiell für effektive Führung in Krisen sind, sind die Beurteilung von Informationen und das Treffen von Entscheidungen (Coombs 2015; Sweeny 2008). Zur Beurteilung von Informationen zählt der Umgang mit unvollständigen und widersprüchlichen Informationen, die Unterscheidung von relevanten und irrelevanten Informationen und die schnelle Reaktion bzw. das Aufbereiten und Weitergeben der für die Krisenbewältigung notwendigen Informationen an die relevanten Stakeholder. Beim Treffen von Entscheidungen geht es darum, den besten Weg aus der Krise zu finden, indem die Führungsperson schnell Entscheidungsalternativen ermittelt, deren jeweilige Folgen abschätzt, Handlungsempfehlungen gibt und deren Umsetzung in die Wege leitet.

Die Effizienz bzw. auch Fähigkeit einer Führungskraft, Informationen zu evaluieren und Entscheidungen, z. B. in einer Krise der öffentlichen Gesundheit und Sicherheit, zu treffen, liegt im Fokus der Forschung von Hadley et al. (2011). Basierend auf bestehender Literatur und Experteninterviews haben sie die C-LEAD (engl.: Crisis Leader Efficacy in Assessing and Deciding) Skala entwickelt, um eben diese Fertigkeit einer Führungskraft zu messen.

\section{Fragebogen}

Crisis Leader Efficacy in Assessing and Deciding (C-LEAD)

Scale nach Hadley et al. (2011, eigene Übersetzung)

\section{Stimme ganz \\ und gar \\ nicht zu}

1
Neutral

4

\section{Stimme voll und ganz zu}

$$
2
$$

\begin{abstract}
5
\end{abstract}
6
Wesentliche

Verhaltensweisen für

effektive Führung in Krisen
Crisis Leader Efficacy in Assessing and Deciding

1. Ich kann die politischen und zwischenmenschlichen Auswirkungen meiner Entscheidungen und Handlungen antizipieren.

2. Ich kann die Kernfragen/-themen einer Situation für andere zusammenfassen, unabhängig davon wie viele Informationen ich habe.

3. Ich kann Entscheidungen treffen und Handlungsempfehlungen aussprechen, auch wenn ich nicht so viele Informationen habe wie ich gerne hätte.

4. Ich kann beurteilen, welche Wirkung Maßnahmen bzw. Untätigkeit meiner Organisationseinheit in schwierigen Zeiten bei Mitgliedern der breiten Öffentlichkeit haben.

5. Ich kann erkennen, welche Informationen so wichtig sind, dass sie an andere Organisationseinheiten weitergegeben werden, noch bevor diese die Informationen anfordern/verlangen.

6. Ich kann andere über meine Arbeit auf dem Laufenden halten ohne ihnen zu viel oder zu wenig Informationen zukommen zu lassen. 
7. Ich kann auch unter enormem Zeitdruck Entscheidungen treffen und Handlungsempfehlungen aussprechen.

8. Ich kann abschätzen, wie viele Tote und Verletzte es aufgrund meiner Entscheidungen und Empfehlungen geben könnte.

9. Ich kann meine Arbeitsroutinen sofort verändern, um auf dringende Bedürfnisse zu reagieren.

Crisis Leader Efficacy in Assessing and Deciding (C-LEAD, Hadley et al. 2011)

\begin{tabular}{l|l}
$\begin{array}{l}\text { Welcher Aspekt von Führung } \\
\text { wird gemessen? }\end{array}$ & Führung in Krisen \\
$\begin{array}{l}\text { Welche Dimensionen enthält } \\
\text { diese Skala? }\end{array}$ & $\begin{array}{l}\text { Führungseffektivität bei der } \\
\text { Situationsbeurteilung und Ent- } \\
\text { scheidungsfindung in Krisen }\end{array}$ \\
\hline $\begin{array}{l}\text { Für welche Unternehmen eignet } \\
\text { sich die Skala besonders? }\end{array}$ & $\begin{array}{l}\text { - Unternehmen in extremen } \\
\text { Krisensituationen } \\
\text { - Einsatzorganisationen, wie } \\
\text { Polizei, Armee, Feuerwehr }\end{array}$ \\
\hline $\begin{array}{l}\text { Für welche Führungskräfte } \\
\text { eignet sich die Skala besonders? }\end{array}$ & $\begin{array}{l}\text { Führungskräfte, die in extremen } \\
\text { Krisen- oder Einsatzsituationen } \\
\text { führen }\end{array}$ \\
\hline $\begin{array}{l}\text { Für welche Einsatzgebiete im } \\
\text { Personalmanagement eignet } \\
\text { sich die Skala besonders? }\end{array}$ & $\begin{array}{l}\text { Führungskräfteentwicklung (z. B. } \\
\text { Training, Coaching, Supervision, } \\
\text { Mentoring) }\end{array}$ \\
\hline
\end{tabular}

Dem demographischen Wandel in der Führung gerecht werden

Leistungswandel mit zunehmendem Alter

\section{- Alter(n)sgerechte Führung}

Vor dem Hintergrund des demographischen Wandels stellt sich zunehmend die Frage, welche Rolle das Alter der Geführten und der Führungskraft für die Führungssituation spielen und inwieweit hier ein spezifisches Führungsverhalten notwendig ist. Teilweise führen Führungskräfte bis zu fünf Generationen und das Senioritätsprinzip hat seine allgemeine Gültigkeit schon lange verloren der/die Vorgesetzte ist nun häufig jünger als die Geführten (Bruch et al. 2010). Wenn von altersgerechter Führung gesprochen wird, geht es aber nicht nur darum, den Bedürfnissen älterer Mitarbeitenden gerecht zu werden, sondern auch den jüngeren, die in dieser Diskussion häufig zu kurz kommen.

In Bezug auf ältere Mitarbeitende beschreibt Schuett (2014) die Folgen des Alterns als eine Form von Leistungswandlung, die nicht mit einer Leistungsabnahme assoziiert werden darf. Das bedeutet, dass eine Verschiebung der Stärken und Schwächen stattfindet, aber natürlich trotzdem Stärken vorhanden sind. So verbessern sich beispielsweise das Erfahrungswissen und auch das Wissen um die Relativität von Werten und 
Zielen über die Jahre, wohingegen die körperliche Leistungsfähigkeit und Weiterbildungsbereitschaft tendenziell abnimmt.

Dieses Verständnis sollte jede Führungskraft, wenn ältere Mitarbeitende Teil ihres Teams sind, mitbringen, damit sie adäquat auf individuelle Bedürfnisse der verschiedenen Generationen eingehen und die Arbeit an die Leistungsfähigkeit der Mitarbeitenden anpassen kann. Nur so kann die Leistungsfähigkeit und Gesundheit der Mitarbeitenden erhalten werden und die Zusammenarbeit in altersgemischten Teams gelingen. Wichtig sind aber auch ein generelles Bewusstsein und eine Sensibilität dafür, dass jede Person anders altert, per se jeder alt wird und jedes Alter seine spezifischen Chancen und Herausforderungen mit sich bringt.

Um die Sensibilität von Führungskräften für diese Thematik zu erfassen, haben Wegge et al. (2012) einen Fragebogen zur Messung alter(n)sgerechter Führung entwickelt.

\section{Fragebogen}

Fragebogen zur Messung alter(n)sgerechter Führung

(FAF 16) von Wegge et al. (2012)

\section{Allgemeine Prinzipien der Führung in altersgemischten}

Teams:

Meine Führungskraft ...

1. ... bietet älteren Mitarbeitenden die gleichen Möglichkeiten, neue Kenntnisse und Fähigkeiten zu erwerben, wie den jüngeren.

2. ... fördert die Zusammenarbeit von jüngeren und älteren Mitarbeitenden.

3. ... behandelt sowohl jüngere als auch ältere Mitarbeitende fair.

4. ... fördert ein positives Miteinander jüngerer und älterer Mitarbeitenden.

5. ... beteiligt Mitarbeitende aller Altersklassen an Entscheidungen, die die Arbeit betreffen.

6. ... sorgt dafür, dass Altersunterschiede in unserem Bereich kein Thema sind.

7. ... stellt die beruflichen Stärken der Mitarbeitenden in den Vordergrund.

\section{Besondere Behandlung Älterer:}

Meine Führungskraft ...

8. ... geht bei der Arbeitsplanung auf die Stärken und Schwächen älterer Mitarbeitenden ein.

9. ... gibt älteren Mitarbeitenden viel Spielraum bei der Organisation ihrer einzelnen Teilarbeitsaufgaben.

10. ... bezieht ältere Mitarbeitende frühzeitig in die Diskussion anstehender Veränderungen bei der Arbeit ein.
Fragebogen zur Messung alter(n)sgerechter Führung 
11. ... fördert die Weitergabe von Berufserfahrung älterer Mitarbeitenden an ihre jüngeren Kolleginnen und Kollegen.

12. ... schätzt die Leistung älterer Mitarbeitenden wert.

\section{Besondere Behandlung Jüngerer:}

Meine Führungskraft ...

13. ... gibt jüngeren Mitarbeitenden die Unterstützung, die sie brauchen.

14. ... gibt jüngeren Mitarbeitenden regelmäßig Rückmeldung über ihre erbrachten Arbeitsleistungen.

15. ... bietet jüngeren Mitarbeitenden Möglichkeiten, ihre berufliche Weiterentwicklung voranzutreiben.

16. ... erteilt jüngeren Mitarbeitenden abwechslungsreiche Arbeitsaufgaben.

Fragebogen zur Messung alter(n)sgerechter Führung (FAF 16, Wegge et al. 2012)

\begin{tabular}{|c|c|}
\hline $\begin{array}{l}\text { Welcher Aspekt von Führung } \\
\text { wird gemessen? }\end{array}$ & Alter(n)sgerechte Führung \\
\hline $\begin{array}{l}\text { Welche Dimensionen enthält } \\
\text { die Skala? }\end{array}$ & $\begin{array}{l}\text { - Allgemeine Prinzipien der } \\
\text { Führung in altersgemischten Teams } \\
\text { - Besondere Behandlung Älterer } \\
\text { - Besondere Behandlung Jüngerer }\end{array}$ \\
\hline $\begin{array}{l}\text { Für welche Unternehmen } \\
\text { eignet sich die Skala } \\
\text { besonders? }\end{array}$ & $\begin{array}{l}\text { - Unternehmen mit alternder } \\
\text { Belegschaft } \\
\text { - Unternehmen mit sehr hetero- } \\
\text { gener Altersstruktur }\end{array}$ \\
\hline $\begin{array}{l}\text { Für welche Führungs- } \\
\text { kräfte eignet sich die Skala } \\
\text { besonders? }\end{array}$ & $\begin{array}{l}\text { - Führungskräfte, die alters- } \\
\text { gemischte Teams führen } \\
\text { - Jüngere Führungskräfte, die } \\
\text { ältere Mitarbeitende führen }\end{array}$ \\
\hline $\begin{array}{l}\text { Für welche Einsatzgebiete im } \\
\text { Personalmanagement eignet } \\
\text { sich die Skala besonders? }\end{array}$ & $\begin{array}{l}\text { Führungskräfteentwicklung, z. B. } \\
\text { Training, Coaching }\end{array}$ \\
\hline
\end{tabular}

Skala "Perzipierte Untergebenen- und Vorgesetztenfunktion"

\subsubsection{Hierarchische vs. Geteilte Führung}

- Selbstwahrnehmung in der Untergebenen- und Vorgesetztenfunktion

In Abschn. 2.2.3 ging es um implizite Führungstheorien und die Zuschreibung einer Führungsrolle durch die Mitarbeitenden. Zentrale Fragestellungen in diesem Zusammenhang waren: Wer wird warum als Führungsperson wahrgenommen? Und welche Faktoren sind neben der offiziellen hierarchischen 
Position entscheidend dafür, ob jemand in seiner Führungsrolle auch wirklich akzeptiert wird. Jetzt wollen wir die Perspektive wechseln und danach fragen, wie Mitarbeitende und Führungskräfte sich in ihrer eigenen Rolle wahrnehmen, inwieweit sie sich also - unabhängig vom offiziellen Jobprofil und Aufgabenspektrum - als „Vorgesetzt“ oder „untergeben“ wahrnehmen.

Fischer und Kohr (1980) haben dafür die Skala „Perzipierte Untergebenen- und Vorgesetztenfunktion“ mit 19 Items entwickelt. Sie misst, inwiefern sich Führungskräfte und Mitarbeitende in der klassischen Untergebenen- oder Vorgesetztenfunktion verorten. Damit kann sichtbar gemacht werden, wie dominant und rigide das Organisationsprinzip "Hierarchie“ in einem Unternehmen ist. Wie in $>$ Abschn. 2.3.5 beschrieben, erfordert die volatile, unsichere, komplexe und unklare Wettbewerbssituation, in der sich viele Branchen und Unternehmen bewegen, selbstorganisierte Teams und agile, kollaborative Organisationsformen, die die Mitarbeitenden zu selbständiger Führung anregen.

Für Unternehmen, die Hierarchien abbauen wollen und auf selbstverantwortliche Mitarbeitende setzen, kann eine Befragung der Belegschaft Klarheit schaffen, ob hier nach wie vor eine große Distanz zwischen Führenden besteht und sich klare Polaritäten erkennen lassen, oder ob die Unterschiede zwischen Führenden und Geführten verschwimmen und Führung als Gemeinschaftsleistung aufgefasst wird.

\section{Fragebogen}

Skala Perzipierte Untergebenen- und Vorgesetztenfunktion

(Fischer und Kohr 1980)

\begin{tabular}{|c|c|c|c|c|}
\hline $\begin{array}{c}\text { Zutref- } \\
\text { fend }\end{array}$ & $\begin{array}{c}\text { Eher } \\
\text { zutreffend }\end{array}$ & $\begin{array}{c}\text { Weder } \\
\text { noch }\end{array}$ & $\begin{array}{c}\text { Eher } \\
\text { unzutreffend }\end{array}$ & $\begin{array}{c}\text { Unzutref- } \\
\text { fend }\end{array}$ \\
\hline 1 & 2 & 3 & 4 & 5 \\
\hline
\end{tabular}

\section{Perzipierte Untergebenenfunktion}

1. Meine Arbeit besteht in der Durchführung von Anweisungen.

2. In meiner Arbeitsleistung richte ich mich nach anderen.

3. Ich bin bei meiner Arbeit von Weisungen abhängig.

4. Vorschriften und Vorgesetzte engen meinen Tätigkeitsbereich stark ein.

5. Ich werde bei meiner Arbeit öfter kontrolliert.

6. Der Ablauf meiner Arbeit ist bis in alle Einzelheiten festgelegt.

7. Mir macht keiner Vorschriften, wie ich meine Arbeit erledigen soll. (-)

8. Meine tägliche Arbeit wird mir zugewiesen.

9. Ich kann mir meine Arbeit selbst einteilen. (-)
Mitarbeiterbefragung zur Identifikation von Nähe/Distanz zwischen Führungskräften und Mitarbeitenden 


\section{Perzipierte Vorgesetztenfunktion}

1. Bei meiner beruflichen Tätigkeit habe ich Untergebene.*

2. Ich muss an meinem Arbeitsplatz auch die Arbeit von anderen verantworten.*

3. Ich bin unentbehrlich an meinem Arbeitsplatz.

4. Bei meiner Arbeit gebe ich öfter Anweisungen.*

5. Es gehört zu meinen beruflichen Aufgaben, Entscheidungen selbständig zu treffen.

6. Ein Teil meiner Arbeit besteht in der Kontrolle von Mitarbeitenden.*

7. Es gibt Dinge, Vorgänge u. a. an meinem Arbeitsplatz, die nur ich genau kenne.

8. Bei meiner beruflichen Tätigkeit habe ich großen Einfluss.*

9. Bei meiner beruflichen Tätigkeit muss ich mich ständig auf dem Laufenden halten.

10. Zu meiner beruflichen Tätigkeit gehört es, Leistungen und Verhalten von Mitarbeitenden zu beurteilen.*

* Items der Kurzversion der Skala zur Perzipierten Vorgesetztenfunktion.

Skala Perzipierte Untergebenen- und Vorgesetztenfunktion (Fischer und Kohr 1980)

\begin{tabular}{|c|c|}
\hline $\begin{array}{l}\text { Welcher Aspekt von Führung } \\
\text { wird gemessen? }\end{array}$ & $\begin{array}{l}\text { Wahrnehmung der Unter- } \\
\text { gebenen- und Vorgesetzten- } \\
\text { funktion }\end{array}$ \\
\hline $\begin{array}{l}\text { Welche Dimensionen enthält } \\
\text { diese Skala? }\end{array}$ & $\begin{array}{l}\text { - Perzipierte } \\
\text { Untergebenenfunktion } \\
\text { - Perzipierte Vorgesetzten- } \\
\text { funktion }\end{array}$ \\
\hline $\begin{array}{l}\text { Für welche Unternehmen eignet } \\
\text { sich die Skala besonders? }\end{array}$ & $\begin{array}{l}\text { - Unternehmen, die ihre } \\
\text { „Hierarchisierung" sichtbar } \\
\text { machen wollen } \\
\text { - Unternehmen, die Hierarchien } \\
\text { abbauen und kollaborative } \\
\text { Führung fördern wollen }\end{array}$ \\
\hline $\begin{array}{l}\text { Für welche Führungskräfte } \\
\text { eignet sich die Skala besonders? }\end{array}$ & $\begin{array}{l}\text { Führungskräfte, die... } \\
\text { - ihre eigene Führungsrolle } \\
\text { reflektieren wollen } \\
\text { - Mitarbeiter- und Führungsrollen } \\
\text { im Team reflektieren wollen }\end{array}$ \\
\hline $\begin{array}{l}\text { Für welche Einsatzgebiete im } \\
\text { Personalmanagement eignet } \\
\text { sich die Skala besonders? }\end{array}$ & $\begin{array}{l}\text { Wandel der Führungskultur } \\
\text { von hierarchischer Führung zu } \\
\text { Führung als Gemeinschaftsauf- } \\
\text { gabe }\end{array}$ \\
\hline
\end{tabular}




\section{- Geteilte Führung}

Aufgrund gravierender Veränderungen in der Arbeitswelt in den letzten Jahrzehnten, werden verstärkt Arbeitsteams eingesetzt. Ziel ist es dabei, gemeinsam an einer Aufgabe zu arbeiten und etwas erreichen zu können, das über das Potenzial eines Einzelnen hinausgeht (Marks et al. 2001). Allerdings stellt sich dieser vermeintliche Erfolg nicht automatisch ein - eine wesentliche Rolle spielt hierbei die Verteilung der Führungsrollen innerhalb des Teams. In den 1950er Jahren schlug Gibb (1954) erstmals zwei Formen der Teamführung vor: Geteilt und fokussiert. Bei der fokussierten Führung bleibt die Führungsfunktion bei einem einzelnen Teammitglied, wohingegen bei der geteilten Führung zwei oder mehrere Mitglieder die Führungsrolle, -verantwortlichkeiten und -funktionen teilen. Teams mit einem hohen Grad an geteilter Führung können diese Funktion auch rotieren lassen, sodass die Führungsrolle von unterschiedlichen Teammitgliedern im Laufe des Teamzyklus und der -entwicklung übernommen wird (Carson et al. 2007).

Basierend auf den elf Faktoren des Managerial Practices Survey von Yukl und Lepsinger (1990), entwickelte Hiller (2001) ein ökonomisch anwendbares Instrument, die Shared Leadership Scale, das die Neigung einzelner Teammitglieder misst, an der geteilten Führungsrolle teilzuhaben.

\section{Fragebogen}

Geteilte Führung (Hiller 2001, eigene Übersetzung)

$$
\text { Nie }
$$

1

2
3

4
Immer

$5 \quad 6$
Geteilte Führung

Fokussierte Führung

Shared Leadership Scale

Wie häufig wirken Teammitglieder mit, wenn es ...

\section{Planung \& Organisation}

1. ... darum geht, zu planen, wie die Arbeit aufgeteilt wird.

2. ... um die Zuteilung von Teamressourcen entsprechend der Prioritäten unseres Teams geht.

3. ... um die Festlegung unserer Teamziele geht.

4. ... darum geht, Aufgaben so zu organisieren, dass die Arbeitsabläufe reibungslos funktionieren.

5. ... darum geht, zu entscheiden, wie unser Team zusammenarbeitet.

6. ... darum geht, hilfreiche Informationen zu arbeitsbezogenen Plänen unseres Teams zur Verfügung zu stellen.

\section{Problemlösen}

7. ... um die Entscheidung über die beste Vorgehensweise geht, wenn ein Problem auftritt.

8. ... um die schnelle Diagnose von Problemen geht. 
9. ... darum geht, die kombinierte Expertise unseres Teams für die Lösung von Problemen zu nutzen.

10. ... darum geht, Lösungen für Probleme zu finden, die die Teamleistung beeinflussen.

11. ... darum geht, Probleme zu identifizieren, bevor sie auftreten.

12. ... um die Entwicklung von Lösungen für Probleme geht.

13. ... darum geht, Probleme zu lösen, sobald sie auftreten.

\section{Unterstützung \& Rücksichtnahme}

14. ... um das Anbieten von Unterstützung für Teammitglieder geht, die Hilfe benötigen.

15. ... darum geht, gegenüber anderen Teammitgliedern Geduld zu zeigen.

16. ... darum geht, andere Teammitglieder zu ermutigen, wenn sie sich Sorgen machen.

17. ... darum geht, anderen Teammitgliedern bei Beschwerden und Problemen zuzuhören.

18. ... darum geht, den Zusammenhalt im Team zu fördern.

19. ... darum geht, sich gegenseitig mit Respekt zu behandeln.

\section{Entwicklung \& Mentoring}

20. ... um den Austausch von karriererelevanten Ratschlägen in unserem Team geht.

21. ... darum geht, sich gegenseitig bei der Entwicklung von Fähigkeiten zu unterstützen.

22. ... darum geht, Fähigkeiten von allen anderen Teammitgliedern zu lernen.

23. ... darum geht, ein positives Vorbild für neue Teammitglieder abzugeben.

24. ... darum geht, leistungsschwache Teammitglieder zu unterweisen, damit sie sich verbessern können.

25. .... darum geht, mitzuhelfen, wenn ein anderes Teammitglied eine neue Fähigkeit erlernt.

Shared Leadership Scale (Hiller 2001)

Welcher Aspekt von Führung wird gemessen?

Welche Dimensionen enthält diese Skala?
Geteilte Führung

- Planung \& Organisation

- Problemlösen

- Unterstützung \& Rücksichtnahme

- Entwicklung \& Mentoring 


\begin{tabular}{|c|c|}
\hline $\begin{array}{l}\text { Für welche Unter- } \\
\text { nehmen eignet sich die } \\
\text { Skala besonders? }\end{array}$ & $\begin{array}{l}\text { - IT-Unternehmen } \\
\text { - Krankenhäuser } \\
\text { - Generell: Unternehmen mit komplexen } \\
\text { Aufgabenstellungen in einem volatilen } \\
\text { Umfeld }\end{array}$ \\
\hline $\begin{array}{l}\text { Für welche Führungs- } \\
\text { kräfte eignet sich die } \\
\text { Skala besonders? }\end{array}$ & $\begin{array}{l}\text { - Führungskräfte mit High Performance } \\
\text { Work Teams } \\
\text { - Führungskräfte in agil arbeitenden } \\
\text { Unternehmen }\end{array}$ \\
\hline $\begin{array}{l}\text { Für welche Einsatz- } \\
\text { gebiete im Personal- } \\
\text { management eignet sich } \\
\text { die Skala besonders? }\end{array}$ & $\begin{array}{l}\text { - Entwicklung einer agilen Führungskultur } \\
\text { - Sensibilisierung für die Idee von } \\
\text { Führung als Gemeinschaftsleistung } \\
\text { - Teamentwicklung }\end{array}$ \\
\hline
\end{tabular}

\subsection{Diagnose des Führungsstils}

Der Begriff Führungsstil bezeichnet häufig auftretende, sich wiederholende Verhaltensweisen, in denen sich bestimmte typische Muster erkennen lassen. Oft offenbaren sich in ihnen auch Grundeinstellungen gegenüber den Mitarbeitenden, der Aufgabenerfüllung und den Quellen von Unternehmenserfolg. Diese Verhaltenstendenzen bestehen über einen längeren Zeitraum und prägen viele Bereiche des Handelns einer Führungskraft, weshalb sie sich auch auf den Führungserfolg auswirken. Im Folgenden sollen einige in der aktuellen Forschung besonders bedeutsamen Führungsstile sowie die dazugehörigen Messinstrumente vorgestellt werden. Bei der Transaktionalen Führung ( Abschn. 6.6.1) steht die Gestaltung der Austauschbeziehung zwischen Führungskraft und Mitarbeitenden im Vordergrund, bei der Transformationalen Führung ( Abschn.6.6.2) geht es darum, durch Führung die Werte, Einstellungen und das Commitment der Geführten dahingehend $\mathrm{zu}$ verändern, dass die Organisationsziele besser erreicht werden können. Der Full-Range-LeadershipAnsatz bildet neben transaktionalen und transformationalen Aspekten von Führung auch noch das Management by Exception (Eingreifen in Ausnahmefällen) und die Laissezfaire-Führung ab (vollständige Verantwortungsabgabe an die Geführten) ( Abschn. 6.6.3). Bei der charismatischen Führung stehen Verhaltensweisen im Fokus, die Ausdruck einer außergewöhnlich visionären, feinfühligen und unkonventionellen Persönlichkeit sind ( Abschn.6.6.4), bei der authentischen Führung basiert das Führungsverhalten auf Idealen, moralischen Überzeugungen und Integrität der Führungskraft, resultiert aber auch aus dem Bemühen der Führungskraft, sich selbst und die eigene Urteilsbildung auf den Prüfstand zu stellen ( $\triangleright$ Abschn. 6.6.5). Bei der ambidextren Führung werden Verhaltensmuster gemessen, die einerseits 
Abstimmung von Leistung und Gegenleistung

Prozesse können transaktionale Führung abbilden
Innovation (Exploration) in Organisationen begünstigen und gleichzeitig dafür sorgen, dass die Effizienz gesteigert und ein höherer Nutzen geschaffen werden kann (Exploitation) ( Abschn. 6.6.7).

\subsubsection{Transaktionale Führung}

Bei der transaktionalen Führung geht es darum, Leistungen, die die Mitarbeitenden erbringen, und Gegenleistungen, die sie dafür von der Führungskraft als Vertreterin der Organisation $\mathrm{zu}$ erwarten haben, möglichst gut aufeinander abzustimmen (Bass und Avolio 1997; Bass 1999). Die zentralen Führungsinstrumente der transaktionalen Führung sind Lob, Belohnungen oder die Zuteilung von Ressourcen. Belohnungen und Anerkennung erhalten die Geführten allerdings nur, wenn sie ihre Aufgaben und Rollen aus Sicht der Vorgesetzten zufriedenstellend ausgeführt haben (Bass et al. 2003; Podsakoff et al. 1982). Die Führungskraft delegiert definierte Aufgaben und setzt klare Ziele, um den Mitarbeitenden Orientierung zu bieten, was von ihnen erwartet wird. Ansonsten interveniert sie möglichst wenig und gibt nach Erfüllung der Aufgabe Feedback bzw. lobt oder belohnt die Leistungen der Mitarbeitenden.

Eine typische Führungssituation könnte so aussehen: Eine Mitarbeiterin erhält von ihrer Führungskraft den Auftrag ein Konzept für eine Werbekampagne zu entwerfen. Die Führungskraft erläutert sehr detailliert, was sie konkret erwartet (u. a. Deadline, formale Anforderungen, Umfang, Gliederung). Sie berücksichtigt dabei die Leistungsfähigkeit und die zur Verfügung stehenden zeitlichen Ressourcen der Mitarbeiterin. Am vereinbarten Termin prüft die Führungskraft das vorgelegte Konzept, gibt detailliertes Feedback, inwieweit die einzelnen vorab besprochenen Erwartungen erfüllt wurden und spricht ggf. ihre Anerkennung aus.

In überspitzter Form findet sich die transaktionale Führung auch in sogenannten Führungssubstituten wieder, wenn Führung nicht mehr durch Menschen, sondern durch vorgegebene Prozesse erfolgt: Ein Bandarbeiter eines Automobilherstellers kennt genau seine Arbeitszeiten von 7 Uhr bis 15:30 Uhr und produziert eine festgelegte Anzahl Bremsscheiben je Schicht. Wenn er seine tägliche Stückzahl erfüllt, wird er regulär entlohnt, bei Überproduktion wird er mit einem Bonus belohnt.

Transaktionale Führung ist trotz ihres etwas mechanistischen Charakters also sehr wirksam, wenn sie zur Arbeitsaufgabe, zur Kultur, zu den Bedürfnissen und zur Persönlichkeit der Geführten passt - wie die zwei folgenden Forschungsergebnisse zeigen. So fanden Liu et al. (2011) heraus, dass transaktionale Führung sich je nach Merkmalen der Arbeitsaufgabe positiv oder negativ auf die Innovationsfähigkeit von chinesischen 
Dienstleistungsteams verschiedener Branchen auswirkte. Pieterse et al. (2010) zeigten in einer Studie mit niederländischen Angestellten, dass transaktionale Führung innovatives Verhalten hemmt, wenn die Angestellten sehr selbstbewusst sind. Das könnte daran liegen, dass selbstbewusste Mitarbeitende diesen Führungsstil als kontrollierend und demotivierend wahrnehmen, was sich letztlich auf ihre Innovationsfähigkeit auswirkt.

Um transaktionale Führung quantitativ erfassen zu können, Leader Behavior Items veröffentlichten Pearce und Sims Jr (2002) die folgenden Leader Behavior Items.

\section{Fragebogen}

Leader Behavior Items - Transaktionale Führung (Pearce und Sims Jr 2002, eigene Übersetzung)

\begin{tabular}{|c|c|}
\hline $\begin{array}{l}\text { Stimme } \\
\text { ganz und } \\
\text { gar nicht }\end{array}$ & Neutral \\
\hline
\end{tabular}

zu

\begin{tabular}{|l|l|l|l|l|}
\hline 1 & 2 & 3 & 4 & 5
\end{tabular}

\section{Materielle Anerkennung}

1. Meine Führungskraft wird sich dafür aussprechen, dass ich bei guter Leistung gut entlohnt werde.

2. Meine Führungskraft wird sich dafür aussprechen, dass ich bei guter Leistung eine höhere Vergütung erhalte.

3. Wenn ich gute Leistung erbringe, wird sich meine Führungskraft für eine höhere Vergütung aussprechen.

\section{Persönliche Anerkennung}

4. Meine Führungskraft gibt mir positives Feedback, wenn ich gute Leistung erbringe.

5. Meine Führungskraft lobt mich, wenn ich überdurchschnittlich gut meine Aufgaben erledige.

6. Meine Führungskraft schenkt mir besondere Anerkennung, wenn meine Arbeitsleistung besonders gut ist.

\section{Management by Exception (aktiv)}

7. Meine Führungskraft konzentriert sich auf Unregelmäßigkeiten, Fehler, Ausnahmen und Abweichungen vom Standard.

8. Meine Führungskraft prüft meine Leistung genau auf Fehler.

9. Meine Führungskraft verbringt Zeit damit „Brände zu löschen".

10. Meine Führungskraft registriert Fehler.

11. Meine Führungskraft konzentriert sich auf die mangelnde Einhaltung von Vorgaben. 


\section{Management by Exception (passiv)}

12. Meine Führungskraft lässt zu, dass die Leistung unter die Mindestanforderungen fällt, bevor er/sie sich um Verbesserungen bemüht.

13. Meine Führungskraft greift erst ein, wenn die Probleme ernst werden.

14. Meine Führungskraft sagt mir eher was ich falsch gemacht habe und nicht, was ich richtig gemacht habe.

15. Meine Führungskraft wartet bis etwas schief gelaufen ist, ehe er/sie eingreift.

16. Meine Führungskraft glaubt fest daran, dass nichts verändert werden muss, solange etwas noch funktioniert.

\begin{tabular}{|c|c|}
\hline $\begin{array}{l}\text { Welcher Aspekt von Führung wird } \\
\text { gemessen? }\end{array}$ & Transaktionale Führung \\
\hline $\begin{array}{l}\text { Welche Dimensionen enthält die } \\
\text { Skala? }\end{array}$ & $\begin{array}{l}\text { - Materielle Anerkennung } \\
\text { - Persönliche Anerkennung } \\
\text { - Management by Exception } \\
\text { (aktiv) } \\
\text { - Management by Exception } \\
\text { (passiv) }\end{array}$ \\
\hline $\begin{array}{l}\text { Für welche Unternehmen eignet } \\
\text { sich die Skala besonders? }\end{array}$ & $\begin{array}{l}\text { Unternehmen, die ihre } \\
\text { Führungskultur evaluieren } \\
\text { wollen }\end{array}$ \\
\hline $\begin{array}{l}\text { Für welche Führungskräfte eignet } \\
\text { sich die Skala besonders? }\end{array}$ & $\begin{array}{l}\text { Führungskräfte, die ihr } \\
\text { Führungsverhalten reflektieren } \\
\text { wollen }\end{array}$ \\
\hline $\begin{array}{l}\text { Für welche Einsatzgebiete im } \\
\text { Personalmanagement eignet sich } \\
\text { die Skala besonders? }\end{array}$ & $\begin{array}{l}\text { - Führungsfeedback } \\
\text { - Führungskräfteentwicklung } \\
\text { (z. B. Training) } \\
\text { - Coaching }\end{array}$ \\
\hline
\end{tabular}

\subsubsection{Transformationale Führung}

Transformationale Führungskräfte gehen auf die Bedürfnisse ihrer Mitarbeitenden ein
Führungskräfte, die transformational führen, verbessern das Selbstwertgefühl ihrer Mitarbeitenden, motivieren sie, über ihre Grenzen hinauszugehen und haben herausfordernde Leistungserwartungen an sie (Bass und Bass 2008). Diese Führungspersönlichkeiten schaffen Visionen und unterstützen Veränderungen mit die bekanntesten „Führungsbeispiele“ finden sich in den Weltreligionen: Jesus, Mohammed und Buddha (Ford 1991). Gerne werden in diesem Zusammenhang auch Barack Obama oder Martin Luther King angeführt (Green und Roberts 2012; McGuire 
und Hutchings 2007). Diese Führungspersönlichkeiten haben es geschafft, bei anderen Vertrauen, Bewunderung, Respekt und Loyalität zu wecken und sie dadurch für ihre Ziele und Anliegen zu gewinnen. Aber nicht nur eine charismatische Persönlichkeit, auch die Verwendung von überzeugenden Symbolen oder symbolischen Handlungen, die emotionale Ansprache der Mitarbeitenden, die Lust Neues auszuprobieren und das Gewohnte nicht nur bei anderen, sondern auch bei sich selbst zu hinterfragen, machen transformationales Führen aus. Auf transformationale Führungskräfte trifft aber auch der „4M-Leitsatz“ für gute Führung zu: Man muss Menschen mögen! - sie haben ein Gespür für Menschen und deren individuelle Bedürfnisse und verhalten sich fair.

Neueste Forschungsergebnisse zeigen, dass Mitarbeitende vor allem dann transformationale Führung benötigen, wenn sie unter Stress stehen oder Herausforderungen bewältigen müssen, wenn sie mit größerer Unsicherheit in der Arbeit konfrontiert sind und wenn sie bedeutungsvolle Aufgaben erledigen müssen. Führungskräfte sollten daher sensibel sein für die Situation und die Bedürfnisse ihrer Mitarbeitenden (Tepper et al. 2018). Vor allem in Teams, deren Mitglieder über mehrere Standorte verteilt sind und die Kommunikation v. a. über elektronische Medien (z. B. in Form von Emails oder Telefonkonferenzen) erfolgt, ist transformationale Führung schwieriger umzusetzen. Offensichtlich ist für den Aufbau einer engen Beziehung zwischen Führungskraft und Geführten der face-to-face-Kontakt enorm wichtig (Wong und Berntzen 2019). Führungskräfte stehen aber auch vor der Herausforderung, gleichzeitig ganze Teams und die individuellen Teammitglieder zu motivieren. Auf die Gruppe ausgerichtete transformative Führung ist dabei wirksamer, da sie die Bindung im Team stärkt, dazu motiviert, sich gegenseitig zu unterstützen und die Gruppenleistung verbessert, während auf das individuelle Teammitglied gerichtete transformationale Führung sich nur dann positiv auf gruppenbezogene Leistungsparameter auswirkt, wenn diese Personen sich gegenüber ihrer Arbeitsgruppe bereits verpflichtet fühlen (Lorinkova und Perry 2019).

Um transformationale Führung messbar zu machen, hat die Forschergruppe um Phil Podsakoff einen Fragebogen entwickelt, der eine interessante Alternative zum häufig verwendeten Multifactor Leadership Questionnaire darstellt: die Transformational Leadership Behavior Scale (Podsakoff et al. 1996).

\section{Fragebogen}

Transformational Leadership Behavior Scale (Podsakoff et al. 1996, eigene Übersetzung)

$$
\begin{gathered}
\text { Stimme gar } \\
\text { nicht zu }
\end{gathered}
$$

Neutral

$$
1
$$

2
3
Stimme voll

und ganz zu
Herausforderung
transformationaler Führung
von Teams

Transformational Leadership

Behavior Scale 
Meine Führungskraft ...

\section{Artikulation einer Vision}

1. ... ist ständig auf der Suche nach neuen Perspektiven für unsere Einheit/Abteilung/Organisation.

2. ... zeichnet ein interessantes Bild der Zukunft für unsere Gruppe.

3. ... hat ein klares Verständnis dafür, wohin wir gehen.

4. ... inspiriert andere mit seinen/ihren Zukunftsplänen.

5. ... ist in der Lage, andere für seinen/ihren Zukunftstraum zu begeistern.

\section{Vorbild sein}

6. ... führt durch "Vorleben" statt nur durch "Reden".

7. ... ist ein gutes Vorbild, dem man folgen kann.

8. ... geht mit gutem Beispiel voran.

\section{Förderung der Akzeptanz von Gruppenzielen}

9. ... fördert die Zusammenarbeit von Arbeitsgruppen.

10. ... ermutigt Mitarbeitende, Teamplayer zu sein.

11. ... schafft es, dass eine Gruppe zusammen für dasselbe Ziel arbeitet.

12. ... fördert Teamhaltung und Teamgeist unter seinen/ihren Mitarbeitenden.

\section{Hohe Leistungserwartung}

13. ... zeigt uns, dass er/sie viel von uns erwartet.

14. ... besteht darauf, dass wir unser Bestes geben.

15. ... gibt sich nicht mit zweitbesten Lösungen zufrieden.

\section{Individuelle Unterstützung}

16. ... handelt ohne Rücksicht auf meine Gefühle. (-)

17. ... zeigt Respekt für meine Gefühle.

18. ... verhält sich auf eine Art und Weise, die auf meine persönlichen Bedürfnisse abgestimmt ist.

19. ... achtet im Umgang mit mir nicht auf meine Gefühle. (-)

\section{Intellektuelle Stimulation}

20. ... hat mir neue Sichtweisen auf Themen eröffnet, die für mich bisher ein Rätsel waren.

21. ... hat Ideen, die mich gezwungen haben, einige meiner eigenen Vorstellungen zu überdenken, die ich bisher nicht infrage gestellt habe.

22. ... hat mich angeregt über alte Probleme auf eine neue Art und Weise nachzudenken. 
Transformational Leadership Behavior Scale (Podsakoff et al. 1996)

Welcher Aspekt von
Führung wird gemessen?

Welche Dimensionen enthält die Skala? eignet sich die Skala besonders?

Für welche Führungskräfte eignet sich die Skala besonders?

Für welche Einsatzgebiete im Personalmanagement eignet sich die Skala besonders?
Transformationale Führung

- Artikulation einer Vision

- Vorbild sein

- Förderung der Akzeptanz von Gruppenzielen

- Hohe Leistungserwartung

- Individuelle Unterstützung

- Intellektuelle Stimulation

- Dynamisches Umfeld

- Intensiver Wettbewerb

- Starker Innovationsdruck

- Disruptiver Wandel

- Top Management

- Obere Hierarchieebenen

- Schlüsselpositionen mit Innovationscharakter

- Führungskräfteentwicklung (z. B. Trainings, Coaching)

- Führungsfeedback

\subsubsection{Full-Range-Leadership}

Das Modell des Full-Range-Leadership bildet das Verhalten von Führungskräften gegenüber ihren Mitarbeitenden in verschiedenen Arbeitssituationen ab. Es wurde in den 1980er Jahren von Bass und Avolio entwickelt und gilt als übergeordnete Führungstheorie, die die transformationale und transaktionale Führung ( Abschn. 2.2.2) mit dem Laissez-faire-Führungsstil ${ }^{5}$ in Bezug setzt - das Modell wurde in zahlreichen Studien empirisch bestätigt. Erfolgsversprechend ist nach diesem Modell ein mitarbeiter- und zukunftsorientiertes Führungsverhalten (Avolio 2011). Das Full-Range-Leadership-Modell unterscheidet acht verschiedene Führungsstile, die das ganze Spektrum von passiven, ineffektiven Verhaltensweisen („Laissez-faire“) bis hin zu aktiven und erwiesenermaßen besonders effektiven Verhaltensweisen umfassen.

Seit den 1980er Jahren hat das Full-Range-Leadership Modell in der weltweiten Leadership-Forschung große Akzeptanz gefunden und ist auf unterschiedlichste kulturelle und fachliche Kontexte angewandt worden, beispielsweise bei pakistanischen Fachkräften (Ryan und Tipu 2013),

5 Führungskräfte, die nach dem Laissez-faire-Prinzip führen, vermeiden jede Art von Führungsverantwortung.

Kombination aus transformationaler, transaktionaler und Laissezfaire Führung 
Leadership Style Assessment

Selbst- und

Fremdwahrnehmung mittels LSA möglich indischen Hochschuldozierenden (Bodla und Nawaz 2010), amerikanischem Krankenhauspersonal (Spinelli 2006), amerikanischen Verwaltungsangestellten (Oberfield 2012) oder in britischen Industriebetrieben (Edwards und Gill 2012).

Außergewöhnlich an dem von Peus et al. (2013) abgeleiteten Test „Leadership Style Assessment (LSA)“ ist die Erfassung des Führungsverhaltens anhand typischer Arbeitssituationen. Bei derartigen situativen Beurteilungsverfahren bewerten die Teilnehmenden alternative Reaktionsmöglichkeiten auf bestimmte Situationen. Führungskräfte und Mitarbeitende erhalten im LSA für den Berufsalltag typische Situationsbeschreibungen zu denen ihnen jeweils acht mögliche Reaktionsmöglichkeiten vorgeschlagen werden, die auf den acht verschiedenen Führungsstilen (=Dimensionen des Full Range Leadership Modells) basieren:

- Transformationale Führungsstile (Inspirierende Motivation, Intellektuelle Stimulation, Individuelle Wertschätzung, Charismatisches Verhalten)

- Transaktionale Führungsstile (Leistungsorientierte Belohnung, Aktive Kontrolle, Eingreifen im Bedarfsfall)

- Laissez-faire-Führungsstil

Führungskräfte können mit dem LSA selbst einschätzen, wie wahrscheinlich sie sich entsprechend verschiedener Reaktionsmöglichkeiten verhalten würden (Selbstbeurteilung). Bei der Fremdbeurteilungsversion des Fragebogens beurteilen Mitarbeitende das Verhalten ihrer Führungskraft.

Der gesamte LSA-Fragebogen ist in der Testzentrale des Hogrefe Verlags kostenpflichtig erhältlich ${ }^{6}$, im Folgenden findet sich eine Beispiel-Frage aus dem LSA (Peus et al. 2013, deutsches Original von Prof. Dr. Peus erhalten):

\section{Fragebogen}

Nachfolgend werden Ihnen acht herausfordernde Situationen der Zusammenarbeit in einer Abteilung geschildert. Für jede Situation sind acht verschiedene Verhaltensoptionen dargestellt. Bitte geben Sie für jede Verhaltensoption an, wie wahrscheinlich es ist, dass sich Ihre Führungskraft - also Ihr(e) direkte(r) Vorgesetzte( $r$ ) - auf diese Weise verhalten würde. Selbstverständlich existieren weitere Verhaltensweisen, die hier nicht dargestellt werden. Für diese Befragung ist jedoch relevant, wie Sie Ihre Führungskraft hinsichtlich der genannten Verhaltensalternativen einschätzen.

Bitte geben Sie Ihre Antworten mithilfe der folgenden Skala an:

6 https://www.testzentrale.de/shop/leadership-style-assessment.html (Stand: 21.06.2019). 


\begin{tabular}{c|c|c|r|r|}
$\begin{array}{c}\text { Sehr } \\
\text { unwahr- } \\
\text { scheinlich }\end{array}$ & Neutral & & $\begin{array}{r}\text { Sehr wa } \\
\text { scheinlich }\end{array}$ \\
\hline 1 & 2 & 3 & 4 & 5 \\
\hline
\end{tabular}

Ein Mitarbeiter der Abteilung hat Ihrer Führungskraft eine Präsentation vorgelegt, die dieser Mitarbeiter bei einem potenziellen Kunden vorstellen soll. Die Präsentation weicht jedoch in ihrer Qualität gravierend von den Erwartungen Ihrer Führungskraft ab. Beispielsweise sind grundlegende formale Richtlinien und graphische Gestaltungsaspekte nicht eingehalten worden. Ihre Führungskraft ist mit dieser Leistung nicht einverstanden.

Meine Führungskraft ...

\section{Intellektuelle Stimulation:}

... fordert den Mitarbeiter zunächst auf, die Stärken und Schwächen seiner Präsentation kritisch zu überprüfen. Zusätzlich macht sie Vorschläge, wie der Mitarbeiter die Überzeugungskraft der Präsentation erhöhen kann.

\section{Inspirierende Motivation:}

... motiviert den Mitarbeiter, die Präsentation noch einmal zu überarbeiten, um mit einer weiter verbesserten Präsentation die Abteilung wirkungsvoll nach außen vertreten zu können, und betont die Stärken seiner bisherigen Arbeit.

\section{Individuelle Unterstützung:}

... nimmt sich Zeit für ein persönliches Gespräch mit dem Mitarbeiter, in dem sie mit ihm detailliert bespricht, warum er Schwierigkeiten hatte und wie sie ihn bei der Verbesserung der Präsentation unterstützen kann.

\section{Idealisierter Einfluss:}

... spricht mit dem Mitarbeiter darüber, dass ihr das professionelle Auftreten gegenüber potenziellen Kunden ausgesprochen wichtig ist und verdeutlicht ihre fachlichen Kritikpunkte, ohne seine Kompetenzen infrage zu stellen.

\section{Leistungsorientierte Belohnung:}

... vereinbart mit dem Mitarbeiter, dass er die Präsentation zunächst grundlegend hinsichtlich der formalen Fehler überarbeitet. Im Gegenzug bietet sie ihm konkrete Unterstützung bei der weiteren Perfektionierung an.

\section{Management by Exception (aktiv):}

... fordert den Mitarbeiter auf, die Präsentation zu überarbeiten und kontrolliert von nun an bei jeder Aufgabe 
des Mitarbeiters regelmäßig, ob dieser Fehler dabei macht oder erneut von den internen Vorgaben abweicht.

Management by Exception (passiv):

... lässt den Mitarbeiter die qualitativ unzureichende Präsentation halten, ohne ihm vorher Feedback zu geben, und spricht das Thema anschließend nur an, wenn sich der potenzielle Kunde direkt über die Präsentation beschwert.

\section{Laissez-faire Führung:}

... fühlt sich nicht dafür verantwortlich, wie der Mitarbeiter die Abteilung beim Kunden repräsentiert. Dementsprechend gibt sie ihm keine Rückmeldung zu seiner qualitativ unzureichenden Präsentation.

(Abdruck erfolgt mit freundlicher Genehmigung von Prof. Dr. Claudia Peus. Das Testverfahren ist zu beziehen bei der Testzentrale www.testzentrale.de)

Leadership Style Assessment (LSA, Peus et al. 2013)

Welcher Aspekt von Führung wird gemessen?

Welche Dimensionen enthält die Skala?

Für welche Unternehmen eignet sich die Skala besonders?

Für welche Führungskräfte eignet sich die Skala besonders?

Für welche Einsatzgebiete im Personalmanagement eignet sich die Skala besonders?
Full-Range-Leadership

- Intellektuelle Stimulation

- Inspirierende Motivation

- Individuelle Unterstützung

- Idealisierter Einfluss

- Leistungsorientierte Belohnung

- Aktive Kontrolle (Management by Exception - aktiv)

- Eingreifen im Bedarfsfall (Management by Exception - passiv)

- Laissez-faire-Führung

Alle Unternehmen, die ihre Führungskultur evaluieren und verändern wollen

Führungskräfte, die ihren Führungsstil situationsbezogen reflektieren wollen

- Führungskräftebeurteilung

- Führungskräfteentwicklung

- Führungskräfteauswahl und -beförderung 


\subsubsection{Charismatische Führung}

Charismatische Führung ist besonders bedeutsam für Unternehmen, deren dynamisches Umfeld eine permanente Erneuerung und einen stetigen Wandel erfordert oder die aufgrund fehlender Anpassungsfähigkeit an Umweltveränderungen auf eine Krise zusteuern bzw. sich bereits in einer Krise befinden.

Mit der 1997 veröffentlichten, überarbeiteten CongerKanungo-Skala kann gemessen werden, wie charismatisch die Führung - insbesondere das obere Management - eines Unternehmens ist (Conger et al. 1997). Die fünf Dimensionen der Skala Strategische Vision und deren Artikulation, Sensibilität für die Umwelt, Sensibilität für die Bedürfnisse der Organisationsmitglieder, Übernahme persönlicher Risiken und unkonventionelles Verhalten - greifen das Konzept des charismatischen Führers von Max Weber (Weber 1956) auf. Nach Conger und Kanungo erkennen die Mitarbeitenden die außergewöhnliche Persönlichkeit des Charismatikers daran, dass er bereit ist, für seine Vision hohe persönliche Risiken einzugehen und dass er sich unkonventionell verhält, um seine Ziele zu verwirklichen. Sein Handeln ist von visionären Vorstellungen und Zielen geleitet, für die er seine Mitarbeitenden durch begeisternde Kommunikation gewinnen kann. Und drittens ist er sich der Bedürfnisse seines Umfelds bewusst, was eine hohe Sensibilität nicht nur für interne und externe Bedingungen, sondern auch für die Organisationsmitglieder voraussetzt.

\section{Fragebogen}

Die überarbeitete C-K-Skala der Charismatischen Führung ${ }^{7}$ (Conger et al. 1997, eigene Übersetzung)

\section{Stimme gar nicht zu}

1
2
Stimme voll und ganz zu

\section{Strategische Vision und Artikulation}

1. Meine Führungskraft hat inspirierende strategische und organisationale Ziele.

2. Meine Führungskraft inspiriert; motiviert, indem sie die Bedeutung dessen, was die Organisationsmitglieder tun, erfolgreich vermittelt.

3. Meine Führungskraft entwickelt laufend neue Ideen für die Zukunft der Organisation.

7 Originaltitel: The revised C-K-Scale of Charismatic Leadership; eine validierte Übersetzung ins Deutsche ist von Rowold und Kersting (2008) verfügbar.
Charismatiker gehen Risiken ein, verhalten sich unkonventionell und kommunizieren enthusiastisch

Conger-Kanungo-Skala 
4. Meine Führungskraft begeistert als Redner/in.

5. Meine Führungskraft hat eine Vision; äußert oft Ideen zu zukünftigen Chancen.

6. Meine Führungskraft ist unternehmerisch; ergreift neue Gelegenheiten um Ziele zu erreichen.

7. Meine Führungskraft erfasst spontan neue Rahmenbedingungen (günstige materielle und soziale Zustände), die das Erreichen der Ziele der Organisation erleichtern könnten.

\section{Sensibilität für die Umwelt}

8. Meine Führungskraft erfasst spontan ungünstige Rahmenbedingungen in der materiellen Umwelt (technologische Grenzen, fehlende Ressourcen, etc.), die das Erreichen der Ziele der Organisation behindern könnten.

9. Meine Führungskraft erfasst spontan ungünstige Rahmenbedingungen in der sozialen und kulturellen Umwelt (kulturelle Normen, fehlender Rückhalt in der Organisation, etc.), die das Erreichen der Ziele der Organisation behindern könnten.

10. Meine Führungskraft kann die Fähigkeiten und Fertigkeiten anderer Organisationsmitglieder einschätzen.

11. Meine Führungskraft kann die Grenzen anderer Organisationsmitglieder einschätzen.

Sensibilität für die Bedürfnisse der Organisationsmitglieder

12. Meine Führungskraft nimmt Einfluss auf andere, indem sie gegenseitige Sympathie und Respekt erzeugt.

13. Meine Führungskraft ist sensibel für die Bedürfnisse und Gefühle anderer Organisationsmitglieder.

14. Meine Führungskraft zeigt häufig persönliches Interesse an den Bedürfnissen und Gefühlen anderer Organisationsmitglieder.

\section{Persönliches Risiko}

15. Meine Führungskraft nimmt um der Organisation willen hohe persönliche Risiken in Kauf.

16. Meine Führungskraft nimmt um der Organisation willen häufig hohe persönliche Kosten in Kauf.

17. Meine Führungskraft beschäftigt sich beim Verfolgen von Zielen der Organisation mit Aktivitäten, die mit einem hohen persönlichen Risiko einhergehen.

\section{Unkonventionelles Verhalten}

18. Meine Führungskraft geht unkonventionell vor, wenn es darum geht, Ziele der Organisation zu erreichen. 
19. Meine Führungskraft nutzt ungewohnte Mittel und Wege, um organisationale Ziele zu erreichen.

20. Meine Führungskraft zeigt oft außergewöhnliches Verhalten, das andere Organisationsmitglieder überrascht.

\section{C-K-Skala der Charismatischen Führung (Conger et al. 1997)}

Welcher Aspekt von

Führung wird gemessen?

Welche Dimensionen enthält die Skala?

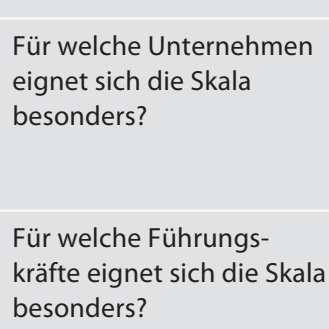

Für welche Einsatzgebiete im Personalmanagement eignet sich die Skala besonders?
Charismatische Führung

- Strategische Vision und Artikulation

- Sensibilität für die Umwelt

- Sensibilität für die Bedürfnisse der Organisationsmitglieder

- Persönliches Risiko

- Unkonventionelles Verhalten

- Dynamisches Umfeld

- Intensiver Wettbewerb

- Starker Innovationsdruck

- In krisenhaften Situationen

- Geplanter Wandel

- Top Management

- Obere Hierarchieebenen

- Schlüsselpositionen mit Innovationscharakter

- Krisenmanagerinnen und Krisenmanager

Personalentwicklung: Reflexion des eigenen Charismas im Rahmen von Potenzialanalyse und 360-GradFeedback; Erhebung des Selbstbilds der Führungskraft und des Fremdbilds der Mitarbeitenden

\subsubsection{Authentische Führung}

Für Götz Werner, den Gründer und langjährigen Geschäftsführer des Unternehmens dm-drogerie markt, bedeutet authentisch zu führen, dass man „wirklich danach strebt, in gelassener Selbstführung und aus eigener Kraft und Einsicht zu arbeiten und zu leben: In Übereinstimmung mit sich selbst.“ (Werner 2006, S. 18).

Voraussetzung dafür ist nach Robbins und Judge (2013), sich selbst zu kennen, zu wissen woran man glaubt und den eigenen moralischen Werten entsprechend, geradlinig und aufrichtig zu handeln. Authentische Führungskräfte teilen Informationen, sie ermutigen dazu, offen miteinander zu reden, und halten notfalls auch gegen Widerstände - an ihren Idealen und Werten

Eigenschaften einer authentischen Führungskraft 
Verständnis von

Authentizität

Authentic Leadership Inventory fest. Deshalb gelten sie als anständig. Ihre Mitarbeitenden vertrauen ihnen, sie glauben an sie. Ob eine Führungskraft als authentisch wahrgenommen wird, hängt also entscheidend von der Beziehung ab, die sie zu ihren Mitarbeitenden aufgebaut hat.

In den letzten Jahrzehnten gab es seitens der Forschung diverse Versuche, das Konzept der authentischen Führung eindeutig zu definieren. Bass und Steidlmeier (1999) sahen die Authentizität als eine Erweiterung der transformationalen Führung ( Abschn. 6.6.2). Ihnen zufolge sind Führungskräfte authentisch transformational (authentically transformational), wenn sie bei ihren Mitarbeitenden das Bewusstsein für das Gute, Wichtige und Richtige schärfen. Sie erkennen das Bedürfnis ihrer Mitarbeitenden nach Leistung und Selbstverwirklichung an und fördern deren Mündigkeit. Eine Führungskraft, die authentisch führt, kann ihre Mitarbeitenden überzeugen, indem sie Eigeninteressen hintanstellt und sich für „das Gute“ einsetzt: In der Gruppe, der Organisation und der Gesellschaft (Bass 1998). Bass und Steidlmeier (1999) zufolge sind bei authentisch transformationalen Führungskräften die vier Hauptdimensionen von transformationaler Führung stark ausgeprägt, nämlich idealisierender Einfluss, inspirierende Motivation, intellektuelle Stimulation und persönliche Berücksichtigung. Mit anderen Worten ist eine authentische Führungskraft ein ,moralischer Agent', der Mitarbeitende dahingehend stärkt, ethisch und legitim zu handeln.

Aktuellere Forschungsarbeiten betrachten authentische Führung als Grundsatzkonzept, das sich in den positiven Aspekten der charismatischen, transformationalen, spirituellen und ethischen Führungstheorien wiederfindet (Avolio und Gardner 2005). Eine authentische Führungskraft wird als selbstbewusst, hoffnungsvoll, optimistisch, belastbar und zukunftsorientiert beschrieben. Hinzu kommt, dass sie ehrlich zu sich selbst ist (Luthans und Avolio 2003).

Neider und Schriesheim (2011) entwickelten das Authentic Leadership Inventory (ALI). Beschrieben wird die authentische Führung hier durch die Dimensionen Selbstwahrnehmung, Beziehungsklarheit, verinnerlichte moralische Sichtweisen und ausgewogene Informationsverarbeitung.

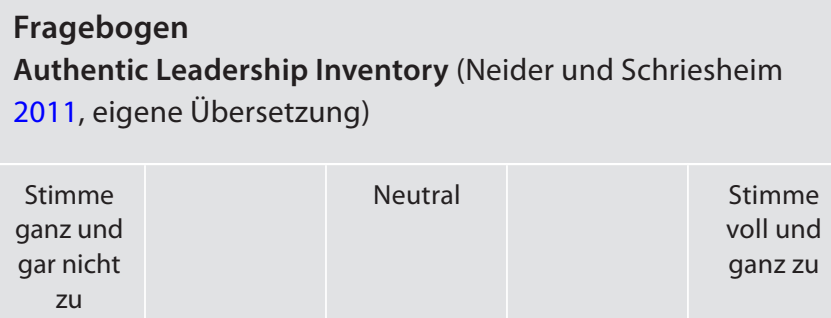




\section{Selbstwahrnehmung}

1. Meine Führungskraft erbittet Feedback, um ihren Umgang mit anderen zu verbessern.

2. Meine Führungskraft kann treffend beschreiben, wie ihre Fähigkeiten von anderen wahrgenommen werden.

3. Meine Führungskraft zeigt, dass sie sich ihrer Stärken und Schwächen bewusst ist.

4. Meine Führungskraft ist sich bewusst, welche Wirkung sie auf andere ausübt.

\section{Beziehungsklarheit}

5. Meine Führungskraft äußert klar und deutlich, was sie meint.

6. Meine Führungskraft gibt zu, wenn Fehler auftreten.

7. Meine Führungskraft teilt Informationen offen mit anderen.

8. Meine Führungskraft drückt ihre Ideen und Gedanken gegenüber anderen klar und deutlich aus.

\section{Verinnerlichte moralische Sichtweisen}

9. Bei meiner Führungskraft stimmen Überzeugungen und Handeln überein.

10. Meine Führungskraft entscheidet auf der Basis seiner/ihrer inneren Überzeugungen.

11. Meine Führungskraft widersteht dem Druck, entgegen eigener Überzeugungen zu handeln.

12. Meine Führungskraft orientiert sich bei ihrem Handeln an inneren moralischen Ansprüchen.

\section{Ausgewogene Informationsverarbeitung}

13. Meine Führungskraft bittet um Ideen, die ihre eigenen Grundüberzeugungen hinterfragen.

14. Meine Führungskraft hört sich aufmerksam andere Ansichten an, bevor sie zu einem Entschluss gelangt.

15. Meine Führungskraft analysiert relevante Informationen sachlich, bevor sie eine Entscheidung trifft.

16. Meine Führungskraft ermutigt andere, gegensätzliche Standpunkte zu äußern.

Bei der finalen Skala wurden die kursiv geschriebenen Items 1 und 6 entfernt. Der Begriff, Führungskraft' bezieht sich immer auf den unmittelbaren oder direkten Vorgesetzten der Befragten. 


\begin{tabular}{|c|c|}
\hline $\begin{array}{l}\text { Welcher Aspekt von Führung } \\
\text { wird gemessen? }\end{array}$ & Authentische Führung \\
\hline $\begin{array}{l}\text { Welche Dimensionen enthält } \\
\text { diese Skala? }\end{array}$ & $\begin{array}{l}\text { - Selbstwahrnehmung } \\
\text { - Beziehungsklarheit } \\
\text { - Verinnerlichte moralische Sicht- } \\
\text { weisen } \\
\text { - Ausgewogene Informationsver- } \\
\text { arbeitung }\end{array}$ \\
\hline $\begin{array}{l}\text { Für welche Unternehmen } \\
\text { eignet sich die Skala } \\
\text { besonders? }\end{array}$ & $\begin{array}{l}\text { - Unternehmen im Wandel } \\
\text { - Schnell wachsende Unternehmen } \\
\text { - Kleinere und mittlere Unternehmen } \\
\text { - Organisationen mit hohem } \\
\text { ethischem Anspruch, z. B. NGOs }\end{array}$ \\
\hline $\begin{array}{l}\text { Für welche Führungs- } \\
\text { kräfte eignet sich die Skala } \\
\text { besonders? }\end{array}$ & $\begin{array}{l}\text { - Führungskräfte aller Ebenen } \\
\text { - Entrepreneure } \\
\text { - Krisenmanagerinnen und Krisen- } \\
\text { manager }\end{array}$ \\
\hline $\begin{array}{l}\text { Für welche Einsatzgebiete } \\
\text { im Personalmanagement } \\
\text { eignet sich die Skala } \\
\text { besonders? }\end{array}$ & $\begin{array}{l}\text { - Führungskräfteentwicklung } \\
\text { - Führungsfeedback } \\
\text { - Coaching }\end{array}$ \\
\hline
\end{tabular}

Entwicklung einer positiven Austauschbeziehung zwischen Führungskraft und Mitarbeitenden

\subsubsection{Beziehungsqualität von Führungskraft und Mitarbeitenden - Leader-Member Exchange}

Bei der in Abschn. 2.2.4 vorgestellten Leader-MemberExchange-Theorie (LMX-Theorie) geht es darum, die Art des Austausches oder der Beziehung zwischen Führungskraft und Geführten zu erforschen. Es überrascht wenig, dass der Führungserfolg, z. B. die Leistungsbereitschaft und Zufriedenheit der Geführten, größer ist, wenn dieses Verhältnis positiv und eng ist. Laut Graen und Uhl-Bien (1995) sind drei Faktoren dafür verantwortlich, dass sich eine positive Austauschbeziehung zwischen Mitarbeitenden und Führungskraft entwickelt: Es bedarf einer gegenseitigen Anerkennung der Kompetenz, einer Vertrauensbasis, sowie einer Verbindlichkeit von beiden Seiten. Nur dann kann sich ein arbeitsbezogener sozialer Austausch zu einer echten Partnerschaft entwickeln.

Über die Jahre wurden verschiedene mehr oder weniger umfangreiche Instrumente entwickelt, um die Qualität der Beziehungen von Führungskräften und Mitarbeitenden zu messen, hier soll zunächst der Fragebogen LMX 7 von Graen und Uhl-Bien (1995) vorgestellt werden, da er trotz der recht 
geringen Anzahl von Items in der Forschung vielfach erfolgreich eingesetzt wurde.

Im Folgenden finden Sie den Fragebogen für die Mitarbeitenden. Die Führungskraft beantwortet dieselben sieben Items, muss diese aber aus der Perspektive der Mitarbeitenden beantworten (jeweils kursiv in Klammern gesetzt). Die Qualität der Beziehung zwischen Führungskraft und Mitarbeitenden bemisst sich einerseits nach dem Grad der Übereinstimmung zwischen den Angaben von Führungskraft und Mitarbeitendem und andererseits nach der positiven Antwortausprägung.

\section{Fragebogen}

Leader-Member Exchange (LMX) 7 (Graen und Uhl-Bien 1995, eigene Übersetzung)

Auswertungshinweise: Die mit 1 bis 5 Punkten codierten Antworten werden addiert. Ein hoher Wert sowie eine hohe Übereinstimmung der Werte von Mitarbeitenden und Führungskraft spricht für eine gute Beziehungsqualität.

1. Wissen Sie, wo Sie bei Ihrer Führungskraft stehen... Wissen Sie normalerweise, wie zufrieden Ihre Führungskraft mit dem ist, was Sie tun?

(Weiß Ihr Teammitglied normalerweise, wie zufrieden Sie mit dem sind, was er/sie tut?)

- Sehr selten

- Selten

- Gelegentlich

- Ziemlich oft

- Sehr oft

2. Wie gut versteht Ihre Führungskraft Ihre beruflichen Probleme und Bedürfnisse?

(Wie gut verstehen Sie die beruflichen Probleme und

Bedürfnisse Ihres/r Mitarbeiters/in?)

- Gar nicht

- Ein wenig

- Einigermaßen

- Ziemlich gut

- Sehrgut

3. Wie gut erkennt Ihre Führungskraft Ihr Potenzial?

(Wie gut erkennen Sie das Potenzial Ihrer/s Mitarbeiters/in?)

- Gar nicht

- Ein wenig

- Einigermaßen

- Ziemlich gut

- Sehrgut 
4. Unabhängig von der Positionsmacht Ihrer Führungskraft wie hoch sind die Chancen, dass Ihre Führungskraft ihren Einfluss nutzen würde, um Ihnen bei der Lösung von Problemen in der Arbeit zu helfen?

(Wie groß ist die Wahrscheinlichkeit, dass Sie Ihren Einfluss nutzen würden, um Ihrem/r Mitarbeiter/in bei der Lösung von Problemen in der Arbeit zu helfen?)

- Keine

- Gering

- Mäßig

- Hoch

- Sehr hoch

5. Nochmals unabhängig von der Positionsmacht Ihrer Führungskraft - wie stehen die Chancen, dass sie Ihnen auf ihre Kosten „aus der Patsche helfen" würde?

(Wie hoch sind die Chancen, dass Sie Ihrem/r Mitarbeiter/in auf Ihre Kosten "aus der Patsche helfen" würden?)

- Keine

- Gering

- Mäßig

- Hoch

- Sehr hoch

6. Ich respektiere meine Führungskraft so, dass ich ihre Entscheidung verteidigen und rechtfertigen würde, wenn sie nicht anwesend wäre.

(Mein/e Mitarbeiter/in würde meine Entscheidung verteidigen und rechtfertigen, wenn ich nicht anwesend wäre.)

- Trifft gar nicht zu

- Trifft wenig zu

- Neutral

- Trifft zu

- Trifft voll und ganz zu

7. Wie würden Sie Ihre Arbeitsbeziehung zu Ihrer Führungskraft beschreiben?

(Wie würde Ihr Teammitglied die Arbeitsbeziehung zu Ihnen beschreiben?)

- Extrem ineffektiv

- Überdurchschnittlich schlecht

- Durchschnittlich

- Überdurchschnittlich gut

- Sehr effektiv 
Leader-Member Exchange (LMX, Graen und Uhl-Bien 1995)

Welcher Aspekt von Führung wird gemessen?

Beziehungsqualität zwischen Führungskraft und Geführten

Welche Dimensionen enthält die Skala?

Beziehungsqualität (LeaderMember-Exchange)

Für welche Unternehmen eignet sich die Skala besonders?

Für welche Führungskräfte eignet sich die Skala besonders?

Für welche Einsatzgebiete im Personalmanagement eignet sich die Skala besonders?
Unternehmen, die die arbeitsbezogenen Einstellungen der Mitarbeitenden verbessern wollen

Führungskräfte, die die Beziehungsqualität zu ihren Mitarbeitenden verbessern wollen

- Arbeitsklima und Mitarbeiterzufriedenheit erhöhen - Leistungsbereitschaft erhöhen

Ein alternatives Instrument, die deutsche Leader-Member Exchange Skala von Schyns und Paul (2006), betrachtet ebenfalls die Aus-

Deutsche Leader-Member Exchange Skala tauschbeziehung im Führungsdual anhand der vier Subskalen Zuneigung, Loyalität, Fachlicher Respekt und Wahrgenommenes Engagement und soll von den Mitarbeitenden ausgefüllt werden. Je nach Grad der Zustimmung zu den Items gehören die Mitarbeitenden zur motivierten und engagierten In-Group oder zur Out-Group, die lediglich „Dienst nach Vorschrift“ leistet.

\section{Fragebogen}

Deutsche Leader-Member Exchange Skala (LMX MDM)

(Schyns und Paul 2006, modifizierte deutsche Version)

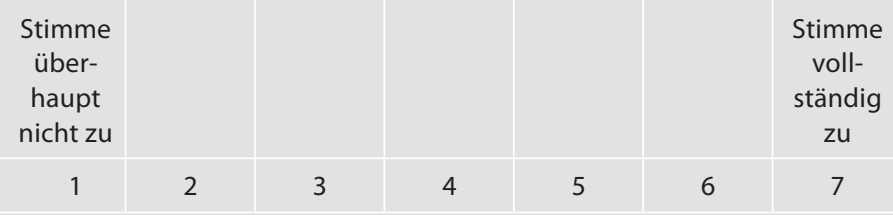

\section{Instruktion:}

Hier werden Fragen zu Ihrem bzw. Ihrer unmittelbaren Vorgesetzten gestellt. Kreuzen Sie bitte bei jeder Frage die für Sie passende Zahl an. Folgen Sie dem ersten Impuls. Es gibt keine richtigen und falschen Antworten, keine guten und schlechten. Lassen Sie bitte keine Frage aus.

\section{Zuneigung}

1. Mein/e Vorgesetzte/r ist ein Mensch, den man gern zum Freund hätte.

2. Ich mag meine/n Vorgesetzte/n als Mensch sehr.

3. Es macht viel Spaß, mit meiner/m Vorgesetzten zu arbeiten. 


\section{Loyalität}

1. Mein/e Vorgesetzte/r würde mich gegenüber anderen im Unternehmen verteidigen, wenn ich einen wirklichen Fehler gemacht hätte.

2. Mein/e Vorgesetzte/r verteidigt meine Handlungen gegenüber einer/m Höhergestellten, auch wenn er/ sie kein vollständiges Wissen über die fragliche Angelegenheit hat.

3. Mein/e Vorgesetzte/ $r$ würde mich verteidigen, wenn ich von anderen angegriffen würde.

\section{Fachlicher Respekt}

1. Ich schätze die beruflichen Fähigkeiten meiner/s Vorgesetzten.

2. Ich respektiere das Wissen und die Kompetenz meiner/s Vorgesetzten bezüglich seiner/ihrer Tätigkeit.

3. Ich bin vom Wissen, das mein/e Vorgesetzte/r bezüglich seiner/ihrer Arbeit hat, beeindruckt.

\section{Wahrgenommenes Engagement}

1. Ich tue für meine/n Vorgesetzte/n mehr, als ich nach meiner Arbeitsbeschreibung müsste.

2. Um die Ziele meines/r Vorgesetzten bei der Arbeit zu erreichen, bin ich bereit, mich mehr als gewöhnlich anzustrengen.

3. Es macht mir nichts aus, meinem/r Vorgesetzten zuliebe sehr hart zu arbeiten.

Deutsche Leader-Member Exchange Skala (LMX MDM, Schyns und Paul 2006, modifizierte deutsche Version)

\begin{abstract}
Welcher Aspekt von
Führung wird gemessen?

Welche Dimensionen enthält die Skala?
\end{abstract}

Für welche Unternehmen eignet sich die Skala besonders?

Für welche Führungskräfte eignet sich die Skala besonders?

Für welche Einsatzgebiete im Personalmanagement eignet sich die Skala besonders?
Beziehungsqualität zwischen Führungskraft und Geführten

- Zuneigung

- Loyalität

- Fachlicher Respekt

- Wahrgenommenes Engagement

Unternehmen, die die arbeitsbezogenen Einstellungen der Mitarbeitenden verbessern wollen

Führungskräfte, die die Beziehungsqualität zu ihren Mitarbeitenden verbessern wollen

- Arbeitsklima und Mitarbeiterzufriedenheit erhöhen

- Leistungsbereitschaft erhöhen 


\subsubsection{Ambidextre Führung}

Typischerweise werden in Unternehmen sowohl erkundende (Exploration) als auch wiederkehrende, nutzbringende (Exploitation) Aufgaben ausgeführt, die jeweils dazu führen, dass sich die Organisation weiterentwickelt, indem sie entweder effizienter oder innovativer wird. Während bei der Exploitation, vorhandene Kompetenzen nutzbringend eingesetzt werden, um anstehende Aufgaben möglichst effizient zu erledigen, müssen bei der Exploration neuartige Erfahrungen zugelassen und neue Kompetenzen entwickelt werden. Nur wenn die Organisation und ihre Mitglieder die nötige Offenheit für Erfahrungen und die Dynamik der Umwelt mitbringen, kann man sich flexibel auf eine neue Situation einstellen (March, 1991). In der Führungsforschung wird daher von Ambidextrie („Beidhändigkeit“) gesprochen, wenn ein Unternehmen es einerseits schafft, effizient zu sein, z. B. Prozesse zu optimieren, und andererseits flexibel auf neue Situationen reagiert, indem es bspw. Innovationen schafft. In einer Vielzahl von Studien wird dieser Ansatz als Königsweg für Unternehmen gesehen, um sich bestmöglich weiterzuentwickeln, wandlungsfähig zu sein und den eigenen Umsatz zu steigern (z. B. Andriopoulos und Lewis 2009; He und Wong 2004; Raisch et al. 2009). Im Idealfall tragen Führungskräfte dazu bei, dass sich eine ambidextre Haltung in einem Unternehmen etablieren kann und folglich nicht nur die Innovationskraft, sondern auch die Wirtschaftlichkeit ansteigen.

Dennoch gibt es auch Forschende, die Exploration und Exploitation als unerreichbares Ideal und sich gegenseitig ausschließende Muster menschlichen Verhaltens (Offenheit vs. Gewissenhaftigkeit) betrachten (Gupta et al. 2006). Dies würde bedeuten, dass Führungskräfte entweder Effizienz oder Innovationen fördern, beides zugleich aber nicht möglich ist. Eine andere Perspektive wird von Forschenden aus den Organisationsund Managementwissenschaften eingenommen, die sich einig sind, dass es für Führungskräfte und einen nachhaltigen Unternehmenserfolg unerlässlich ist, sich sowohl effizient als auch flexibel zu zeigen (z. B. Floyd und Lane 2000; Rosing et al. 2011).

Damit Führungskräfte selbst einschätzen können, ob sie effizient oder flexibel (oder sogar beides zugleich) sind, haben Keller und Weibler (2014) das Instrument von Weibler und Keller (2011) zur Messung von ambidextrer Führung weiterentwickelt und validiert. Dabei messen acht Items den Grad, inwieweit sich eine Führungskraft neuen, komplexen Aufgaben stellt und sich in neuen Aufgabenfeldern bewegt (Exploration) und acht Items das Ausmaß, in dem eine Führungskraft Routineaufgaben (Exploitation) bewältigt. Die Führungskräfte
Ambidextrie

Exploration und Exploitation

Perspektiven zu Ambidextrie aus der Wissenschaft

Ambidextre Führung

messen 
bewerten ihren Einsatz in beiden Aufgabentypen auf einer siebenstufigen Likert-Skala, die von eins (sehr selten) bis sieben (sehr oft) reicht. Die Fragen beziehen sich auf den Zeitraum des vergangenen Jahres.

\section{Fragebogen}

Ambidextre Führung (Keller und Weibler 2014, eigene Übersetzung)

\begin{tabular}{c|c|c|c|c|c|c|}
$\begin{array}{c}\text { Sehr } \\
\text { selten }\end{array}$ & & & & & & $\begin{array}{c}\text { Sehr } \\
\text { oft }\end{array}$ \\
\hline 1 & 2 & 3 & 4 & 5 & 6 & 7 \\
\hline
\end{tabular}

Bitte bewerten Sie wie häufig Sie die folgenden Tätigkeiten in Ihrem Arbeitsalltag ausführen.

\section{Exploration}

1. Tätigkeiten, bei denen man mit unbekannten Situationen umgehen muss.

2. Tätigkeiten, die so komplex sind, dass sie anfangs schwierig zu umreißen sind.

3. Tätigkeiten, bei denen man sich auf unbekanntes Terrain wagt.

4. Tätigkeiten, die viel Anpassungsfähigkeit abverlangen.

5. Tätigkeiten, für die man die notwendigen Kompetenzen erst erwirbt, wenn man sie ausführt.

6. Tätigkeiten, die eine komplett andere Strategie erfordern.

7. Tätigkeiten, deren Konsequenzen zum Zeitpunkt der Ausführung noch nicht genau vorhersehbar sind.

8. Tätigkeiten, bei denen man an die Grenzen seines Wissens stößt.

\section{Exploitation}

9. Tätigkeiten, die man ganz routinemäßig ausführt.

10. Tätigkeiten, die man nach einem bekannten Muster ausführt.

11. Tätigkeiten, deren Ausführung völlig klar ist.

12. Tätigkeiten, auf die man gut vorbereitet ist.

13. Leicht planbare Tätigkeiten.

14. Regelmäßig wiederkehrende Tätigkeiten.

15. Tätigkeiten, die sich auf ein klar definiertes Problemfeld beziehen.

16. Tätigkeiten, die innerhalb eines vorab definierten Zeitraums ausgeführt werden können. 
Ambidextre Führung (Keller und Weibler 2014)

\begin{tabular}{|c|c|}
\hline $\begin{array}{l}\text { Welcher Aspekt von Führung } \\
\text { wird gemessen? }\end{array}$ & Ambidextre Führung \\
\hline $\begin{array}{l}\text { Welche Dimensionen enthält } \\
\text { diese Skala? }\end{array}$ & $\begin{array}{l}\text { - Exploration } \\
\text { - Exploitation }\end{array}$ \\
\hline $\begin{array}{l}\text { Für welche Unternehmen eignet } \\
\text { sich die Skala besonders? }\end{array}$ & $\begin{array}{l}\text { - Banken } \\
\text { - Software-Unternehmen } \\
\text { - Krankenhäuser }\end{array}$ \\
\hline $\begin{array}{l}\text { Für welche Führungskräfte } \\
\text { eignet sich die Skala besonders? }\end{array}$ & $\begin{array}{l}\text { - Top Management } \\
\text { - Mittleres Management }\end{array}$ \\
\hline $\begin{array}{l}\text { Für welche Einsatzgebiete im } \\
\text { Personalmanagement eignet } \\
\text { sich die Skala besonders? }\end{array}$ & $\begin{array}{l}\text { Personalentwicklung, z. B. } \\
\text { Coaching, Förderung von } \\
\text { Innovationsmanagement und } \\
\text { Intrapreneurship }\end{array}$ \\
\hline
\end{tabular}

\section{Literatur}

Abler, B., \& Kessler, H. (2009). Emotion Regulation Questionnaire - Eine deutschsprachige Fassung des ERQ von Gross und John. Diagnostica, 55(3), 144-152.

Allport, G. W. (1959). Persönlichkeit. Struktur, Entwicklung und Erfassung der menschlichen Eigenart. Meiseheim: Anton Hain.

Amthauer, R., Brocke, B., Liepmann, D., \& Beauducel, A. (2001). Intelligenz-Struktur-Test 2000 R. Göttingen: Hogrefe.

Andriopoulos, C., \& Lewis, M. W. (2009). Exploitation-exploration tensions and organizational ambidexterity: Managing paradoxes of innovation. Organization Science, 20(4), 696-717.

Aryee, S., Sun, L.-Y., Chen, Z. X. G., \& Debrah, Y. A. (2008). Abusive supervision and contextual performance. The mediating role of emotional exhaustion and the moderating role of work unit structure. Management and Organization Review, 4(3), 393-411.

Asendorpf, J. B., \& Neyer, F. J. (2012). Psychologie der Persönlichkeit. Berlin: Springer.

Aster, M. von, Neubauer, A., \& Horn, R. V. (2006). Wechsler Intelligenztest für Erwachsene. WIE; Übersetzung und Adaption der WAIS-III. Frankfurt: Harcourt Test Services.

Avery, G. C., \& Ryan, J. (2002). Applying situational leadership in Australia. Journal of Management Development, 21(4), 242-262.

Avolio, B. J. (2011). Full range leadership development. Los Angeles: SAGE.

Avolio, B. J., \& Gardner, W. L. (2005). Authentic leadership development: Getting to the root of positive forms of leadership. The Leadership Quarterly, 16(3), 315-338.

Babiak, P., Neumann, C. S., \& Hare, R. D. (2010). Corporate psychopathy: Talking the walk. Behavioral Sciences \& the Law, 28(2), 174-193.

Bandura, A. (1977). Self-efficacy. Toward a unifying theory of behavioral change. Psychological Review, 84(2), 191-215.

Bandura, A. (1991). Social cognitive theory of self-regulation. Organizational Behavior and Human Decision Processes, 50(2), 248-287.

Bass, B. M. (1998). The ethics of transformational leadership. In J. B. Ciulla (Hrsg.), Ethics, the heart of leadership (S. 169-192). Westport: Praeger. 
Bass, B. M. (1999). Two decades of research and development in transformational leadership. European Journal of Work and Organizational Psychology, 8(1), 9-32.

Bass, B. M., \& Avolio, B. J. (1997). Full range leadership development: Manual for the multifactor leadership questionnaire. Palo Alto: Mind Garden.

Bass, B. M., \& Bass, R.-E. (2008). The Bass handbook of leadership. Theory, research, and managerial applications (4. Aufl.). New York: Free Press.

Bass, B. M., \& Steidlmeier, P. (1999). Ethics, character, and authentic transformational leadership behavior. The Leadership Quarterly, 10(2), 181-218.

Bass, B. M., Avolio, B. J., Jung, D. I., \& Berson, Y. (2003). Predicting unit performance by assessing transformational and transactional leadership. Journal of Applied Psychology, 88(2), 207-218.

Baughman, H. M., Dearing, S., Giammarco, E., \& Vernon, P. A. (2012). Relationships between bullying behaviours and the dark triad: A study with adults. Personality and Individual Differences, 52(5), 571-575.

Beyer, P. D. (2010). Authentic leadership in-extremis: A study of combat leadership. Dissertation, Capella University.

Blessin, B., \& Wick, A. (2015). Führen und führen lassen. Ansätze, Ergebnisse und Kritik der Führungsforschung (7. Aufl.). Konstanz: UTB.

Blickle, G. (2004). Einfluss ausüben, Ziele verwirklichen. Ein Überblick über Einflusstaktiken in Organisationen und ihre situationsspezifischen Wirkmechanismen. Personalführung, 37(6), 58-70.

Block, J. (1961). The Q-sort method in personality assessment and psychiatric research. Citeseer: University of Michigan.

Boddy, C. R. (2017). Psychopathic leadership. A case study of a corporate psychopath CEO. Journal of Business Ethics, 145(1), 141-156.

Bodla, M. A., \& Nawaz, M. M. (2010). Comparative study of full range leadership model among faculty members in public and private sector higher education institutes and universities. International Journal of Business and Management, 5(4), 208.

Boezeman, E. J., \& Ellemers, N. (2008). Pride and respect in volunteers' organizational commitment. European Journal of Social Psychology, 38(1), 159-172.

Brown, M. E., \& Treviño, L. K. (2006). Ethical leadership. A review and future directions. The Leadership Quarterly, 17(6), 595-616.

Brown, M. E., Treviño, L. K., \& Harrison, D. A. (2005). Ethical leadership: A social learning perspective for construct development and testing. Organizational Behavior and Human Decision Processes, 97(2), 117-134.

Bruch, H., Kunze, F., \& Böhm, S. (2010). Generationen erfolgreich führen. Konzepte und Praxiserfahrungen zum Management des demographischen Wandels. Wiesbaden: Springer.

Burk, C. L., \& Amelang, M. (2015). TBS-TK Rezension: MSCEIT-Mayer-SaloveyCaruso Test zur Emotionalen Intelligenz. Deutschsprachige Adaptation des Mayer-Salovey-Caruso Emotional Intelligence Test (MSCEIT). Zeitschrift für Arbeits- und Organisationspsychologie, 59, 155-157.

Butler, J. K. (1991). Toward understanding and measuring conditions of trust: Evolution of a conditions of trust inventory. Journal of Management, $17(3), 643-663$.

Carroll, J. B. (1993). Human cognitive abilities. A survey of factor-analytic studies. Cambridge: Cambridge University Press.

Carroll, J. B. (2005). The three-stratum theory of cognitive abilities. In D. P. Flanagan \& P. L. Harrison (Hrsg.), Contemporary intellectual assessment: Theories, tests, and issues (S. 69-76). New York: Guilford Press.

Carson, J. B., Tesluk, P. E., \& Marrone, J. A. (2007). Shared leadership in teams: An investigation of antecedent conditions and performance. The Academy of Management Journal, 50(5), 1217-1234. 
Cattell, R. B. (1943). The measurement of adult intelligence. Psychological Bulletin, 40(3), 153-193.

Chan, K.-Y., \& Drasgow, F. (2001). Toward a theory of individual differences and leadership: Understanding the motivation to lead. Journal of Applied Psychology, 86(3), 481-498.

Chatterjee, A., \& Hambrick, D. C. (2007). It's all about me: Narcissistic chief executive officers and their effects on company strategy and performance. Administrative Science Quarterly, 52(3), 351-386.

Chopra, R. (2013). A Narcissist, a Psychopath and a Machiavellian Walk into a Bar... https://psychometricsforumblog.wordpress.com/2013/06/23/ a-narcissist-a-psychopath-and-a-machiavellian-walk-into-a-bar/. Zugegriffen: 25. Juni 2019.

Christie, R., \& Geis, F. L. (1970). Studies in machiavellianism. New York: Academic Press.

Clemmons, A. B., \& Fields, D. (2011). Values as determinants of the motivation to lead. Military Psychology, 23(6), 587-600.

Clinard, M., \& Yeager, P. (2011). Corporate crime. New Brunswick: Transaction Publishers.

Conger, J. A., Kanungo, R. N., Menon, S. T., \& Mathur, P. (1997). Measuring charisma: Dimensionality and validity of the Conger-Kanungo scale of charismatic leadership. Canadian Journal of Administrative Sciences, 14(3), 290-301.

Cook, J., \& Wall, T. (1980). New work attitude measures of trust, organizational commitment and personal need non-fulfilment. Journal of Occupational Psychology, 53(1), 39-52.

Coombs, W. T. (2015). Ongoing crisis communication: Planning, managing, and responding (4. Aufl.). Los Angeles: SAGE.

Costa, P. T., \& McCrae, R. R. (2008). The revised NEO personality inventory (NEO-PI-R). In G. J. Boyle, G. Matthews, \& D. H. Saklofske (Hrsg.), The SAGE handbook of personality theory and assessment: Personality measurement and testing (Bd. 2, S. 179-198). London: SAGE.

Dahling, J. J., Whitaker, B. G., \& Levy, P. E. (2009). The development and validation of a new machiavellianism scale. Journal of Management, 35(2), 219-257.

de Jonge, J., \& Scherm, M. (2015). Führung und Vertrauen - Konzepte und neue Befunde. In J. Felfe (Hrsg.), Trends der psychologischen Führungsforschung (Psychologie für das Personalmanagement (S. 203-212). Göttingen: Hogrefe.

de Vries, R. E., Bakker-Pieper, A., \& Oostenveld, W. (2010). Leadership $=$ communication? The relations of leaders' communication styles with leadership styles, knowledge sharing and leadership outcomes. Journal of Business and Psychology, 25(3), 367-380.

DeCicco, J., Laschinger, H., \& Kerr, M. (2006). Perceptions of empowerment and respect: Effect on nurses organizational commitment in nursing homes. Journal of Gerontological Nursing, 32(5), 49-56.

Deluga, R. J. (1997). Relationship among American presidential charismatic leadership, narcissism, and rated performance. The Leadership Quarterly, 8(1), 49-65.

Dietz, G., \& Den Hartog, D. N. (2006). Measuring trust inside organisations. Personnel Review, 35(5), 557-588.

Dirks, K. T. (2000). Trust in leadership and team performance. Evidence from NCAA basketball. Journal of Applied Psychology, 85(6), 1004-1012.

Dixon, D. P. (2014). Staying alive: The experience of in-extremis leadership. Dissertation, Case Western Reserve University.

Dixon, D. P., Weeks, M., Boland, R., Jr., \& Perelli, S. (2017). Making sense when it matters most: An exploratory study of leadership in extremis. Journal of Leadership \& Organizational Studies, 24(3), 294-317. 
Eberl, P. (2003). Vertrauen und Management. Studien zu einer theoretischen Fundierung des Vertrauenskonstruktes in der Managementlehre (Betriebswirtschaftliche Abhandlungen). Zugl.: Berlin, Freie Univ., Habil.-Schr., 2003. Stuttgart: Schäffer-Poeschel.

Edwards, G., \& Gill, R. (2012). Transformational leadership across hierarchical levels in UK manufacturing organizations. Leadership \& Organization Development Journal, 33(1), 25-50.

Ellis, H. (1898). Auto-eroticism: A psychological study. Alienist and Neurologist, 19, 260-299.

Externbrink, K., Keil, M., \& Bierhoff, H.-W. (2018). Narzissmus, Machiavellismus und Psychopathie in Organisationen. Theorien, Methoden und Befunde zur dunklen Triade. Wiesbaden: Springer.

Felfe, J. (Hrsg.). (2015). Trends der psychologischen Führungsforschung (Psychologie für das Personalmanagement). Göttingen: Hogrefe.

Felfe, J., Elprana, G., Gatzka, M., \& Stiehl, S. (2012). FÜMO. Hamburger Führungsmotivationsinventar. Göttingen: Hogrefe.

Fiederer, S., \& Ternès, A. (2017). Einführung in die Krisenkommunikation am Beispiel der Coca-Cola-Krise. Effiziente Krisenkommunikation - transparent und authentisch. Wiesbaden: Springer.

Fischer, A., \& Kohr, H. (1980). Politisches Verhalten und empirische Sozialforschung: Leistung und Grenzen von Befragungsinstrumenten. München: Juventa.

Floyd, S. W., \& Lane, P. J. (2000). Strategizing throughout the organization: Managing role conflict in strategic renewal. Academy of Management Review, 25(1), 154-177.

Ford, L. (1991). Transforming leadership. Jesus' way of creating vision, shaping values \& empowering change. Downer Growe: InterVarsity Press.

Furtner, M. (2017). Dark Leadership. Narzisstische, machiavellistische und psychopathische Führung (essentials). Wiesbaden: Springer.

Gardner, W. L., \& Martinko, M. J. (1988). Impression management in organizations. Journal of Management, 14(2), 321-338.

George, J. M. (2000). Emotions and leadership: The role of emotional intelligence. Human Relations, 53(8), 1027-1055.

Gibb, C. A. (1954). Leadership. In G. Lindzey (Hrsg.), Handbook of social psychology (S. 877-917). Oxford: Addison-Wesley.

Gillespie, N. A. (2003). Measuring trust in working relationships. The behavioral trust inventory. Seattle: Academy of Management Conference.

Gillespie, N. A., \& Mann, L. (2004). Transformational leadership and shared values: The building blocks of trust. Journal of Managerial Psychology, 19(6), 588-607.

Goleman, D. (2000). Working with emotional intelligence. New York: Bantam Books.

Goleman, D., \& Boyatzis, R. (2008). Social intelligence and the biology of leadership. Harvard Business Review, 86(9), 74-81.

Graeff, C. L. (1997). Evolution of situational leadership theory: A critical review. The Leadership Quarterly, 8(2), 153-170.

Graen, G. B., \& Uhl-Bien, M. (1995). Relationship-based approach to leadership: Development of leader-member exchange (LMX) theory of leadership over 25 years: Applying a multi-level multi-domain perspective. The Leadership Quarterly, 6(2), 219-247.

Green, D. D., \& Roberts, G. E. (2012). Transformational leadership in a postmodern world: The presidential election of Barack Obama. Academy of Strategic Management Journal, 11(1), 9-25.

Gross, J. J. (1998). Antecedent-and response-focused emotion regulation: Divergent consequences for experience, expression, and physiology. Journal of Personality and Social Psychology, 74(1), 224-237. 
Gross, J. J., \& John, O. P. (2003). Individual differences in two emotion regulation processes: Implications for affect, relationships, and well-being. Journal of Personality and Social Psychology, 85(2), 348-362.

Gupta, A. K., Smith, K. G., \& Shalley, C. E. (2006). The interplay between exploration and exploitation. The Academy of Management Journal, 49(4), 693-706.

Hackman, M. Z., \& Johnson, C. E. (2013). Leadership. A communication perspective (6. Aufl.). Long Grove: Waveland Press.

Hadley, C. N., Pittinsky, T. L., Sommer, S. A., \& Zhu, W. (2011). Measuring the efficacy of leaders to assess information and make decisions in a crisis: The C-LEAD scale. The Leadership Quarterly, 22(4), 633-648.

Hannah, S. T., \& Avolio, B. J. (2013). Leader efficacy questionnaire. Mind Garden.

Hannah, S. T., Woolfolk, R. L., \& Lord, R. G. (2009). Leader self-structure: A framework for positive leadership. Journal of Organizational Behavior, 30(2), 269-290.

Hannah, S. T., Campbell, D. J., \& Matthews, M. D. (2010). Advancing a research agenda for leadership in dangerous contexts. Military Psychology, 22(S1), 157-189.

Hannah, S. T., Avolio, B. J., Walumbwa, F. O., \& Chan, A. (2012). Leader self and means efficacy: A multi-component approach. Organizational Behavior and Human Decision Processes, 118(2), 143-161.

Hare, R. D. (2002). The predators among us. Keynote address. Canadian Police Association Annual General Meeting, St. John's, Newfoundland and Labrador, August 27, 2002.

Harris, K. J., Kacmar, K. M., \& Zivnuska, S. (2007). An investigation of abusive supervision as a predictor of performance and the meaning of work as a moderator of the relationship. The Leadership Quarterly, 18(3), 252-263.

Hersey, P., \& Blanchard, K. H. (1976). Leader effectiveness and adaptability description (LEAD). In J. W. Pfeiffer \& J. E. Jones (Hrsg.), The annual handbook for group facilitators (Series in Human Relations Training, Bd. 5, S. 133-142). University Associates Publishers: University of California.

He, Z.-L., \& Wong, P.-K. (2004). Exploration vs. exploitation: An empirical test of the ambidexterity hypothesis. Organization Science, 15(4), 481-494.

Hiller, N. J. (2001). Understanding and measuring shared leadership in work teams. State College: Pennsylvania State University.

Holenweger, M., Jager, M. K., \& Kernic, F. (2017). Leadership in extreme situations. Cham: Springer.

Hossiep, R., \& Mühlhaus, O. (2015). Personalauswahl und-entwicklung mit Persönlichkeitstests (2. Aufl.). Göttingen: Hogrefe.

Hossiep, R., \& Paschen, M. (2003). Bochumer Inventar zur berufsbezogenen Persönlichkeitsbeschreibung-6 Faktoren. Modul zur Selbstbeschreibung. Göttingen: Hogrefe.

Hossiep, R., Krüger, C., \& Weiß, S. (2012). BIP-6F. Bochumer Inventar zur berufsbezogenen Persönlichkeitsbeschreibung-6 Faktoren. Göttingen: Hogrefe.

House, R. J., Spangler, W. D., \& Woycke, J. (1991). Personality and charisma in the U.S. presidency. A psychological theory of leader effectiveness. Administrative Science Quarterly, 36(3), 364-396.

Hülsheger, U. R., Maier, G. W., \& Stumpp, T. (2007). Validity of general mental ability for the prediction of job performance and training success in Germany. A meta-analysis. International Journal of Selection and Assessment, 15(1), 3-18.

Ilgen, D. R., Fisher, C. D., \& Taylor, M. S. (1979). Consequences of individual feedback on behavior in organizations. Journal of Applied Psychology, 64(4), 349-371.

Johnson, C. (2003). Enron's ethical collapse: Lessons for leadership educators. Journal of Leadership Education, 2(1), 45-57. 
Jonason, P. K., \& Webster, G. D. (2010). The dirty dozen: A concise measure of the dark triad. Psychological Assessment, 22(2), 420-432.

Jonason, P. K., Slomski, S., \& Partyka, J. (2012). The dark triad at work: How toxic employees get their way. Personality and Individual Differences, 52(3), 449-453.

Jones, D. N., \& Paulhus, D. L. (2014). Introducing the short dark triad (SD3) a brief measure of dark personality traits. Assessment, 21(1), 28-41.

Judge, T. A., Bono, J. E., Ilies, R., \& Gerhardt, M. W. (2002). Personality and leadership. A qualitative and quantitative review. Journal of Applied Psychology, 87(4), 765-780.

Judge, T. A., Colbert, A. E., \& Ilies, R. (2004). Intelligence and leadership. A quantitative review and test of theoretical propositions. Journal of Applied Psychology, 89(3), 542-552.

Kalshoven, K., Den Hartog, D. N., \& de Hoogh, A. H. B. (2011). Ethical leadership at work questionnaire (ELW): Development and validation of a multidimensional measure. The Leadership Quarterly, 22(1), 51-69.

Kark, R., \& van Dijk, D. (2007). Motivation to lead, motivation to follow: The role of the self-regulatory focus in leadership processes. Academy of Management Review, 32(2), 500-528.

Keller, T., \& Weibler, J. (2014). Behind managers' ambidexterity - studying personality traits, leadership, and environmental conditions associated with exploration and exploitation. Schmalenbach Business Review, 66(3), 309-333.

Kerschreiter, R., \& Eisenbeiss, S. A. (2015). Ethische Führung. In J. Felfe (Hrsg.), Trends der psychologischen Führungsforschung (Psychologie für das Personalmanagement) (S. 27-37). Göttingen: Hogrefe.

Kim, H. J., Shin, K. H., \& Swanger, N. (2009). Burnout and engagement. A comparative analysis using the big five personality dimensions. International Journal of Hospitality Management, 28(1), 96-104.

Kipnis, D., Schmidt, S. M., \& Wilkinson, I. (1980). Intraorganizational influence tactics: Explorations in getting one's way. Journal of Applied Psychology, 65(4), 440-452.

Kolditz, T. A. (2005). The in extremis leader. Leader to Leader, S1, 6-18.

Kolditz, T. A. (2006). Research in in extremis settings: Expanding the critique of ,why they fight'. Armed Forces \& Society, 32(4), 655-658.

Kramer, J. (2009). Allgemeine Intelligenz und beruflicher Erfolg in Deutschland. Vertiefende und weiterführende Metaanalysen. Psychologische Rundschau, 60(2), 82-98.

Kuhn, T., \& Weibler, J. (2003). Führungsethik: Notwendigkeit, Ansätze und Vorbedingungen ethikbewusster Mitarbeiterführung. Die Unternehmung, 57(5), 375-392.

Landay, K., Harms, P. D., \& Credé, M. (2019). Shall we serve the dark lords? A meta-analytic review of psychopathy and leadership. Journal of Applied Psychology, 104(1), 183-196.

Larzelere, R. E., \& Huston, T. L. (1980). The dyadic trust scale: Toward understanding interpersonal trust in close relationships. Journal of Marriage and the Family, 42(3), 595-604.

Lazarus, R. S., \& Alfert, E. (1964). Short-circuiting of threat by experimentally altering cognitive appraisal. The Journal of Abnormal and Social Psychology, 69(2), 195-205.

Levy, P. E., \& Williams, J. R. (2004). The social context of performance appraisal. A review and framework for the future. Journal of Management, 30(6), 881-905.

Lewis, K. M. (2000). When leaders display emotion: How followers respond to negative emotional expression of male and female leaders. Journal of Organizational Behavior, 21(2), 221-234. 
Linderbaum, B. A., \& Levy, P. E. (2010). The development and validation of the feedback orientation scale (FOS). Journal of Management, 36(6), 1372-1405.

Liu, J., Liu, X., \& Zeng, X. (2011). Does transactional leadership count for team innovativeness? Journal of Organizational Change Management, 24(3), 282-298.

Liu, D., Liao, H., \& Loi, R. (2012). The dark side of leadership. A three-level investigation of the cascading effect of abusive supervision on employee creativity. Academy of Management Journal, 55(5), 11871212

London, M. (2003). Job feedback. Giving, seeking, and using feedback for performance improvement (Series in applied psychology (2. Aufl.). Mahwah: Lawrence Erlbaum Associates.

Lorinkova, N. M., \& Perry, S. J. (2019). The importance of group-focused transformational leadership and felt obligation for helping and group performance. Journal of Organizational Behavior, 40(3), 231-247.

Luthans, F., \& Avolio, B. J. (2003). Authentic leadership: A positive development approach. In K. S. Cameron, J. E. Dutton, \& R. E. Quinn (Hrsg.), Positive organizational scholarship: Foundations of a new discipline (S. 241-261). San Francisco: Berrett-Koehler.

Machiavelli, N. (2013). Der Fürst (6. Aufl.). Hamburg: Nikol.

March, J. G. (1991). Exploration and exploitation in organizational learning. Organization Science, 2(1), 71-87.

Marcus, B. (2004). Rezension der 2. Auflage des Bochumer Inventars zur berufsbezogenen Persönlichkeitsbeschreibung (BIP) von R. Hossiep und M. Paschen. Zeitschrift für Arbeits-und Organisationspsychologie, 48(2), 79-86.

Marks, M. A., Mathieu, J. E., \& Zaccaro, S. J. (2001). A temporally based framework and taxonomy of team processes. Academy of Management Review, 26(3), 356-376.

Mayer, R. C., Davis, J. H., \& Schoorman, F. D. (1995). An integrative model of organizational trust. Academy of Management Review, 20(3), 709-734.

Mayer, J. D., Salovey, P., \& Caruso, D. R. (2002). Mayer-Salovey-Caruso Emotional Intelligence Test (MSCEIT). Item Booklet. $>$ https:// mikegosling.com/pdf/MSCEITDescription.pdf. Zugegriffen: 11. Sept. 2019.

McCrae, R. R., \& Costa, P. T. (1987). Validation of the five-factor model of personality across instruments and observers. Journal of Personality and Social Psychology, 52(1), 81-90.

McCrae, R. R., \& Costa, P. T., Jr. (2004). A contemplated revision of the NEO five-factor inventory. Personality and Individual Differences, 36(3), 587-596.

McCrae, R. R., \& John, O. P. (1992). An introduction to the five-factor model and its applications. Journal of Personality, 60(2), 175-215.

McGuire, D., \& Hutchings, K. (2007). Portrait of a transformational leader: The legacy of Dr Martin Luther King Jr. Leadership \& Organization Development Journal, 28(2), 154-166.

Miller, D. T. (2001). Disrespect and the experience of injustice. Annual Review of Psychology, 52(1), 527-553.

Mitroff, I. I. (2004). Crisis leadership. Planning for the unthinkable. Hoboken: Wiley.

Näcke, P. (1899). Die sexuellen perversitaten in der irrenanstalt. Psychiatrische en Neurologische Bladen, 3, 20-30.

Neider, L. L., \& Schriesheim, C. A. (2011). The authentic leadership inventory (ALI): Development and empirical tests. The Leadership Quarterly, 22(6), 1146-1164. 
Norman, S. M., Avolio, B. J., \& Luthans, F. (2010). The impact of positivity and transparency on trust in leaders and their perceived effectiveness. The Leadership Quarterly, 21(3), 350-364.

Northouse, P. G. (2015). Leadership. Theory and practice (7. Aufl.). Los Angeles: SAGE.

Oberfield, Z. W. (2012). Public management in time: A longitudinal examination of the full range of leadership theory. Journal of Public Administration Research and Theory, 24(2), 407-429.

Ostendorf, F., \& Angleitner, A. (2004). NEO-PI-R. NEO-Persönlichkeitsinventar nach Costa und McCrae. Revidierte Fassung. Göttingen: Hogrefe.

Paglis, L. L., \& Green, S. G. (2002). Leadership self-efficacy and managers' motivation for leading change. Journal of Organizational Behavior, 23(2), 215-235.

Paulhus, D. L., \& Williams, K. M. (2002). The dark triad of personality: Narcissism, machiavellianism, and psychopathy. Journal of Research in Personality, 36(6), 556-563.

Pearce, C. L., \& Sims, H. P., Jr. (2002). Vertical versus shared leadership as predictors of the effectiveness of change management teams: An examination of aversive, directive, transactional, transformational, and empowering leader behaviors. Group dynamics: Theory, research, and practice, 6(2), 172-197.

Pearson, C. M., \& Clair, J. A. (1998). Reframing crisis management. Academy of Management Review, 23(1), 59-76.

Peus, C., Braun, S., \& Frey, D. (2013). Situation-based measurement of the full range of leadership model-Development and validation of a situational judgment test. The Leadership Quarterly, 24(5), 777-795.

Pieterse, A. N., van Knippenberg, D., Schippers, M., \& Stam, D. (2010). Transformational and transactional leadership and innovative behavior: The moderating role of psychological empowerment. Journal of Organizational Behavior, 31(4), 609-623.

Podsakoff, P. M., Todor, W. M., \& Skov, R. (1982). Effects of leader contingent and noncontingent reward and punishment behaviors on subordinate performance and satisfaction. Academy of Management Journal, 25(4), 810-821.

Podsakoff, P. M., MacKenzie, S. B., Moorman, R. H., \& Fetter, R. (1990). Transformational leader behaviors and their effects on followers' trust in leader, satisfaction, and organizational citizenship behaviors. The Leadership Quarterly, 1(2), 107-142.

Podsakoff, P. M., MacKenzie, S. B., \& Bommer, W. H. (1996). Transformational leader behaviors and substitutes for leadership as determinants of employee satisfaction, commitment, trust, and organizational citizenship behaviors. Journal of Management, 22(2), 259-298.

Raisch, S., Birkinshaw, J., Probst, G., \& Tushman, M. L. (2009). Organizational ambidexterity: Balancing exploitation and exploration for sustained performance. Organization Science, 20(4), 685-695.

Raskin, R., \& Terry, H. (1988). A principal-components analysis of the narcissistic personality inventory and further evidence of its construct validity. Journal of Personality and Social Psychology, 54(5), 890-902.

Rauthmann, J. F. (2017). Persönlichkeitspsychologie. ParadigmenStrömungen-Theorien. Berlin: Springer.

Riggio, R. E., Zhu, W., Reina, C., \& Maroosis, J. A. (2010). Virtue-based measurement of ethical leadership: The leadership virtues questionnaire. Consulting Psychology Journal: Practice and Research, 62(4), 235-250.

Robbins, S. P., \& Judge, T. (2013). Organizational behavior. Boston: Pearson. 
Roberts, B. W., Walton, K. E., \& Viechtbauer, W. (2006). Patterns of mean-level change in personality traits across the life course. A meta-analysis of longitudinal studies. Psychological Bulletin, 132(1), 1-25.

Rosenthal, S. A., \& Pittinsky, T. L. (2006). Narcissistic leadership. The Leadership Quarterly, 17(6), 617-633.

Rosing, K., Frese, M., \& Bausch, A. (2011). Explaining the heterogeneity of the leadership-innovation relationship: ambidextrous leadership. The Leadership Quarterly, 22(5), 956-974.

Rowold, J., \& Kersting, M. (2008). The assessment of charismatic leadership. European Journal of Psychological Assessment, 24(2), 124-130.

Rowold, J., Borgmann, L., \& Heinitz, K. (2009). Ethische Führung-Gütekriterien einer deutschen Adaptation der ethical leadership scale (ELS-D) von Brown et al. (2005). Zeitschrift für Arbeits-und Organisationspsychologie, 53(2), 57-69.

Ryan, J. C., \& Tipu, S. A. A. (2013). Leadership effects on innovation propensity: A two-factor full range leadership model. Journal of Business Research, 66(10), 2116-2129.

Satow, L. (2012). Big-Five-Persönlichkeitstest (B5T): Test- und Skalendokumentation. http://www.drsatow.de. Zugegriffen: 18. Sept. 2019.

Satow, L. (2017). Allgemeiner Intelligenz-Test (AIT): Test- und Skalendokumentation. http://www.drsatow.de. Zugegriffen: 28. Aug. 2019.

Schmidt, S. M., \& Yeh, R.-S. (1992). The structure of leader influence. A cross-national comparison. Journal of Cross-Cultural Psychology, 23(2), 251-264.

Schneider, F. M., Maier, M., Lovrekovic, S., \& Retzbach, A. (2015). The perceived leadership communication questionnaire (PLCQ): Development and validation. Journal of Psychology, 149(2), 175-192.

Schottländer, R. (1957). Theorie des Vertrauens. Berlin: De Gruyter.

Schuett, S. (2014). Führung im demografischen Wandel. Ein Leitfaden für Führungskräfte und Personalmanager. Wiesbaden: Springer.

Schyns, B. \& Paul, T. (2006). Skala zur Erfassung des Leader-Member Exchange (LMX7 nach Graen \& Uhl-Bien, 1995) Übersetzung. In A. Glockner-Rist (Hrsg.), Elektronisches Handbuch sozialwissenschaftlicher Erhebungsinstrumente (ZUMA-Informationssystem).

Shamir, B., House, R. J., \& Arthur, M. B. (1993). The motivational effects of charismatic leadership: A self-concept based theory. Organization Science, 4(4), 577-594.

Six, B. (2014). Einstellung. In M. A. Wirtz (Hrsg.), Dorsch-Lexikon der Psychologie (18. Aufl., S. 424). Bern: Hogrefe.

Solomon, R. C. (1983). The Passions. [The Myth and Nature of Human Emotion]. Notre Dame: University of Notre Dame Press.

Spearman, C. (1904). "General intelligence," objectively determined and measured. The American Journal of Psychology, 15(2), 201-292.

Spinelli, R. J. (2006). The applicability of Bass's model of transformational, transactional, and Laissez-Faire leadership in the hospital administrative environment. Hospital Topics, 84(2), 11-18.

Steinmayr, R., Schütz, A., Hertel, J., \& Schröder-Abé, M. (2011). Mayer-Salovey-Caruso Test zur Emotionalen Intelligenz (MSCEIT $T^{\mathrm{M}}$ ). Deutschsprachige Adaptation des Mayer-Salovey-Caruso Emotional Intelligence Test (MSCEIT ${ }^{\mathrm{M}}$ ) von John D. Mayer, Peter Salovey und David R. Caruso. Bern: Hans Huber.

Strickland, L. H. (1958). Surveillance and trust. Journal of Personality, 26(2), 200-215.

Sweeny, K. (2008). Crisis decision theory: Decisions in the face of negative events. Psychological Bulletin, 134(1), 61-76.

Tepper, B. J. (2000). Consequences of abusive supervision. Academy of Management Journal, 43(2), 178-190. 
Tepper, B. J., Dimotakis, N., Lambert, L. S., Koopman, J., Matta, F. K., Man Park, H., et al. (2018). Examining follower responses to transformational leadership from a dynamic, person-environment fit perspective. Academy of Management Journal, 61(4), 1343-1368.

Van Quaquebeke, N. (2011). Defining respectful leadership. RSM Insight, 1, 12-14.

Van Quaquebeke, N., \& Eckloff, T. (2010). Defining respectful leadership: What it is, how it can be measured, and another glimpse at what it is related to. Journal of Business Ethics, 91(3), 343-358.

Villanueva, J. J., \& Sánchez, J. C. (2007). trait emotional intelligence and leadership self-efficacy: Their relationship with collective efficacy. The Spanish Journal of Psychology, 10(2), 349-357.

Waldman, D. A., Galvin, B. M., \& Walumbwa, F. O. (2013). The development of motivation to lead and leader role identity. Journal of Leadership \& Organizational Studies, 20(2), 156-168.

Wayne, S. J., \& Ferris, G. R. (1990). Influence tactics, affect, and exchange quality in supervisor-subordinate interactions: A laboratory experiment and field study. Journal of Applied Psychology, 75(5), 487-499.

Weber, M. (1956). Wirtschaft und Gesellschaft: Grundriss der verstehenden Soziologie. Tübingen: Mohr Siebeck.

Wechsler, D. (1972). The measurement and appraisal of adult intelligence. Baltimore: Williams \& Wilkins.

Weibler, J., \& Keller, T. (2011). Ambidextrie in Abhängigkeit von Führungsverantwortung und Marktwahrnehmung: Eine empirische Analyse des individuellen Arbeitsverhaltens in Unternehmen. Schmalenbachs Zeitschrift für betriebswirtschaftliche Forschung, 63(2), 155-188.

Wegge, J., Schmidt, K.-H., Piecha, A., Ellwart, T., Jungmann, F., \& Liebermann, S. C. (2012). Führung im demografischen Wandel. Report Psychologie, 37(9), 344-354.

Werner, G. W. (2006). Führung für Mündige. Subsidiarität und Marke als Herausforderungen für eine moderne Führung (Studienhefte des Interfakultativen Instituts für Entrepreneurship an der Universität Karlsruhe). Karlsruhe: Univ.-Verl. Karlsruhe. http://www.uvka.de/univerlag/volltexte/2006/105/pdf/Werner_IEP_Studienheft2.pdf.

Wong, S. I., \& Berntzen, M. N. (2019). Transformational leadership and leader-member exchange in distributed teams: the roles of electronic dependence and team task interdependence. Computers in Human Behavior, 92, 381-392.

Wright, W. (2013). Born that way: Genes, behavior, personality. New York: Routledge.

Yang, J., \& Mossholder, K. W. (2010). Examining the effects of trust in leaders: A bases-and-foci approach. The Leadership Quarterly, 21(1), 50-63.

Yukl, G. A. (2010). Leadership in organizations (7. Aufl.). Upper Saddle River: Pearson.

Yukl, G., \& Falbe, C. M. (1990). Influence tactics and objectives in upward, downward, and lateral influence attempts. Journal of Applied Psychology, 75(2), 132-140.

Yukl, G., \& Lepsinger, R. (1990). Preliminary report on validation of the managerial practices survey. In K. E. Clark \& M. B. Clark (Hrsg.), Measures of leadership (S. 223-237). West Orange: Leadership Library of America.

Yukl, G., Kim, H., \& Falbe, C. M. (1996). Antecedents of influence outcomes. Journal of Applied Psychology, 81(3), 309-317.

Yukl, G., Seifert, C. F., \& Chavez, C. (2008). Validation of the extended influence behavior questionnaire. The Leadership Quarterly, 19(5), 609-621. 